\title{
ORGANIC CHEMISTRY.
}

THE present report embraces the subject matter of four separate reports in previous annual volumes, dealing respectively with aliphatic, homocyclic, and heterocyclic compounds, and with stereochemistry. A glance at the Abstracts for the year 1908 will show that the space allotted to summaries of organic research is equal to that devoted to the résumés of all other sections of chemical activity. It is therefore inevitable that references to many valuable reseaches have been omitted, for only by making a selection of the year's output in organic chemistry has it been found possible to keep this report within reasonable bounds.

The theoretical views implied in the conventional structural formulæ have held their own with remarkable success throughout the development of organic chemistry, but their insufficiency to express the whole of the facts is becoming more obvious every year, and great uncertainty still prevails as to the nature of the changes to be made in order to bring certain of these formulæ into closer accordance with the experimental evidence. There can be little doubt that ideas derived from the consideration of plane formulæ require to be constantly verified by reference to the steric relationships of the component parts of the molecule of organic compounds. In certain cases the uncertainty or ambiguity attaching to the use of static conjugations has led to the adoption of dynamic formulæ. The direct application of such a physical hypothesis as that of the electron to organic chemistry would seem to be premature, probably because the hypothesis is still imperfectly developed, even in its simpler applications to the question of chemical affinity, but it has already furnished several suggestive qualitative ideas.

The recent developments in the theory of chemical valency implied in such conceptions as those of principal and subsidiary valencies and co-ordinated compounds have been adopted only in very few instances. Many of this year's researches have an important bearing on the valency of oxygen, and afford ample confirmatory evidence as to the quadrivalent nature of this element, particularly as manifested in the cyclic oxonium salts. On the other hand, no definite conclusion has been 
reached in regard to the assumed tervalency of carbon in triphenglmethyl.

A striking feature of the year's work is the number of investigations dealing directly or indirectly with the influence of unsaturation, especially of the nature and arrangement of double linkings. The ideas put forward by Thiele, in 1899, recur frequently in recent work, notably those of partial valency and of the conjugation of double linkings. The first will be discussed below in connexion with the question of colour and fluorescence; the second finds an important place in many discussions as to the origin of colour and the reactivity of tautomeric compounds.

\section{The Mechanism of Reactions.}

The great advances made in recent years in our knowledge of the structure of organic compounds have directed attention all the more vividly to the gaps which remain. This is especially the case with regard to reactions. The chemical equation only represents, as a rule, the initial and final stages, the mechanism by which the result is obtained remaining obscure, and only to be filled by the assumption of hypothetical intermediate products, the nature of which it is often very difficult to define. Much recent work has been directed to the elucidation of the mechanism of familiar reactions, such as the catalytic hydrogenation and dehydrogenation of organic compounds by metals, the reactions depending on the employment of magnesium organic compounds, the condensations in presence of aluminium chloride and of sodium ethoxide, and the formation of esters, etc.

\section{Catalytic Action of Metals and Inorganic Substances.}

The remarkable results achieved by Sabatier and Senderens on the hydrogenation of organic compounds in the presence of finely-divided nickel at moderately high temperatures have led to numerous researches on the influence of catalysts in the synthesis and decomposition of organic substances.

Many aromatic compounds have been converted by the Sabatier and Senderens' method into the corresponding hydroaromatic derivatives. With hydrogen at $200^{\circ}$ in the presence of nickel, $p$-benzoquinone and its homologues are reduced quantitatively to quinols. At $220-250^{\circ}$ the quinols are decomposed into the corresponding phenols, and water is liberated, but at lower temperatures the quinols undergo further hydrogenation, becoming converted into cyclohexane-1:4-diols. Quinol itself at $160-170^{\circ}$ gives a mixture of phenol, cyclohexanol, 
and cis- and trans-cyclohexane-1:4-diols; at $130^{\circ}$ this cis-modification is formed exclusively.

Catechol under similar conditions gives cis-cyclohexane-1 : 2-diol exclusively, resorcinol does not yield definite products, but pyrogallol is reduced to cyclohexane-1:2:3-triol. ${ }^{1}$

Other unsaturated rings may be hydrogenated by this method.

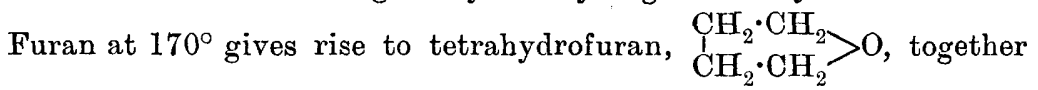
with a small amount of butyl alcohol and some saturated hydrocarbons. $^{2}$

In some cases the reactions have showed signs of reversibility. The reverse change has been observed at $200-300^{\circ}$ with indene and acenaphthene when reduced to hydrindene and tetrahydroacenaphthene, but decomposition products also arise. The hydrogenation of naphthalene to tetrahydronaphthalene which occurs at $200^{\circ}$ is reversed at $300^{\circ}$.

In certain instances, hydrogenation, ${ }^{3}$ under ordinary pressures in the presence of nickel, leads to the formation of secondary products, and even to the total suppression of the primary reaction. Quinoline, for example, is transformed into methylketol. When nickel oxide is employed as the catalyst at high temperatures $\left(200-300^{\circ}\right)$ and under high pressures (100-200 atmospheres), the hydrogenation runs its normal course, and the method has proved remarkably successful in yielding highly hydrogenated products, which are obtained only with considerable difficulty by other processes. Aniline yields principally hexahydroaniline, together with cyclohexylaniline and dicyclohexylamine. The last of these is the chief product of the hydrogenation of diphenylamine.

Quinoline is readily reduced, first to tetrahydroquinoline, and then to decahydroquinoline, an almost quantitative yield of the latter being obtained. Anthracene can be reduced in three successive stages to dihydroanthracene, tetrahydroanthracene, and, finally, perhydroanthracene.

Phenanthrene, which requires a higher temperature $\left(320-370^{\circ} \%\right.$ 150-170 atmos.), is similarly reduced in stages to its dihydro-, tetrahydro-, and octahydro-derivatives, and, finally, perhydrophenanthrene; the yield of the last is so good that the method is recommended for the preparation of the compound.

When potassium phthalate is mixed with nickel oxide and heated in

1 P. Sabatier and A. Mailhe, Compt. rend., 1908, 146, 437, 1193; A., i, 278, 529.

2 A. Bourguignon, Bull. Soc. chim. Belg., 1908, 22, 87 ; A., i, 280.

3 M. Padoa and U. Fabris, Atti R. Accad. Lincei, 1908, [v], 17, i, 111 ; A., i, 255. 
hydrogen at $300^{\circ} / 100$ atmos., an excellent yield of potassium transhexahydrophthalate (trans-cyclohexane-1:2-dicarboxylate) is produced. Sodium benzoate is readily converted into sodium hexahydrobenzoate (cyclohexanecarboxylate), the potassium salt being less affected.

Experiments conducted under ordinary pressures show that the nickel oxide acts as a catalyst only under high pressures. On the other hand, the presence of the catalyst is essential in the foregoing reductions, for heating with hydrogen alone under high pressure does not lead to the hydrogenation of the organic compounds. ${ }^{4}$

The use of metals as catalysts at high temperatures has led to the repetition and extension of certain old experiments on the use of platinum-black in reductions carried out on substances in solution. Compounds containing the ethylene linking are readily reduced with hydrogen in the presence of this catalyst even at the ordinary temperature. Ethyl oleate in ethereal solution gave ethyl stearate in quantitative yield, and oleyl and erucyl alcohols were similarly reduced to the fully saturated alcohols. Geraniol was converted into a mixture of $\beta \zeta$-dimethyloctane and $\gamma \eta$-dimethyloctanol. Cholesterol in ethereal solution furnished a dihydrocholesterol identical with $\beta$-cholestanol. Aromatic substances can be hydrogenated to hydroaromatic derivatives by this method, but somewhat less readily than by the high temperature processes; benzoic acid, for example, gives about 12 per cent. of cyclohexanecarboxylic acid. ${ }^{5}$

A powerful catalytic reducing agent has been prepared by adding hydrazine to a solution of palladium chloride and sodium protoalbinate, when the hydrosol of palladium is formed. The colloidal solution takes up a large amount of hydrogen, and when unsaturated substances are dissolved therein, and the liquid left in contact with hydrogen, the gas is quickly absorbed, and an energetic reduction is effected. Fumaric (maleic) and cinnamic acid in the form of their alkali salts are converted into succinic and $\beta$-phenylpropionic acids respectively. The method is applicable to the unsaturated glycerides occurring in many fats and oils; these substances are quantitatively converted into the saturated glycerides, this being the only process yet discovered which will effect this reduction at the ordinary temperature. ${ }^{6}$

Hydrogenation is not the only chemical change promoted by the catalytic influence of inorganic materials. Dehydration of alcohols

4 W. N. Ipatieff, Ber., 1908, 41, 991 ; W. N. Ipatieff, W. Jakowleff, and L. Rakitin, ibid., 1908, 41, 996 ; W. N. Ipatieff and O. Philipoff, ibid., 1908, 41, 1001 ; A., i, 330, 332, and 342.

5 R. Willstätter and E. W. Mayer, ibid., 1908, 41, 1475, 2199 ; A., i, 383, 636.

${ }^{6}$ C. Paal and J. Gerum, ibid., 1908, 41, 805, 2273 ; A., ii, 392, i, 599 ; C. Paal and K. Roth, ibid., $2283 ; A_{\text {., i, } 599 .}$ 
and similar substances is induced by certain oxides. Precipitated alumina and silica, when dried and gently calcined, promote the decomposition of ethyl alcohol into ethylene and water at temperatures much below those at which heat alone would be effective in decomposing this substance. At $280^{\circ}$ the alcohol is quantitatively decomposed into water and ethylene. Prolonged calcination diminishes very considerably this catalytic power, for after being heated at a white heat, the oxides have no effect on the alcohol below $400^{\circ}$, and then only a small amount of ethylene is produced.

At $300^{\circ}$ in the presence of gently-calcined alumina, ether is decomposed into ethylene and water, the reaction being recommended as a process for preparing this hydrocarbon. Acetic and propionic acids at $350^{\circ}$ give respectively acetone and methyl ethyl ketone, together with carbon dioxide and water. Alumina also induces the elimination of hydrogen halides: at $280^{\circ}$ chloropropane gives propylene, and ethylene dichloride yields vinyl chloride.

Carefully-calcined gypsum promotes the decomposition of alcohol at $420^{\circ}, 90$ per cent. of the gas evolved being ethylene and the rest hydrogen. Anhydrite has no effect below $460^{\circ}$. Aluminium silicate and kaolin have been shown to possess in some degree this catalytic power, which is somewhat diminished by calcination. ${ }^{7}$

A few general principles are apparent. When heated alone the primary aliphatic alcohols decompose at a red heat into (i) water and an olefine and (ii) hydrogen and an aldehyde, but they show no appreciable decomposition below $400^{\circ}$. In contact with finely-divided copper, nickel, cobalt, iron, and platinum, the alcohols undergo dehydrogenation at about $350^{\circ}$, the products being hydrogen and an aldehyde. At the same temperature, certain oxides, and particularly alumina, induce dehydration, the products now being water and an olefine.

\section{The Grignard Reaction.}

Although every year sees a great increase in the applications of the Grignard reaction in the synthesis of organic compounds, the exact mechanism of the process is even yet imperfectly understood, especially in respect of the true nature of the intermediate additive products. The complexes which the reagent forms with ether are generally uncrystallisable, but it has now been found ${ }^{8}$ that by the employment of amyl ether in place of ethyl ether, crystalline compounds, such as $\left(\mathrm{C}_{5} \mathrm{H}_{11}\right)_{2} \mathrm{O}, \mathrm{CH}_{3} \mathrm{MgI}$, may be prepared. Whilst magnesium alkyl halides can also add on a second molecule of ether, the additive compounds with tertiary amines never contain more than one mol. of the

7 J. B. Senderens, Compt. rend., 1908, 146, 125, 1211 ; Bull. Soc. chim., 1908, [iv], 3, $633 ; A .$, i, 494, 495, i, 168.

8 T. Zerewitinoff, Ber., J908, 41, 2244 ; A., i, 616. 
latter. They are, however, capable of combining also with a molecule of ether, yielding mixed ether-amine complexes. Replacement of ether by amine, or conversely, may take place, the change proceeding in the one or the other direction according to the relative stability of the resulting additive compounds, as shown by thermochemical measurements. Ethers are not capable of expelling aliphatic amines, the final product being one containing one mol. of ether and one mol. of amine. ${ }^{9}$ It is concluded from these results that addition takes place at two dissimilar positions in the molecule of the magnesium organic halide.

The Grignard reaction may also take place, although less readily and less smoothly, in the absence of ether or even of a solvent. Aromatic halogen compounds combine with magnesium almost quantitatively on heating, and the products react with water, yielding the parent hydrocarbon. Aryl chlorides, and the halides of alkyls lower in the series than amyl, must be heated in a sealed tube at $270^{\circ}$. Bromo- and iodobenzene yield some diphenyl as well as benzene, and the lower alkyl iodides give rise to hydrogen and unsaturated hydrocarbons in addition to the principal product. These results indicate that the first stage in the reaction is the direct addition of magnesium to the alkyl or aryl halide, and that the formation of an oxonium compound in the presence of ether is a subsequent stage. ${ }^{10}$

Other metals behave in a similar manner to magnesium when heated with organic halides. The products obtained with aluminium, indium, and thallium yield the hydrocarbons on treatment with water. ${ }^{11}$

The varying degree in which metals of different groups are capable of replacing magnesium in the Grignard synthesis has been studied and tabulated.12

From the action of sodium and alkyl halides on certain compounds, the intermediate formation of sodium alkyl seems to be established. Thus acetophenone, isoamyl iodide, and sodium yield phenylmethylisoamylcarbinol, $\mathrm{OH} \cdot \mathrm{CPhMe}_{e} \cdot \mathrm{C}_{5} \mathrm{H}_{11}$. A mixture of sodium with a mercury dialkyl, which must contain a mercury alkyl compound, may also be used. Thus mercury diethyl, sodium, and benzaldehyde react in ether to form phenylethylcarbinol, identical with that obtained by means of Grignard's reagent. Carbon dioxide forms the corresponding carboxylic acid with a mixture of sodium and mercury alkyl. Aromatic acids may be prepared by the action of carbon dioxide on the same mercury alkyl-sodium mixture in presence of an aromatic

9 W. Tschelinzeff, Ber., 1908, 41, 646;A., i, 254.

${ }_{10}$ J. F. Spencer and E. M. Stokes, Trans., 1908, 93, 68; J. F. Spencer and M. S. Crewdson, ibid., 1821.

11 J. F. Spencer and M. L. Wallace, ibid., 1908, 93, 1827.

12 J. Zeltner, J. pr. Chem., 1908, [ii], 77, 393 ; A., i, 401. 
hydrocarbon. When a side-chain is present, the carboxyl group enters this, so that, for instance, $m$-xylene gives $m$-tolylacetic acid, and ethylbenzene gives $\alpha$-phenylpropionic acid. ${ }^{13}$

Magnesium aryl chlorides, which cannot be prepared by the ordinary method, are readily obtained when the reaction between the metal and the aryl chloride is induced by the introduction of a more reactive halide, such as ethyl iodide. ${ }^{14}$

The chlorine in chlorodimethyl ether is not replaceable by magnesium, even when iodine is added, but this ether reacts vigorously with magnesium phenyl bromide, giving benzyl methyl ether, and this reaction is found to be general. ${ }^{15}$

Among new Grignard syntheses to be noted are the production of $\beta$-ketonic esters from $\alpha$-halogen fatty esters ${ }^{16}$ :

$$
\mathrm{CHRBr} \cdot \mathrm{CO}_{2} \mathrm{Et} \stackrel{\mathrm{Mg}}{\longrightarrow} \mathrm{CH}_{2} \mathrm{R} \cdot \mathrm{CO} \cdot \mathrm{CHR} \cdot \mathrm{CO}_{2} \mathrm{Et} ;
$$

the production of propiolic acid by the action of carbon dioxide on magnesium acetylene bromide ${ }^{17}$ :

$$
\mathrm{CH}: \mathrm{C} \cdot \mathrm{MgBr}+\mathrm{CO}_{2} \rightarrow \mathrm{CH}: \mathrm{C} \cdot \mathrm{CO}_{2} \mathrm{H}
$$

and the preparation of thienyl derivatives from iodothiophen. ${ }^{18}$ Thus 2-iodothiophen and acetone condense with magnesium in ethereal solution, yielding thienyldimethylcarbinol and $\beta$-thienylpropylene:

$$
\mathrm{C}_{4} \mathrm{SH}_{3} \cdot \mathrm{CMe}_{2} \cdot \mathrm{OH} \longrightarrow \mathrm{C}_{4} \mathrm{SH}_{3} \cdot \mathrm{CMe} \mathrm{CH}_{2} \text {. }
$$

Anhydrides of dibasic acids generally react with Grignard's reagent in such a way that both the carbonyl oxygen atoms are replaced by alkyl or amyl groups, succinic anhydride, for instance, giving compounds of the type $\underset{\mathrm{I}_{2} \mathrm{H}_{2} \cdot \mathrm{CR}_{2} \cdot \mathrm{CR}_{2} \cdot \mathrm{OH}}{\mathrm{CR}^{\circ}}$ Camphoric anhydride, on the other hand, reacts abnormally, only one oxygen atom being replaced, giving a mixture of the isomeric dialkyl-campholides ${ }^{19}$ :<smiles>[R12]C1CCC(C(=O)OC)C1</smiles>

and

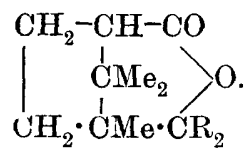

13 P. Schorigin, Ber., 1908, 41, 2711, 2717, 2723 ; A., i, 866, 881, 886.

14 A. Hesse, D.R. -P. $189476 ;$ A., i, 592.

15 A. Reychler, Bull. Soc. chim., 1907, [iv], 1, 1198 ; A., i, 159 ; J. L. Hamonet, ibid., 1908, [iv], 3, 254 ; A., i, 242.

${ }^{16}$ J. Zeltner, Ber., 1908, 41, 589 ; J. pr. Chem., 1908, [ii], 78, 97 ; A., i, 243, 759 .

17 B. Oddo, Gazzetta, 1908, 38, i, $625 ;$ A., i, 748.

18 V. Thomas, Compt. rend., 1908, 146, $642 ; A$., i, 360.

19 J. Houben and A. Hahn, Ber., 1908, 41, 1580;A., i, 539. 
o-Phthalaldehyde forms dihydroxyalkylbenzenes, which on distillation pass into $1: 3$-dialkylphthalans ${ }^{20}$ :

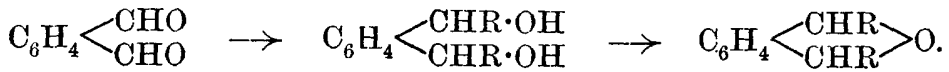

Since $C$-alkylated primary bases may be prepared by the action of magnesium organic compounds on Schiff's bases, the hydramides, $\mathrm{CHR}: \mathrm{N} \cdot \mathrm{CHR} \cdot \mathrm{N}: \mathrm{CHR}$, which contain the characteristic grouping of Schiff's bases twice, have been examined from the same point of view. The reaction is, however, abnormal, addition at the unsaturated groupings being accompanied by the resolution of a carbon-nitrogen single linking, according to two different schemes :

(I). $\mathrm{CHPh}(\mathrm{N}: \mathrm{CHPh})_{2}$ with $\mathrm{MgMeI}$, followed by water, $\rightarrow$ $\mathrm{CHMePh} \cdot \mathrm{NH}_{2}+\mathrm{NH}(\mathrm{CHMePh})_{2}$.

(II). $\mathrm{CHPh}(\mathrm{N}: \mathrm{CHPh})_{2} \rightarrow \mathrm{CHO} \cdot \mathrm{Ph}+\mathrm{NH}_{2} \cdot \mathrm{CHMePh}$,

magnesium aryl halides reacting only according to the second scheme. ${ }^{21}$

A reducing action of magnesium organic compounds has also been observed in the aliphatic series. Thus ethyl hydroxypivalate, $\mathrm{OH} \cdot \mathrm{CH}_{2} \cdot \mathrm{CMe}_{2} \cdot \mathrm{CO}_{2} \mathrm{Et}$, reacts with magnesium ethyl bromide, the ketone formed being partly reduced, especially at low temperatures, with evolution of ethylene, forming $\beta \beta$-dimethylpentane- $\alpha \gamma$-diol, $\mathrm{CH}_{2} \mathrm{Me} \cdot \mathrm{CH}(\mathrm{OH}) \cdot \mathrm{CMe}_{2} \cdot \mathrm{CH}_{2} \cdot \mathrm{OH}$.

\section{The Friedel and Crafts Reaction.}

In the condensation of phthalic anhydride with benzene, it is found that the presence of exactly one (double) molecule of aluminium chloride is necessary to bring about the reaction, and the formation of an intermediate product is thus rendered highly probable :

$$
\begin{array}{r}
\mathrm{C}_{8} \mathrm{H}_{4} \mathrm{O}_{3}+\mathrm{Al}_{2} \mathrm{Cl}_{6}+\mathrm{C}_{6} \mathrm{H}_{6} \rightarrow \mathrm{C}_{8} \mathrm{H}_{4} \mathrm{O}_{3}, \mathrm{Al}_{2} \mathrm{Cl}_{6}, \mathrm{C}_{6} \mathrm{H}_{6} \rightarrow \mathrm{C}_{14} \mathrm{H}_{9} \mathrm{O}_{3}, \mathrm{Al}_{2} \mathrm{Cl}_{5}+\mathrm{HCl} \text {. }
\end{array}
$$

Naphthalene will not readily condense with phthalic anhydride in an indifferent solvent under the influence of aluminium chloride, but when benzene or one of its homologues is added, the whole of the naphthalene reacts to form naphthoylbenzoic acid, even although the benzene may be in great excess. Naphthalene (or anthracene) is thus capable of displacing benzene from the additive product. ${ }^{22}$

When nitro-compounds are condensed with hydrocarbons, the nitrogroup is eliminated, and some oxidation takes place. Thus trichloronitromethane and benzene react in presence of aluminium chloride, giving triphenylmethane and some triphenylcarbinol, the latter

20 F. Nelken and H. Simonis, Ber., 1908, 41, 986 ; A., i, 348.

${ }^{21}$ M. Busch and L. Leefhelm, $J$. pr. Chem., 1908, [ii], 77, 1, 20 ; A., i, 151, 153.

222 G. Heller and K. Schülke, Ber., 1908, 41, 3627 ; A., i, 994. 
produced by oxidation. Ethyl nitrate under similar conditions acts as a nitrating agent, giving nitrobenzene with benzene. Benzene amyl nitrite, and aluminium chloride give small quantities of nitrosobenzene. ${ }^{23}$

When benzene is condensed with carbon tetrachloride, the chlorine atoms are replaced in pairs, the first product capable of isolation being dichlorodiphenylmethane, no trichloro-compound being detected :

$$
\mathrm{CCl}_{4}+2 \mathrm{C}_{6} \mathrm{H}_{6} \rightarrow \mathrm{CCl}_{2} \mathrm{~Pb}_{2} \text {. }
$$

A study of the behaviour of halogen derivatives of benzene in this reaction, the condensation product being subsequently boiled with sulphuric and acetic acids, leads to the conclusion that the substitution is not simultaneous, but that the velocity of replacement of the second chlorine atom is very great. ${ }^{24}$

\section{The Claisen Condensation.}

Although several different explanations of the Claisen condensation have been suggested by different workers, that put forward by Claisen in 1887 is still the most generally accepted, namely, that the ester first forms an additive compound with sodium ethoxide. A study of the velocity of formation of ethyl acetonyloxalate from acetone, ethyl oxalate, and sodium ethoxide in alcoholic solution, as measured by the colour produced by ferric chloride after neutralisation, is interpreted by Clark as favouring this explanation when the dependence of the velocity on the concentration of the reacting substances is taken into account. ${ }^{25}$ A quantitative comparison of different reacting esters, and of the influence of catalysts shows that, as required by this hypothesis, the addition of alcoholic sodium ethoxide greatly accelerates the reaction between ketones and esters in presence of sodium. ${ }^{26}$

On the other hand, experiments with menthone and pulegone, reacting with amyl nitrite (instead of a carboxylic ester) in presence of sodium ethoxide, shows that the group ${ }^{\circ} \mathrm{CH}_{2} \cdot \mathrm{CO} \cdot \mathrm{CH}$ : is attacked, not at the $\cdot \mathrm{CH}_{2} \cdot \mathrm{CO} \cdot$ point, as might be expected, but at the $\cdot \mathrm{CO} \cdot \mathrm{CH}$ : group. ${ }^{27}$ A discussion of the mechanism of this reaction leads to the conclusion that, as suggested by several authors, the metallic derivative of the ketone must react to some extent in the $C$-form. In other words, there must be in the solution a real or virtual equilibrium (that is, either an equilibrium of the ions or one within the molecule itself,

23 E. Bödtker, Bull. Soc. chim., 1908, [iv], 3, 726 ; A., i, 621.

${ }^{24}$ J. Böeseken, Rec. trav. chim., 1908, 27, 5 ; A., i, 189.

25 R. H. Clark, J. Physical Chem., 1908, 12, 1 ; A., i, 124.

${ }_{26}$ J. B. Tingle and E. E Gorsline, Amer. Chem. J., 1908, 40, 46 ; A., i, 732.

27 R. W. L. Clarke, A. Lapworth, and E. Wechsler, Trans., 1908, 93, 30.

REP.-VOL. V. 
without actual dissociation) between the $C$-sodium and the $O$-sodium derivatives :

$$
: \mathrm{C}: \dot{\mathrm{C}} \cdot \mathrm{ONa} \rightleftarrows: \mathrm{CNa} \cdot \dot{\mathrm{C}}: \mathrm{O} \text {. }
$$

These $C$-metallic derivatives must react in a similar manner to organo-metallic compounds, and the aceto-acetic ester synthesis thus becomes a particular case of the reaction between esters and organometallic compounds. The authors give a theoretical discussion of the whole question on this basis.

The reversibility of the acetoacetic condensation, that is, the decomposition of the diketone by sodium ethoxide, is found to depend on the acidity of the compound, the more acid its character the greater being its stability. Thus methyl $\gamma$-acetyldimethylacetoacetate, $\mathrm{CH}_{3} \cdot \mathrm{CO} \cdot \mathrm{CH}_{2} \cdot \mathrm{CO} \cdot \mathrm{CMe}_{2} \cdot \mathrm{CO}_{2} \mathrm{Me}$, is hardly attacked by sodium ethoxide even on boiling, but when the acidity of the central methylene group is reduced by methylation, as in ethyl trimethylacetonedicarboxylate, $\mathrm{CO}_{2} \mathrm{Et} \cdot \mathrm{CHMe} \cdot \mathrm{CO} \cdot \mathrm{CMe}_{2} \cdot \mathrm{CO}_{2} \mathrm{Et}$, this power of resistance disappears. ${ }^{28}$

\section{Esterification and Catalysis.}

Perhaps the most interesting problems in connexion with the formation of esters from acids and alcohols are the influence of catalysts on the velocity of the reaction and the effect of steric hindrance, both of which have received attention during the past year. The influence of catalysts in the formation of ethyl benzoate has been the subject of a very extensive series of measurements, ${ }^{29}$ the results of which prove that a large number of factors enter into the process, but do not allow any general conclusion to be drawn. The efficiency of the catalyst could not be shown to depend on its degree of ionisation. The effect of neutral salts is also a complex one, and dehydration plays a considerable part, as urged by H. E. Armstrong in numerous papers.

An important theoretical paper has quite recently appeared dealing with the general catalytic function of hydrogen ions. ${ }^{30}$ The treatment of the subject is mainly physical and mathematical; so far as esterification and ester hydrolysis are concerned, the most striking suggestion is that the addition of water to an acid in a less basic solvent diminishes the availability of the acid, or diminishes the

28 W. Dieckmann and A. Kron, Ber., 1908, 41, $1260 ; A .$, i, 388.

29 I. K. Phelps, M. A. Phelps, E. A. Eddy, H. E. Palmer, R. W. Osborne, and R. Smillie, Amer. J. Sei., 1908, [iv], 25, 39; 26, 281, 290, $296 ; A$., i, 166, 789, 790.

${ }^{30}$ A. Lapworth, Trans., 1908, 93, 2203 ; E. Fitzgerald and A. Lapworth, ibid., 2163. 
concentration of those "ions" which bring about catalysis. These ions are not identical with the "hydrogen ions" to which the electrical conductivity is due, which are probably complex. The ideas propounded are likely to form the basis of an interesting discussion of the nature of catalysis.

Many experiments on the catalytic function of acids in the hydrolysis of imino-esters, ${ }^{31}$ the formation of oximes ${ }^{32}$ and the acetylation of amino-groups ${ }^{33}$ have also been made, and the importance of considering the basic character of the substances undergoing change is in all cases pointed out.

An examination of the absorption spectra of certain unsaturated ketonic compounds, of which cinnamylideneacetic acid and cinnamylideneacetone are types, leads to conclusions of some interest in connexion with the different rate of esterification of different acids. ${ }^{34}$ It has been conjectured that the process of esterification depenas on the residual affinity of the carbonyl group in the acid, to which the alcohol adds itself. The spectroscopic evidence shows that the residual affinity of a carbonyl group is greatest when the atom attached to the hydroxylic oxygen is not ionised, the effect of adding an acid, and thus diminishing the ionisation of the organic acid, therefore being to increase the residual affinity of the carbonyl. In connexion with this, the effect of small quantities of hydrogen chloride on the spectra of aromatic amino-aldehydes and -ketones has been examined. The development of a new band indicates that the residual affinity of the amino-group is increased by such addition, and this would account for the catalytic action of acids in the acetylation of such compounds. ${ }^{35}$

The effect of steric hindrance is illustrated by experiments with arylated acetic acids. ${ }^{36}$ Triphenylacetic acid is much more difficult to esterify than trialkylated acetic acids, the introduction of the third phenyl group having also a much greater effect than that of the first or second. The same thing is shown by a comparison of benzilic acid, $\mathrm{CPh}_{2} \cdot \mathrm{C}(\mathrm{OH}) \cdot \mathrm{CO}_{2} \mathrm{H}$, with glycollic and mandelic acids, the phenyl group having a far greater influence than hydroxyl in retarding esterification.

\footnotetext{
31 J. Stieglitz, Aner. Chem. J., 1908, 39, 29, 166 ; A., i, 167, 168.

32 S. F. Acree, ibid., $300 ; A$., i, 169.

33 A. E. Smith and K. J. P. Orton, Trans., 1908, 93, 1212.

34 E. C. C. Baly and K. Schaefer, ibid., 1808.

35 E. C. C. Baly and F. G. Marsden, itid., 2108.

36 J. Gyr, Ber., 1908, 41, 4308; A., 1909, ii, 33.
} 


\section{Simple Hydrocarbons and Aliphatic Derivatives.}

The complicated and much discussed problem of the behaviour of the simpler saturated and unsaturated hydrocarbons at high temperatures has been submitted to further experiment, with the result that methane is found to be always the main product of the thermal decomposition of ethane, ethylene, and acetylene. Methane itself decomposes directly into carbon and hydrogen, mainly at the contact with the walls of the vessel, whereas the other hydrocarbons undergo decomposition throughout their mass. Acetylene is only produced in notable quantity from ethylene. ${ }^{37}$ The authors suggest that such residues as $: \mathrm{CH}_{2}$ and $: \mathrm{CH}$ have at least a momentary existence, and give rise to methane by combination with hydrogen. All these processes take place slowly in comparison with those of combustion.

The direct formation: of methane from carbon and bydrogen, which was questioned by Mayer and Altmayer, ${ }^{38}$ has now been placed beyond doubt by the production of 73 per cent. of the theoretical quantity of methane by the action of hydrogen on purified carbon. ${ }^{39}$

Aliphatic derivatives of great complexity are of frequent occurrence in recent chemical literature, and the need of further classification has been felt. Meldola ${ }^{40}$ has proposed the grouping of open-chain systems into those composed respectively of similar and dissimilar atoms, and has suggested for these, from analogy to homocyclic and heterocyclic compounds, the designations "homocatenic" and "heterocatenic," the latter including, for instance, the long chain-systems of the polypeptides.

The interesting and highly reactive group of the ketens has been further studied. The parent substance, keten, $\mathrm{CH}_{2}: \mathrm{CO}$, the isolation of which was announced last year ${ }^{41}$ as a product of the thermal decomposition of acetic anhydride, has been proved to have the constitution then assigned to it. It has also been found possible to prepare it by the general method for the production of ketens, namely, by the action of zinc on bromoacetyl bromide :

$$
\mathrm{CH}_{2} \mathrm{Br} \cdot \mathrm{CO} \cdot \mathrm{Br}+\mathrm{Zn}=\mathrm{CH}_{2}: \mathrm{CO}+\mathrm{ZnBr}_{2}{ }^{42}
$$

The simplest polymerisation product of keten is acetylketen,

$$
\mathrm{CH}_{3} \cdot \mathrm{CO} \cdot \mathrm{CH}: \mathrm{CO} \text {, }
$$

a colourless liquid, which reacts with water to form acetoacetic acid,

37 W. A. Bone and H. F. Coward, Trans., 1908, 93, 1197.

38 Ann. Report, 1907, 74.

39 W. A. Bone and H. F. Coward, Trans., 1908, 93, 1975.

40 Trans., 1908, 93, 1665, footnote.

41 Ann. Report, 1907, 85.

${ }^{42}$ H. Staudinger and H. W. Klever, Ber., 1908, 41, 594 ; A., i, 246. 
and with aniline to form acetoacetanilide. With phenylhydrazine it forms a phenylhydrazone-phenylhydrazide..$^{43}$

A new method for the preparation of dimethyl- and diethyl-keten has been found in the decomposition of di-substituted malonic anhydrides by heat:<smiles>CC(=O)CCCOP1OCC(C)(C)CO1</smiles>

The anhydrides required for the above reaction are prepared by heating the semi-chlorides of the acids; they are highly polymerised. A second method of preparation is that of treating the acid dichlorides with aqueous pyridine. ${ }^{45}$

When, instead of dialkylmalonic acids, malonic acid is treated by a method for producing the anhydride, as by the action of acid chlorides on silver malonate, or of silver oxide on malonyl dichloride, keten is not produced, but in its place carbon suboxide is obtained, the hypothetical intermediate anhydride thus decomposing according to the equation :

$$
\mathrm{CH}_{2}<\mathrm{CO}>\mathrm{O}=\mathrm{C} \ll_{\mathrm{CO}}^{\mathrm{CO}}+\mathrm{H}_{2} \mathrm{O} \text {. }
$$

Dibromomalonyl dichloride, $\mathrm{CBr}_{2}(\mathrm{COCl})_{2}$, readily reacts with zinc, giving a good yield of carbon suboxide. ${ }^{46}$

These methods of preparation indicate that carbon suboxide is itself to be regarded as a keten. It combines with formic and acetic acids to form compounds in which the characteristic structure appears to be preserved, the formic acid compound, for instance, reacting in accordance with the formula $\mathrm{CO}_{2} \mathrm{H}>\mathrm{C}: \mathrm{C}: \mathrm{C}<{ }_{\mathrm{OH}}^{\mathrm{CO}_{2} \mathrm{H}}$. The acetic acid compound breaks up in a remarkable manner on heating, yielding acetic anhydride and a syrup which is completely converted by water into malonic acid. Whilst this substance may be only a polymeride of carbon suboxide, it is at least possible that it may represent the hitherto unknown malonic anhydride, $\mathrm{CH}_{2}<\mathrm{CO}>0 .{ }^{47}$

A comparison of the properties of the ketens now known has suggested their classification in two groups, of which the first includes keten and its monoalkyl derivatives and earbon suboxide, all of which are colourless, incapable of autoxidation, and are polymerised by pyridine. They are termed aldoketens. The members of the second group, consisting of the di-substituted ketens, are coloured, undergo

43 F. Chick and N. T. M. Wilsmore, Trans., 1908, 93, 946.

44 H. Staudingor and E. Ott, Ber., 1908, 41, 2208, 3829 ; A., i, 602, 939.

45 A. Einhorn, Annalen, 1908, 359, $145 ;$ A., i, 312.

$46 \mathrm{H}$. Standinger and S. Bereza, Ber., 1908, 41, 4461 ; A., 1909, i, 83 ,

47 O. Diels and L. Lalin, ibid., 1908, 41, 3426; A., i, 839 
autoxidation, yield keten bases with pyridine, and, unlike the aldoketens, yield additive products with benzylideneaniline and quinone containing the groups $\mathrm{C}: \mathrm{N}$ and $\mathrm{C}: \mathrm{O}$ respectively, They are termed keto-ketens. Thus diphenylketen combines with quinones to form $\beta$-lactones, such as $\mathrm{O}: \mathrm{C}_{6} \mathrm{H}_{4}\left\langle\mathrm{CPh}_{2}\right\rangle \mathrm{CO}$, which decompose when heated, giving derivatives of diphenylquinonemethane. The additive compound with dibenzylideneacetone loses carbon dioxide spontaneously, the product being aє-diphenyl- $\gamma$-diphenylmethylene- $\Delta^{\alpha \delta_{-}}$ pentadiene,

$$
\mathrm{CPh}_{2}: \mathrm{C}<\mathrm{CH}: \mathrm{CHPh} \text {, CHPh }
$$

a compound belonging to a class which may be described as acyclic fulvenes, from their resemblance to the fulvenes :

$$
\mathrm{CH}_{2}: \mathrm{C}<\mathrm{CH}: \mathrm{CH}_{2}
$$<smiles>[CH]=CC1C=CC=C1</smiles>

Their colour is much less intense than that of the fulvenes, as might be expected from the absence of the ring structure. ${ }^{48}$

Previous attempts to prepare the aldehyde of lactic acid, the simplest methyl sugar, have failed, and it has been conjectured that it must isomerise to acetol :

$$
\mathrm{CH}_{3} \cdot \mathrm{CH}(\mathrm{OH}) \cdot \mathrm{CHO} \longrightarrow \mathrm{CH}_{3} \cdot \mathrm{CO} \cdot \mathrm{CH}_{2} \cdot \mathrm{OH} \text {. }
$$

It has now been found that its acetal may be prepared by the reduction of methylglyoxalacetal :

$$
\mathrm{CH}_{3} \cdot \mathrm{CO} \cdot \mathrm{CH}(\mathrm{OEt})_{2} \rightarrow \mathrm{CH}_{3} \cdot \mathrm{CH}(\mathrm{OH}) \cdot \mathrm{CH}(\mathrm{OEt})_{2},
$$

and the latter compound, which may be regarded as the methyl ketone of diethoxyacetic acid, may be prepared by the action of magnesium methyl iodide on the amide of that acid. It was found better to employ the piperidide, from which the acetal was readily prepared. The lactaldehydeacetal obtained on reduction was readily decomposed by acids, yielding the bimolecular crystalline form of lactaldehyde, which slowly dissociates in solution, as shown by determinations of the molecular weight. 49

The condensation of malonic acid with acetone in the presence of acetic anhydride leads to the formation of the $\beta$-lactone of $\beta$-hydroxyisopropylmalonic acid (I). It is remarkable that the only other aliphatic $\beta$-lactone known is an isomeride of this (II) derived from as-dimethylmalic acid : ${ }^{50}$<smiles>CC(C)C1OCOC1C(=O)O</smiles><smiles>CC(C)OC(C(=O)O)C(=O)O</smiles>

48 H. Staudinger, Ber., 1908, 41, 906, 1355, 1493; A., i, 318, 410, 411.

49 A. Wohl, ibid., 1908, 41, 3599 ; A., i, 941.

50 A. N. Meldrum, Trans., $1908,93,598$. 
The oxidation of butyric acid to acetone is probably typical of a number of oxidations which take place in the living plant, and an examination of this reaction proves that it is readily effected in the case of the higher acids. Thus lauric acid ismoxidised by hydrogen peroxide: an unstable ketonic acid is the first product, readily passing into methyl $n$-nonyl ketone. ${ }^{50 a}$

\section{Carbohydrates.}

Further evidence for the $\gamma$-oxidic formula for glucose and other reducing sugars has now been brought forward. Thus glucoseanilide exists in two stereoisomeric modifications, and on methylation yields tetramethyl glucoseanilide, identical with that prepared from tetramethyl glucose. Similarly, glucoseoxime is methylated to tetramethyl glucoseoxime methyl ether. That the tetramethyl derivatives possess the $\gamma$-oxidic structure is shown by the impossibility of further methylation, since an aldehydic derivative would allow of the introduction of two more methyl groups. The oxime therefore has the constitution :

$\mathrm{OMe} \cdot \mathrm{CH}_{2} \cdot \mathrm{CH}(\mathrm{OMe}) \cdot{ }_{1}^{\mathrm{CH}} \cdot \mathrm{CH}(\mathrm{OMe}) \cdot \mathrm{CH}(\mathrm{OMe}) \cdot \mathrm{CH} \cdot \mathrm{NH} \cdot \mathrm{OH}$,

and exists in two stereoisomeric modifications. A similar result was obtained with the anilides. The results of acetylation and reduction of glucoseoxime are difficult to reconcile with the formula proposed, but it is pointed out that the reagents used in these cases are more liable to cause isomeric change than the methyl iodide and silver oxide used in methylation. ${ }^{51}$

The mutarotation of lactose has been shown to be due to the gradual establishment of equilibrium between the hydrated $a$-modification and the anhydrous $\beta$-modification. In the scheme below, the first equilibrium is attained instantly, the second only slowly : ${ }^{52}$

$$
a \text {-form }+\mathrm{H}_{2} \mathrm{O} \rightleftarrows \text { hydrated form } \rightleftarrows \mathrm{H}_{2} \mathrm{O}+\beta \text {-form. }
$$

The change of dextrosephenylhydrazone into the isomeric modification is accelerated by acids and retarded by alkalis. It is suggested that, if not syn-and anti-modifications, one of the isomerides may be the true hydrazone and the other one of the stereoisomeric forms of the $\gamma$-oxidic derivative, as suggested by Irvine for the oxime and anilide : ${ }^{53}$

$\mathrm{OH} \cdot \mathrm{CH}_{2} \cdot \mathrm{CH}(\mathrm{OH}) \cdot{ }_{\text {IH }}^{\mathrm{CH}} \cdot \mathrm{CH}(\mathrm{OH}) \cdot \mathrm{CH}(\mathrm{OH}) \cdot{ }_{1}^{\mathrm{CH}} \cdot \mathrm{NH} \cdot \mathrm{NHPh}$.

50a H. D. Dakin, J. Biol. Chem., 1908, 4, 221 ; A., i, 134.

51 J. C. Irvine and A. M. Moodie, Trans., 1908, 93, 95 ; J. C. Irvine and R. Gilmour, ibid., 1429.

52 C. S. Hudson, J. Amer. Chem. Soc., 1908, 30, 1767 ; A., i, 952.

53 R. Behrend and F. Lohr, Annalen, 1908, 362, 78 ; A., i, 765. 
When pure glycerose is polymerised by contact with colloidal barium carbonate in methyl alcohol, a pentose is formed. It thus appears that polymerisation does not take place directly, but that the simple sugar is first depolymerised to formaldehyde. ${ }^{54}$ The view has also been taken that alcoholic fermentation consists in a breaking down of the sugar molecule to formaldehyde, followed by the conversion of this into alcohol and carbon dioxide. Formaldehyde is converted by zinc carbonate into formic acid, methyl alcohol, acetol, and methylketol. Zinc dust reacts in the same way, the product then including several sugars, among which $\beta$-acrose could be detected, and polyhydroxy-acids. Dextrose and zinc dust yield formic acid, diacetyl, methylglyoxal, and polyhydroxy-acids, but no methyl alcohol. ${ }^{55}$

The action of dilute alkalis on the hexoses has been further studied. Since alkalis have been found to convert aldoses partly into the corresponding hexoses, it should be found that $l$-gulose and $l$-idose should be converted into $l$-sorbose, and this was confirmed. As might be expected from the fact that dextrose and levulose form an equilibrium mixture in alkaline solutions, these two sugars are found to behave similarly on prolonged treatment with dilute alkali. The principal product of decomposition is $i$-lactic acid, but polyhydroxyacids and small quantities of formic acid, carbon dioxide, and alcohol are also formed.56 The lactic acid formed in these experiments is almost certainly produced from methylglyoxal, dihydroxyacetone, or glyceraldehyde. An examination of the polyhydroxy-acids, however, leads to conclusions which are not in accordance with those of Nef, ${ }^{57}$ saccharins with less than six carbon atoms being undoubtedly present. Nef's views, also, would indicate that isosaccharinic acid should be readily obtained from lævulose, but this is not the case, only a very small yield being obtained. On the other hand, lactose gives a considerable yield of isosaccharinic acid. 58

Of other carbohydrate problems, that which has led to the most discussion is the question of the chemical behaviour of cellulose, especially on esterification. Analyses of several anhydrous polysaccharides indicate that the generally-accepted formula for starch, cellulose, etc. $\left(\mathrm{C}_{6} \mathrm{H}_{10} \mathrm{O}_{5}\right)_{n}$, is incorrect, and should be replaced by $\left(\mathrm{C}_{6} \mathrm{H}_{10} \mathrm{O}_{5}\right)_{n}, \mathrm{H}_{2} \mathrm{O}$. In raffinose, melezitose, and mannasaccharide, $n=3$; in inulin, $n=6.59$

54 C. Neuberg, Biochem. Zeitsch., 1908, 12, 337 ; A., i, 765.

55 W. Löb, ibid., 78, 466 ; A., i, 715, 765.

56 J. Meisenheimer, Ber., 1908, 41, 1009 ; A., i, 319.

57 Ann. Report, 1907, 87; also Annalen, 1907, 357, 214 ; A., i, 5.

58 H. Kiliani, Ber., 1908, 41, 469 ; A., i, 246.

59 H. Kiliani, Chem. Zeit., 1908, 32, $366 ; A .$, i, 320. 
Cellulose formate is prepared by the action of formic and sulphuric acids on cellulose, but the number of formyl groups introduced is as yet undetermined.60 A new acetylating agent, by means of which three acetyl groups are introduced, consists of 100 grams of glacial acetic acid, 50 grams of zinc chloride, and 100 grams of acetic anhydride. It does not react with starch. ${ }^{61}$ When cellulose is heated with nitric acid and acetic anhydride, the latter being in excess, only nitrates are obtained, unless sulphuric acid is also present, when some of the nitrate groups are removed and acetonitrates are produced. ${ }^{62}$ When mixtures of anhydrous sulphuric and nitric acids, the latter in large excess, are used, the cellulose nitrate always contains less nitrate groups than when more dilute acid is employed. ${ }^{63}$

Agreement has not yet been reached between different observers as to the true nature of "soda-cellulose." Whilst one observer finds a distinct break in the curve representing the partition of sodium hydroxide between cellulose and water, at the composition corresponding with the formula $\mathrm{C}_{12} \mathrm{H}_{19} \mathrm{O}_{10} \mathrm{Na},{ }^{64}$ another, making use of the former data as well as of new measurements, concludes that no definite composition can be assigned to the solid substance, but that the process is one of adsorption, closely resembling the behaviour of palladium towards hydrogen, and probably susceptible of the same physical explanation. ${ }^{65}$

\section{Isomeric Change and Tautomerism.}

The influence of catalytic agents in bringing about isomeric change, as shown by the mutarotation of nitrocamphor, has been investigated in various solvents. ${ }^{66}$ That the presence of a catalyst is essential, and that an ionising solvent is not itself capable of bringing about the change, is shown by the complete arrest of mutarotation when carbonyl chloride is added. This reagent combines with the traces of ammonia or amines present in most of the solutions, and thus destroys their catalytic function. The addition of acids does not have the same effect, as neutral salts also exert an accelerating action.

A systematic review of the different forms of structural isomerism has been given by the original author of the theory of tautomerism. ${ }^{67}$

60 J. P. Bemberg, D.R.-P. 189836, 189837 ; A., i, 321.

a1 D. J. Law, Chem. Zeit., 1908, 32, $365 ; A .$, i, 321.

${ }^{62}$ F. Berl and W. Smith, jun., Ber., 1908, 41, 1837 ; A., i, 505.

${ }_{63}$ B. Rassow and W. v. Bongé, Zeitsch. angew. Chem., 1908, 21, 732 ; A., i, 394.

${ }^{64}$ W. Vieweg, Ber., 1908, 41, 3269; A., i, 857.

${ }^{65}$ O. Miller, ibid., 4297 ; A., 1909, i, 13.

66 T. M. Lowry and E. H. Magson, Trans., 1908, 93, 107, 119.

67 C. Laar, $J$. pr. Chem., 1908, [ii], 78, $165 ; A$., i, 749. 
The thirty-nine types are classified by him according to the number of changes of linking involved, and, further, into those which respectively do and do not involve change of valency. The scheme affords a useful review of the labile types of isomerism.

The equilibrium between ketonic and enolic modifications has been studied from many points of view. Michael, in a theoretical review of the whole subject, ${ }^{68}$ insists on the necessity of distinguishing clearly between desmotropy, the reversible transformation of two isomerides into each other through the wandering of a labile hydrogen atom, and mesotropy, the process of irreversible isomerisation during the formation of derivatives. In subsequent papers, he and others have investigated the suitability of various reagents for distinguishing between enolic and ketonic substances. The best modification of Hantzsch's ammonia reaction consists in employing triethylamine or tripropylamine, and in noting the development of heat rather than the formation of a precipitate. ${ }^{69}$ This is quite satisfactory when the compound is mesotropic, only enolic substances then reacting, but desmotropic compounds are, as might be expected, generally converted into the more stable modification by the amine. The results obtained with phenylcarbimide ${ }^{70}$ and with acetyl chloride or acetic anhydride ${ }^{71}$ are also indecisive in such cases, for similar reasons.

Ethyl oxalosuccinonitrile, $\mathrm{CN} \cdot \mathrm{CH}_{2} \cdot \mathrm{CH}(\mathrm{CN}) \cdot \mathrm{CO} \cdot \mathrm{CO}_{2} \mathrm{Et}$, prepared by condensing ethyl oxalate with succinonitrile, has been obtained ${ }^{72}$ in an enolic and a ketonic modification, both of which are crystalline. The latter form dissolves alcohol in to a violet, fluorescent solution. If confirmed, this would be the first case of fluorescence observed in the aliphatic series, and Kauffmann has therefore suggested the presence of a ring; the chemical reactions, however, indicate that the compound has the simple structure assigned to it.

The enolic (I) and ketonic (II) modifications of ethyl methylcyclohexenonedicarboxylate :

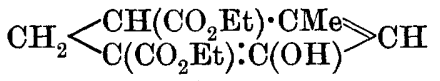

(I.)

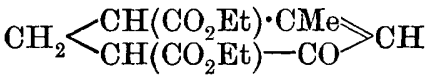

(II.)

are stated ${ }^{73}$ to give different vapours when distilled, although both modifications have the same boiling point. Desmotropy has not previously been observed to persist in the state of vapour.

68 A. Michael, Annalen, 1908, 363, 20 ; A., i, 943.

69 A. Michael and H. D. Smith, ibid., $36 ; A .$, i, 943.

70 A. Michael and P. H. Cobb, ibid., $64 ; A$., i, 947.

71 A. Michael and A. Murphy, jun., ibid., 94 ; $A .$, i, 949.

72 W. Wislicenus and P. Berg, Ber., 1908, 41, 3757; A., i, 965.

73 P. Rabe, Annculen, 1908, 360, 289 ; A., i, 530. 
9-Nitrofluorene has been isolated in two desmotropic forms, of which the aci-form, $\mathrm{C}_{6} \mathrm{H}_{4} \mathrm{H}_{4}>\mathrm{C}$ : $\mathrm{NO} \cdot \mathrm{OH}$, is comparatively stable. It is prepared from fluorene, ethyl nitrite, and potassium ethoxide. ${ }^{74}$

The well-known tautomerism of cyclic ketones, such as phloroglucinol and dihydroresorcinol, is also exhibited by monoketones containing a simple ring if a sufficiently powerful reagent, such as an acid anhydride, be employed to detect the enolic hydroxyl group. ${ }^{75}$ In this way, acetyl derivatives of the enolic forms of cyclohexanone and its three methyl derivatives, and of mentbone, cyclopentanone, and suberone, have been prepared. Camphor gave no indication of any acetylation.

An addition to the many physical properties which have been utilised to give indications as to the ketonic or enolic condition of tautomeric substances is made in a recent communication, which deals with the viscosity of liquids of this class, these compounds being mixed with various solvents. ${ }^{76}$ The measurements show that ethyl acetoacetate is partly enolised, both alone and in solution. The addition of piperidine has a marked effect in increasing the viscosity.

The peculiar isomerism of di-o-derivatives of benzene, referred to in last year's Report (p. 111), and there considered in relation to Kekulé's formula for benzene, has received surprisingly little attention, and it is therefore uncertain how far the formation of such isomerides is a general one. A certain number of nitrated derivatives of benzene, it is true, have been shown to exist in two modifications, but this is now attributed by the author 77 to isomerism of the nitro-group. Thus 1-chloro-2 : 4-dinitrobenzene exists in a stable and in a highly labile form, the two forms being chemically identical. The fact that both modifications have the same colour excludes the possibility that one of them has the aci-constitution.

The two modifications of 2:4-dinitrophenol, however, differ in colour, one of them being pale green in solution or when fused. The two substances give a eutectic mixture, they form similar salts, and are formulated as :<smiles>O=[N+]([O-])C1CCC(O)[N+](=O)C1</smiles>

and<smiles>O=[N+]([O-])C1CCC(O)C12OO2</smiles>

${ }_{74} \mathrm{~W}$. Wislicenus and M. Waldmüller, Ber., 1908, 41, 3334 ; A., i, 973.

75 C. Mannich and V. H. Hâncu, iżid., 1908, 41, 564; A., i, 275.

76 A. E. Dunstan and J. A. Stubbs, Trans., 1908, 93, 1919.

77 I. Ostromisslensky, J. pr. Chem., 1908, [ii], 78, 263 ; A., i, 868. 
The very remarkable changes undergone by the aromatic fulgides, of which triphenylfulgide,

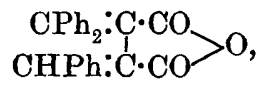

is a type, when exposed to light have been fully studied. ${ }^{78}$ The change from orange to brown, brought about by light, is strictly reversible, but after frequent repetition of the change, an irreversible transformation occurs, resulting in the formation of "photoanhydrides," the investigation of which has not yet been published. A thearetical discussion is at present hardly possible, but it may be noted that the triarylated fulgides (with one exception) and certain of those containing two aryl groups are phototropic, whereas tetraphenylfulgide is not. Certain compounds outside this group behave in a similar manner.

An isomeric change of a more definite character, also taking place under the influence of light, is that of carvone. ${ }^{79}$ Whilst solutions of dihydrocarvone were hydrolysed by exposure to sunlight, thus behaving similarly to other cyclic ketones, carvone was converted into an isomeride, resisting the action of permanganate. It is suggested that a process of "internal polymerisation," such as that represented below, takes place :
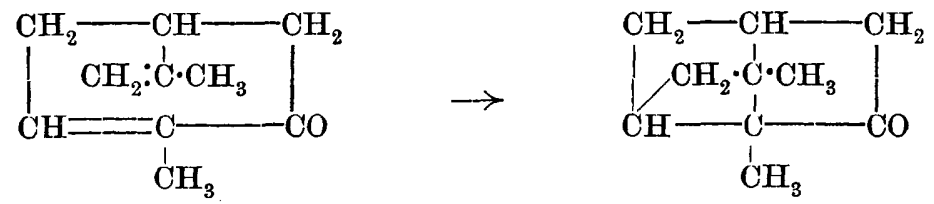

The migration of acyl groups in certain instances will be discussed later in connexion with the structure of hydroxyazo-compounds. The migration of aryl groups in iodohydrins during the elimination of hydrogen iodide has been exhaustively. studied. ${ }^{80}$ Thus $\alpha$-1-naphthylpropylene, $\mathrm{C}_{10} \mathrm{H}_{7} \cdot \mathrm{CH}: \mathrm{CH} \cdot \mathrm{CH}_{3}$, on treatment with mercuric oxide and iodine, is transformed into $a$-1-naphthylpropaldehyde, the iodohydrin isomerising and losing hydrogen iodide at the same time :

$$
\mathrm{C}_{10} \mathrm{H}_{7} \cdot \mathrm{CH}(\mathrm{OH}) \cdot \mathrm{CHI} \cdot \mathrm{CH}_{3} \longrightarrow \mathrm{CHO} \cdot \mathrm{CH}\left(\mathrm{C}_{10} \mathrm{H}_{7}\right) \cdot \mathrm{CH}_{3} \text {. }
$$

Similarly, $\beta$-1-naphthylpropylene passes into $\alpha$-naphthylacetone : $\mathrm{C}_{10} \mathrm{H}_{7} \cdot \mathrm{CMe}: \mathrm{CH}_{2} \rightarrow \mathrm{C}_{10} \mathrm{H}_{7} \cdot \mathrm{CMe}(\mathrm{OH}) \cdot \mathrm{CH}_{2} \mathrm{I} \rightarrow \mathrm{CH}_{3} \cdot \mathrm{CO} \cdot \mathrm{CH}_{2} \cdot \mathrm{C}_{10} \mathrm{H}_{7}$.

A case of wandering of bromine has been observed in the transformation of nitroamines. ${ }^{81} \quad 2: 6$-Dibromo-1-nitroaminobenzene under-

${ }^{78}$ H. Stobbe, Annalen, 1908, 359, 1 ; A., ii, 339.

79 G. Ciamician and P. Silber, Ber., 1908, 41, 1928 ; A., i, 555.

80 M. Tiffeneau, Bull. Soc. chim., 1907, [iv], 1, 1205 ; Compt. rend., 1908, 146, $29 ; 147,678 ; A$., i, 165, 166, 972.

81 K. J. P. Orton and C. Pearson, Trans., 1908, 93, 725. 
goes rearrangement in the usual way to $2: 6$-dibromo-4-nitroaniline, but at the same time a part of it forms the isomeric $2: 4$-dibromo6-nitroaniline, the migrating nitro-group actually expelling a bromine atom, which re-enters the nucleus in a different position:

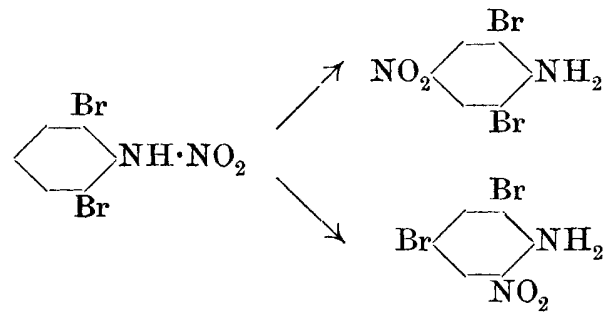

With s-tribromo-1-nitroaminobenzene, the same change takes place, but the para-position now being occupied, the bromine is unable to reenter the nucleus, and is found in the solution.

In conclading this section, reference should be made to the interesting method of studying the process of isomeric change by observing the change in rotatory power of an active solvent, not itself undergoing change, as described in last year's Report (p. 184). The method is particularly applicable to the oximes, and one case has been investigated, that of $p$-iodobenz-syn.-aldoxime,"in which no other method for measuring the velocity of change is available. The change in rotation of $n$-propyl tartrate brought about by the presence of $\omega$-isonitromethane undergoing change to the stable nitro-compound :

$$
\mathrm{C}_{6} \mathrm{H}_{5} \cdot \mathrm{CH}: \mathrm{NO} \cdot \mathrm{OH} \rightarrow \mathrm{C}_{6} \mathrm{H}_{5} \cdot \mathrm{CH}_{2} \cdot \mathrm{NO}_{2} \text {, }
$$

is less than that due to the oximes, but is still considerable. The change of ammonium cyanate and thiocyanate into carbamide and thiocarbamide respectively may be followed by dissolving a portion of the substance which is being heated from time to time in an aqueous solution of ethyl tartrate and measuring the rotation, or in the former case, by allowing the change to take place in the ethyl tartrate solution. ${ }^{82}$

\section{Ozonides.}

The value of the ozone method for recognising the presence of ethylenic linkings continues to be disputed. Whilst Molinari states that such linkings only are attacked by ozone, Harries finds that substances containing triple linkings also react readily with ozone to form unstable products having the properties of ozonides. It is suggested that the differences observed may be due to the fact that Molinari employs ozonised air, and Harries, the presumably more energetic ozonised oxygen. The simpler olefines yield very stable ozonides, which may be distilled in a vacuum, when treated with ozone in an 82 T. S. Patterson and A. McMillan, Trans., 1908, 93, 1041. 
indifferent solvent. ${ }^{33}$ The formulation of such compounds as containing a chain of three oxygen atoms :

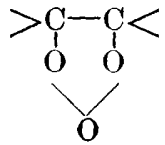

is not in accordance with their optical constants, and it appears rather that only two of the oxygen atoms have an ether linking, the third being "carbonyl oxygen," but further study is required before a definite formula can be assigned to them. The decomposition products of ozonides of oleic acid and triolein by water and alkalis are very complex, although the "saponification number" of such compounds is a fairly definite constant. ${ }^{84}$

\section{Aliphatic Diazo- and Triazo-compounds.}

In 1907 an investigation of the action of sodium azide on various diazonium salts led to the production of a number of aromatic azides, of which the most noteworthy were the hydroxyphenylazoimides, obtained from the aminophenols, and the triazo-derivatives of the naphthalene series, prepared from the isomeric nitronaphthalenediazonium salts. ${ }^{55}$

An extension of this research to the aliphatic series has resulted in the isolation of triazo-derivatives of the simplest organic compounds. By double decomposition, ethyl chloroacetate and sodium azide have furnished ethyl triazoacetate, $\mathrm{N}_{3} \cdot \mathrm{CH}_{2} \cdot \mathrm{CO}_{2} \mathrm{Et}$, from which triazoacetic acid, $\mathrm{N}_{3} \cdot \mathrm{CH}_{2} \cdot \mathrm{CO}_{2} \mathrm{H}$, and triazoacetamide, $\mathrm{N}_{3} \cdot \mathrm{CH}_{2} \cdot \mathrm{CO} \cdot \mathrm{NH}_{2}$, have been prepared by the usual methods. The simplest triazo-ketone, acetonylazoimide, or triazoacetone, $\mathrm{N}_{3} \cdot \mathrm{CH}_{2} \cdot \mathrm{CO} \cdot \mathrm{CH}_{3}$, has been obtained, and compared with its cyclic analogue, camphorylazoimide. Triazoacetoxime has been isolated, and the isomeric ethyl $\alpha$ - and $\beta$-triazopropionates have been prepared, but only the former ester could be hydrolysed into $\alpha$-triazopropionic acid, $\mathrm{CH}_{3} \cdot \mathrm{CH}\left(\mathrm{N}_{3}\right) \cdot \mathrm{CO}_{2} \mathrm{H}$, the $\beta$-ester being decomposed by caustic alkalis, and even by ammonia, with the elimination of the triazo-group. Triazoethyl alcohol, $\mathrm{N}_{3} \cdot \mathrm{CH}_{2} \cdot \mathrm{CH}_{2} \mathrm{OH}$, and triazoacetaldehyde, $\mathrm{N}_{3} \cdot \mathrm{CH}_{2} \cdot \mathrm{COH}$, were obtained from ethylene chlorohydrin and chloroacetaldehyde; the former was a fairly stable substance, giving rise to esters, such as triazoethyl acetate,

$$
\mathrm{CH}_{3} \cdot \mathrm{CO}_{2} \cdot \mathrm{CH}_{2} \cdot \mathrm{CH}_{2} \mathrm{~N}_{3} \text {, }
$$

isomeric with ethyl triazoacetate, and the latter was an extremely explosive and unstable liquid, which was decomposed by hydroxylamine, phenylhydrazine, and other reagents for aldehydes.

83 C. D. Harries and K. Haeffner, Ber., 1908, 41, 3098 ; A., i, 846.

${ }^{84}$ E. Molinari, ibid., 585, 2782, 2789, 2794 ; A., i, 244, 849.

85 M. O. Forster and H. E. Fierz, Trans., 1907, 91, 855, 1350, 1942. 
The refraction and dispersion of certain of these triazo-compounds were determined, so also were the dissociation constants of triazoacetic and $\alpha$-triazopropionic acids, the latter determinations showing that the effect on the strength of acetic acid produced by the introduction of a triazo-group is less than that due to a bromine atom but greater than that due to an iodine atom. ${ }^{86}$

Bistriazo-compounds were also prepared: 1:2-bistriazoethane, $\mathrm{N}_{3} \cdot \mathrm{CH}_{2} \cdot \mathrm{CH}_{2} \cdot \mathrm{N}_{3}$, and ethyl bistriazoacetate, $\mathrm{CH}\left(\mathrm{N}_{2}\right)_{2} \cdot \mathrm{CO}_{2} \cdot \mathrm{C}_{2} \mathrm{H}_{5}$, the latter being distilled and analysed in spite of its explosive properties. 1:1-Bistriazoethane, $\mathrm{CH}_{3} \cdot \mathrm{CH}\left(\mathrm{N}_{3}\right)_{2}$, which was produced by the general method from ethylidene dichloride and sodium azide, could not be distilled even under greatly reduced pressure, owing to the violence with which it explodes at temperatures below $50^{\circ}$.

$a$-Triazopropionic acid, which is a racemic compound, was resolved by means of brucine, and the lævorotatory component reduced to $d$-alanine. ${ }^{87}$

Ethyl diazoacetate, first discovered by Curtius, gives rise to a complicated series of transformation products under the influence of alkalis. A tabulated summary of some of these derivatives was given in last year's Report (p. 158). Among the points studied since this table was published is the action of hydrazine on ethyl diazoacetate and bisdiazoacetate and their imides.

Triazoacetylhydrazide (I) is produced either by the action of hydrazine hydrate on diazoacetamide or by treating ethyl diazoacetate with anhydrous hydrazine; its constitution is demonstrated by the following synthesis :

$$
\mathrm{CH}_{2} \mathrm{I} \cdot \mathrm{CO}_{2} \mathrm{Et} \stackrel{\mathrm{AgN}}{\longrightarrow} \mathrm{N}_{3} \cdot \mathrm{CH}_{2} \cdot \mathrm{CO}_{2} \mathrm{Et} \stackrel{\mathrm{N}_{2} \mathrm{H}_{4}}{\rightarrow} \mathrm{N}_{3} \cdot \mathrm{CH}_{2} \cdot \mathrm{CO} \cdot \mathrm{NH} \cdot \mathrm{NH}_{2} \cdot
$$

The six-membered dihydrotetrazine ring in ethyl bisdiazoacetate (I), $\mathrm{CO}_{2} \mathrm{Et} \cdot \mathrm{C}<\mathrm{NH} \cdot \mathrm{NH}>\mathrm{N} \cdot \mathrm{CO}_{2} \mathrm{Et} \rightarrow$

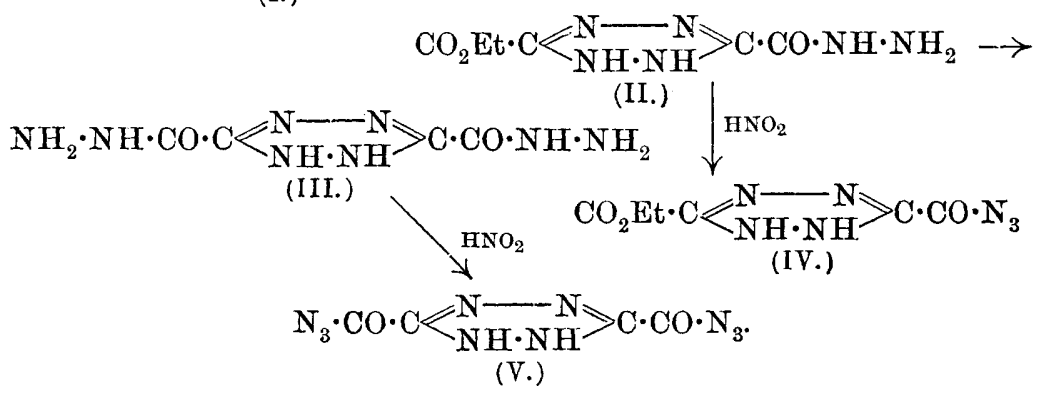

86 J. C. Philip, Trans., 1908, 93, 918, 925.

si M. O. Forster and H. E. Fierz, ibid., 72, 669, 1070, 1174, 1859, 1865. 
is not affected by hydrazine, the action of which is effective only on the carbethoxy-groups, thus giving rise to ethyl bisdiazoacetate hydrazide (II) and bisdiazoacetic acid dihydrazide (III).

These hydrazides are converted respectively by nitrous acid into ethyl tetrazinedicarboxylate azide (IV) and tetrazinedicarboxyl bisazide $(\mathrm{V}) .88$

The action of cold concentrated aqueous potassium hydroxide on ethyl diazoacetate leads to the production of tripotassium $\psi$-diazoacetate (I), a compound which is transformed by this alkali at $100^{\circ}$ into potassium bisdiazoacetate :

$\mathrm{CO}_{2} \mathrm{~K} \cdot \mathrm{C}\left\langle\mathrm{N}=\mathrm{N}>\mathrm{NK} \cdot \mathrm{CO}_{2} \mathrm{~K} \quad \mathrm{CO} \cdot \mathrm{NH}_{2} \cdot \mathrm{C}<\mathrm{N}=\mathrm{NH}>\mathrm{C}\left(\mathrm{NH}_{4}\right) \cdot \mathrm{CO} \cdot \mathrm{NH}_{2}\right.$.

This tripotassium salt corresponds with the amide (II) produced by the action of liquid ammonia on ethyl diazoacetate. On treatment with alkali nitrite and acetic acid, this potassium salt yields potassium nitrosodihydrotetrazinecarboxylate (III), from which reduction with hydrogen sulphide leads to dihydrotetrazinecarboxylic acid (IV), a substance which, even at $60^{\circ}$, loses carbon dioxide and passes into $N$-1-amino-1 : $3: 4$-triazole (V). ${ }^{89}$

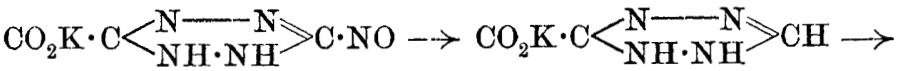
(III.)

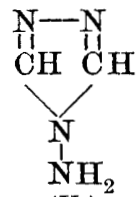

(IV.)

(V.)

The compound obtained by the action of potassium ethoxide on ethyl diazoacetate is not, as was formerly supposed by Hantzsch and Lehmann, ${ }^{90}$ a potassium ethyl isodiazoacetate, $\mathrm{CO}_{2} \mathrm{Et} \cdot \mathrm{C}<\frac{1}{\mathrm{~N}}$, but a $\psi$-diazoacetate derivative (potassium ethyl $\psi$-diazoacetate) containing a molecule of potassium ethoxide:

$$
\mathrm{CO}_{2} \mathrm{Et} \cdot \mathrm{C}<\mathrm{N}=\mathrm{NH}>\mathrm{CK} \cdot \mathrm{CO}_{2} \mathrm{Et}, \mathrm{C}_{2} \mathrm{H}_{5} \cdot \mathrm{OK} \text {. }
$$

The corresponding sodium derivative is known, and both substances have all the properties of $\psi$-diazoacetates ( $C N$-dihydro-1 :2:4:5-tetrazine-3:6-dicarboxylates). ${ }^{91}$

88 T. Curtius and E. Rimele, Ber., 1908, 41, 3108; A., i, 921.

89 Ernst Müller, ibid., 3116 ; A., i, 922.

90 Ber., 1901, 34, 2506 ; A., 1901, i, 678.

91 T. Curtius, A. Darapsky, ana Ernst Muiller, ibid., 1908 41, 3140 ; A., i, 923. 
Further details of the transformations of ethyl diazoacetate will be found in a recently-published résumé of the work. ${ }^{92}$

\section{The Terpene Group.}

Great activity has been shown in the investigation of the terpenes and allied substances during the past year, and important progress has been made in the establishment of the constitution of several members of the group. The great services rendered to this branch of chemistry, as to so many others, by the discovery of Grignard's reaction are obvious on an examination of the papers dealing with terpene syntheses. It is in connexion with the study of the terpenes, also, that the optical method, the determination of the refractive index and dispersion, has proved of the greatest value. Several cases of apparent exception to the regularities in the relation of refractive index to constitution have been removed recently, as the result of a more complete purification of the substances supposed to be anomalous. There still remain some marked apparent exceptions, some of which may be due to unnoticed isomerisation during the preparation. Such isomeric changes, usually involving the shift of a double linking, are frequent. In a recent instance, the process of heating with quinoline and quinoline hydriodide, a procedure sometimes adopted, is found to cause the rearrangement of methylenecyclohexane to methyl- $\Delta^{1}-c y c l o-$ hexene, the double linking changing its position : ${ }^{93}$<smiles>C=C1CCCCC1</smiles>

The synthesis of carvestrene ${ }^{94}$ has now been supplemented by the synthesis of an isomeride, also of the m-menthadiene series, for which the name isocarvestrene is proposed, the two terpenes differing only in the position of the double bond in the ring. ${ }^{95}$ Starting with ethyl cyclohexanone-2 : 4-dicarboxylate (I), methylation gives ethyl 1-methylcyclohexan-6-one-1:3-dicarboxylate (II), which loses a carbethoxyl group on hydrolysis, yielding 1-methylcyclohexan-6-one-3-carboxylic acid (III).

By reduction to the hydroxy-acid, treatment with hydrogen bromide, and subsequent removal of hydrogen bromide by diethylaniline, an

92 Ber., 1908, 41, 3161 ; A., i, 924.

93 A. E. Faworsky and I. Borgmann, Ber., 1907, 40, 4863; A., i, 15.

94 Ann. Report, 1907, 129.

95 K. Fisher and W. H. Perkin, jun., Trans., 1908, 98, 1876.

REP.- VOL. $\nabla$. 
<smiles>CCOC(=O)CCCCCC(=O)OCC</smiles>

(I.)<smiles>[Y6]C(C)(CC(=O)OCC)C(=O)OCC</smiles>

(II.)<smiles>CCCCC(=O)OCC</smiles>

(III.)

acid is obtained which is shown to be 1-methyl- $\Delta^{6}$-cyclohexene-3carboxylic acid (IV). Magnesium methyl iodide converts the unsaturated acid into $\Delta^{6}-m$-menthenol $(\mathrm{V})$, the terpineol of the series, from which isocarvestrene (VI) is obtained by removing water with magnesium methyl iodide.

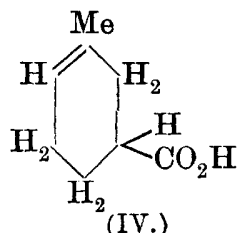

(IV.)

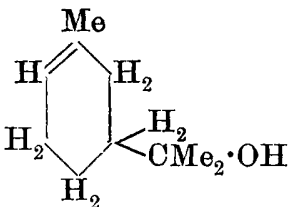

(V.)<smiles>CCCCCCCCCCCCCC</smiles>

(VI.)

The new terpene is found to possess somewhat remarkable properties, the high refraction and dispersion, and the formation of a dibromide instead of a tetrabromide, causing it to resemble a terpene with conjugated double linkings, a constitution which appears to be excluded by the conditions of the synthesis.

The important synthesis of terpineol by W. H. Perkin, jun., in $1904,{ }^{96}$ has been completed by the production of the two active terpineols, the original product having been inactive. This has been effected by the resolution of $d l-1$-methyl- $\Delta^{3}$-cyclohexene-4-carboxylicacid,

$$
\mathrm{CHMe}<\mathrm{CH}_{2}^{2} \cdot \mathrm{CH}_{2}>\mathrm{CH} \cdot \mathrm{CO}_{2} \mathrm{H},
$$

by crystallisation of its strychnine and brucine salts. ${ }^{97}$

Another interesting synthesis from the same laboratory has been that of a terpineol, terpin, and terpene containing a five-membered ring. ${ }^{98}$ Ethyl cyclopentanone-3-carboxylate (I) reacts with magnesium methyl iodide, forming 1-methyl-3-isopropenol- $\Delta^{5}$-cyclopentene (II) the terpineol of the five-carbon series, which yields the corresponding terpin (III) with acids :

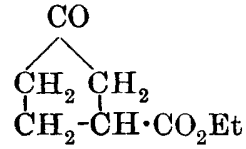

(I.)

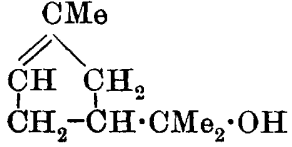

(II.)

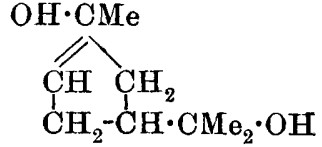

(III.)

96 Ann. Report, 1904, 116.

97 K. Fisher and W. H. Perkin, jun., Trans., 1908, 93, 1871.

98 W. N. Haworth and W. H. Perkin, jun., Trans., 1908, 93, 573. 
A second method of synthesis leads equally to members of this series. Ethyl 2-methylcyclopentan-2-one-3-dicarboxylate (IV) may be broken down by hydrolysis to pentane- $\beta \gamma \epsilon$-tricarboxylic acid (V), the ethyl ester of which condenses under the influence of sodium, forming ethyl 2-methylcyclopentanone-3:5-dicarboxylate (VI). By reduction and addition and subsequent removal of hydrogen bromide, a

$\stackrel{\mathrm{CH}}{\mathrm{CH}} \underset{\mathrm{CH}}{\mathrm{CH}}-\stackrel{\mathrm{CO}_{2} \mathrm{Et}}{\mathrm{CO}} \cdot \mathrm{CO}_{2} \mathrm{Et}$

(IV.)

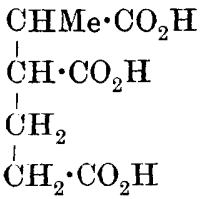

(V.)

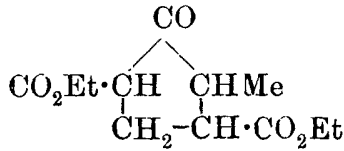

(VI.)

mixture of unsaturated esters is obtained, from which ethyl 1-methyl$\Delta^{4}$-cyclopentene-2-carboxylate (VII) has been isolated by an ingenious process. Magnesium methyl iodide converts it into the terpineol (VIII) The corresponding terpene, 1-methyl-2-isopropenyl- $\Delta^{4}$-cyclopentene

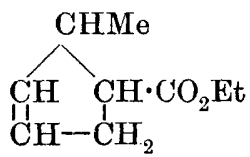

(VII.)<smiles>CCCC1CC=CC1C(=O)O</smiles>

(VIII.)<smiles>CCCCCCCC(C)CCCC</smiles>

(IX.)

(IX) is obtained from this by dehydration ; with succinic anhydride. This hydrocarbon is possibly identical with that obtained by Semmler from sabina ketone.

It is only possible to make a selection from the very numerous papers dealing with terpene chemistry. Terpinene, although rarely present in natural products, is of interest from the fact that it is frequently produced by the action of acids on other terpenes, and therefore appears to be one of the most stable members of the group. It has been previously suggested that terpinene is identical with carvenene, and this is confirmed by the conversion of carvenone (I) by way of the oxime into 2 -amino- $\Delta^{3}$-menthene (II), distillation of the phosphate of the latter yields a pure $\Delta^{1: 3}$-menthadiene (carvenene) (III), which, from its conversion into terpinene nitrosite, appears to be identical with terpinene. ${ }^{99}$ Whilst fornier preparations of terpinene<smiles>[R16]1CCCCC1</smiles>

(I.)

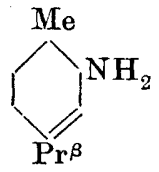

(II.)

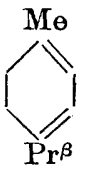

(III.)

have failed to show the optical exaltation corresponding with the con99 C. D. Harries and R. Majima, Ber., 1908, 41, 2516 ; A., i, 733. 
jugated double linkings, it is exhibited by the carvenene prepared by this method. ${ }^{1}$ A study of the oxidation products of $\alpha$ - and $\beta$-terpinene also leads to the conclusion that the hydrocarbon yielding the nitrosite is $\Delta^{1: 3}$-menthadiene ( $\alpha$-terpinene). ${ }^{2}$

The new terpene obtained from Cyprus origanum oil, and described as origanene, has also the properties of $\Delta^{1 \cdot 3}-p$-menthadiene, and shows optical exaltation. Its properties agree fairly well with those of carvenene or $a$-terpinene. ${ }^{3}$

2-Methylcarvenene has been prepared by the action of magnesium methyl iodide on carvenone. ${ }^{4}$

The first synthesis of $\alpha$-phellandrene from a substance containing a smaller number of carbon atoms has been accomplished by treating isopropyl- $\Delta^{2}$-cyclohexen-4-one, prepared by the isomerisation of sabina ketone, with magnesium methyl iodide. ${ }^{5}$

Turning now to bicyclic terpenes, a comparative study of the action of hydration in breaking down bridged linkings has been made by Wallach. ${ }^{6}$ The addition is very commonly accompanied by molecular rearrangement, sabinene and pinene hydrates, for instance, probably first losing water, which is then added on in a different position, yielding terpinene-4.ol and $a$-terpineol respectively. The relative behaviour of three- and four-atom rings on hydration confirms Perkin's conclusion, derived from experiments of a different kind, that the relative stability of cyclopropane and cyclobutane rings depends much more on the nature and position of the attached groups than on the number of carbon atoms in the ring.

Of the two possible formulæ for umbellulone ${ }^{7}$ proposed by Tutin (I) and by Semmler (II) respectively, the first is preferred, since the

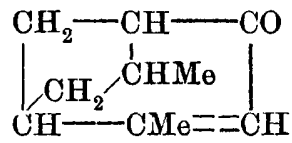

(I.)

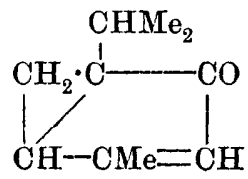

(II.)

second would require that tetrahydroumbellulone should be menthone, whereas the mixture of stereoisomeric tetrahydro-derivatives actually obtained is unlike menthone.

1 J. W. Brühl, Ber., 1908, 41, 3712 ; A., ii, 1002.

2 O. Wallach, Annalen, 1908, 362, 261, 285; A., i, 811, 813 ; Semmler, however (Ber., 1908, 41, 4474;A., 1909, i, 110), dissents from this conclusion, and Inaintains the $\Delta^{1: 4}$ constitution for terpinene.

${ }^{3}$ S. S. Pickles, Trans., 1908, 93, 862.

4 H. Rupe and F. Emmerich Ber., 1908, 41, 1750 ; A., i, 556.

5 O. Wallach, Annalen, 1908, 359, 265 ; A., i, 424.

6 Annalen, 1908, 360, 82; A., i, 429.

7 F. Tutin, Trans., 1908, 93, 252 ; F. W. Semmler, Ber., 1908, 41, 3988; A., $1909, \mathrm{i}, 38$. 
Santene has received the constitution (I) on the ground that gentle oxidation with permanganate yields a glycol (II), further oxidation giving a diketone (III), the constitution of which is proved by its oxidation to trans-yclopentanedicarboxylic acid. ${ }^{8}$<smiles>CC1CC2CC(C1)C2C</smiles>

(I.)<smiles>CC1CC2CC(O)C(O)C1C2</smiles>

(II.)<smiles>CO[C@H]1C[CH]C(OC(C)=O)C1</smiles>

(III.)

A further attempt has been made to elucidate the nature of the isomerism of the two modifications of isonitrosocamphor by the study of the action of diazomethane. ${ }^{9}$ This reagent converts the unstable into the stable modification, and the latter into the $N$-ether, which is possibly $\mathrm{C}_{8} \mathrm{H}_{14}<_{\mathrm{CO}}^{\mathrm{C}}: \mathrm{NMe}: \mathrm{O}$. The presence of a nitroso-group is improbable, from the absence of a blue or green colour and of the Liebermann reaction, and the production of the $N$-ether is in better agreement with the formulation of isonitrosocamphor as<smiles>OC(O)C1=C=N[O+]=C1</smiles>

Several investigations have been directed to the establishment of the constitution of fenchone. Three formulæ have been proposed, due respectively to Wallach (I), Semmler (II), and Glover (III). Of these,<smiles>CCCC1CCC(C)C1C</smiles>

(I.)<smiles>CC(C)(C)[C@H]1C[C@H]2C[CH][C@H]1C2=O</smiles>

(II.)<smiles>CC1(C)CCC[C@H]1C=O</smiles>

(III.)

the first formula is very similar to that of $a$-methylcamphor, and the second to that of $a \alpha$-dimethylcamphor. Both are open to the objection that fenchone behaves very differently from camphor in many of its reactions. The oxidation of fenchene and fenchone ${ }^{10}$ leads to indecisive results, it being difficult to reconcile the reactions observed with either of the proposed formulæ. The production of dihydrofencholenamide, $\begin{array}{r}\mathrm{NH}_{2} \cdot \mathrm{CO} \cdot \mathrm{CMe}_{1} \cdot \mathrm{CH}_{2} \\ \mathrm{CH}_{2}-\mathrm{CH}_{2}\end{array}>\mathrm{CH} \cdot \mathrm{CHMe}_{2}$, by the action of sodamide on fenchone, and the formation of apofenchene,

$$
\underset{\mathrm{CH}-\mathrm{CH}_{2}}{\mathrm{CM} \cdot \mathrm{CH}_{2}}>\mathrm{CH} \cdot \mathrm{CHMe}_{2}
$$

(the constitution of which is established by its oxidation through a

8 F. W. Semmler and K. Bartelt, Ber., 1908, 41, 385, 866 ; A., i, 195, 355.

9 M. O. Forster and H. Holmes, Trans., 1908, 93, 242.

10 O. Wallach, Annalen, 1908, 362, $174 ; A$., i, 809. 
ketonic acid to $\beta$-isopropylglutaric acid) from the latter, is considered ${ }^{11}$ to favour Semmler's formula.

aa-Dimethylcamphor (III) should be capable of preparation from dimethylcampholide (I) by addition of potassium cyanide, hydrolysis to dimethylhomocamphoric acid (II), and distillation of the calcium salt. A comparison of this compound with fenchone should then be of considerable interest. It was found, however, ${ }^{12}$ that although the

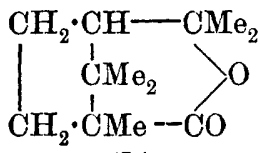

(I.)

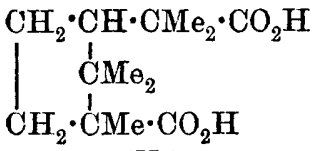

(II.)<smiles>CC(C)C1CCC1C(C)(C)C</smiles>

(III.)

required dimethylcampholide was readily obtained by the action of magnesium methyl iodide on camphoric anhydride, it was impossible to cause combination with potassium cyanide, isomerisation to an unsaturated acid always taking place.

The preparation of a number of derivatives of $a$-methylcamphor has shown ${ }^{13}$ that this compound is entirely similar to camphor, and consequently unlike fenchone. $\alpha$-Methylcamphor forms bromo- and sulpho-derivatives closely resembling those of camphor.

The synthesis of an isomeride of $\beta$-pinene from nopinone, described in last year's Report (p. 132), has been modified, and decomposition of the unsaturated acid is now found to yield fenchene or $\beta$-pinene, according to the conditions of dehydration of the nopinolacetic acid. The fenchene is probably formed by intramolecular change of $\beta$-pinene. Since $\beta$-pinene yields bornyl chloride with hydrogen chloride, both camphor and camphene may be prepared from it, this being the first synthesis of camphor from a compound (nopinone) containing a smaller number of carbon atoms. ${ }^{14}$

A cyclooctadiene was obtained by Willstätter and Veraguth in 1905 from the alkaloid $\psi$-pelletierine, and its ready polymerisation suggested the presence of conjugated double linkings in the molecule. ${ }^{15}$ This compound derives its principal interest from the fact that caoutchouc is supposed to be a polymerised dimethyl derizative of the same hydrocarbon. Since, however, the $\Delta^{1: 5}$-members of this series also polymerise readily, this constitution also becomes a possible one. An examination of the diozonide, which is hydrolysed by water to succindialdehyde, proves that the double linkings are in the 1:5-position : ${ }^{16}$

11 L. Bouveault and Levallois, Compt. rend., 1908, 146, 180 ; A., i, 193.

12 G. Komppa, Ber., 1908, 41, 1039 ; A., i, 352.

13 W. H. Glover, Trans., 1908, 93, 1285.

14 O. Wallach, Annalen, 1908, 363, 1 ; A., i, 997.

${ }^{15}$ Ann. Report, 1905, $121 . \quad{ }_{16}$ C. D. Harries, Ber., 1908, 41, 671; A., i, 254. 


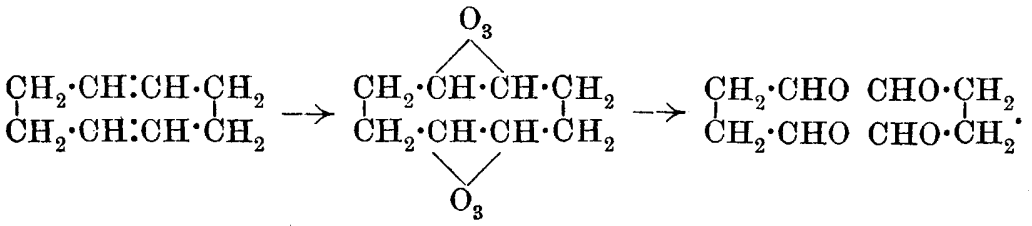

The investigation of the polymerisation products showed that there was no direct connexion between the constitution of the hydrocarbon and that of caoutchouc. The simplest polymeride, dicyclooctadiene, appears from its behaviour with ozone to have the constitution:

$$
\begin{aligned}
& \mathrm{CH} \cdot \mathrm{CH}_{2} \cdot \mathrm{CH}_{2} \cdot \mathrm{C}-\mathrm{CH}-\mathrm{CH}_{2} \cdot \mathrm{CH}_{2} \cdot \mathrm{CH}_{1} \\
& \stackrel{\mathrm{CH}}{\mathrm{CH}} \cdot \mathrm{CH}_{2} \cdot \mathrm{CH}_{2} \cdot \mathrm{CH} \quad \stackrel{\mathrm{CH}}{\mathrm{CH}_{2}} \cdot \mathrm{CH}_{2} \cdot \mathrm{CH}=\mathrm{CH} \text {. }
\end{aligned}
$$

Connected with the ethereal oils, although not a member of the terpene group, is elemicin, isolated by Semmler from elemi resin. ${ }^{17}$ This is proved to be 3:4:5-trimethoxy-1-allylbenzene (I). When distilled over sodium, it is converted into the isomeric propenyl

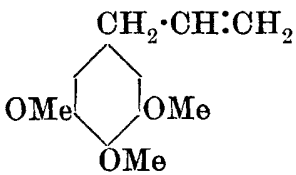

(I.)

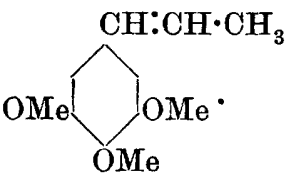

(II.)

derivative, isoelemicin (II). Permanganate oxidises it to $3: 4: 5$-trimethoxybenzoic acid. Sodium and alcohol reduce both elemicin and isoelemicin to $3: 5$-dimethoxy-1-n-propylbenzene, the $p$-methoxyl group being eliminated.

\section{Crystalline Liquids.}

The property of existing in a liquid phase, which exhibits certain of the optical properties of crystalline solids, for example, double refraction, is possessed by many organic substances, and the relationship which in all probability exists between their chemical constitution and the development of this crystalline liquid condition is at present under investigation.

In $p$-methoxycinnamic acid, which exhibits this peculiarity, the property is probably due to the presence of the group

$$
\mathrm{CH}_{3} \cdot \mathrm{O} \cdot \mathrm{C}_{6} \mathrm{H}_{4} \cdot \mathrm{CH}: \mathrm{CH}-\text {, }
$$

for dianisyltetrylene, which consists of two of these radicles, still retains the power of forming an anisotropic liquid. $p$-Methylaminobenzaldehydephenylhydrazone, $\mathrm{CH}_{3} \cdot \mathrm{NH} \cdot \mathrm{C}_{6} \mathrm{H}_{4} \cdot \mathrm{CH}: \mathrm{N} \cdot \mathrm{NH} \cdot \mathrm{C}_{6} \mathrm{H}_{5}, s$-di734.

17 F. W. Semmler, Ber., 1908, 41, 1768, 1918, 2183, 2556; A., i, 557, 558, 664, 
ethylbenzidine, $\quad \mathrm{C}_{2} \mathrm{H}_{5} \cdot \mathrm{NH} \cdot \mathrm{C}_{6} \mathrm{H}_{4} \cdot \mathrm{C}_{6} \mathrm{H}_{4} \cdot \mathrm{NH} \cdot \mathrm{C}_{2} \mathrm{H}_{5}, \quad$ and $p$-methoxycinnamaldazine,

$$
\mathrm{CH}_{3} \cdot \mathrm{O} \cdot \mathrm{C}_{6} \mathrm{H}_{4} \cdot \mathrm{CH}: \mathrm{CH} \cdot \mathrm{CH}: \mathrm{N} \cdot \mathrm{N}: \mathrm{CH} \cdot \mathrm{CH}: \mathrm{CH} \cdot \mathrm{C}_{6} \mathrm{H}_{4} \cdot \mathrm{O} \cdot \mathrm{CH}_{3} \text {, }
$$

which likewise display this phenomenon, are either para-substituted compounds or possess long, straight chains. ${ }^{18}$ Cholesterol derivatives, which frequently exhibit the crystalline liquid condition, probably contain an asymmetric group and a long, straight chain.

The turbidity of many of these crystalline liquids is not due to suspended impurities, emulsions, or inclusions of foreign substances, but is a natural consequence of the presence of differently situated anisotropic, crystalline fragments. Moreover, perfectly clear crystal line liquids have now been prepared, some of which maintain their transparency in any position, whilst others are clear or turbid according to the incidence of the light.

The chemical constitution of substances forming crystalline liquid phases warrants the view that a linear structure favours the development of the property, whilst a cruciform or many-branched configuration inhibits this condition.

Para-substituted benzylidene-p-amino- $a$-alkylcinnamates having the following general formula have been prepared and examined from this standpoint :

$$
\text { para- } \mathrm{X} \cdot \mathrm{C}_{6} \mathrm{H}_{4} \cdot \mathrm{CH} \cdot \mathrm{N} \cdot \mathrm{C}_{6} \mathrm{H}_{4} \cdot \mathrm{CH}: \mathrm{Y}_{\mathrm{Y}} \cdot \mathrm{CO}_{2} \mathrm{R} \text {. }
$$

The tendency to develop the crystalline liquid condition reaches its maximum when an ethyl or a $n$-propyl group is introduced at $\mathrm{R}$ (the ester radicle); it is also increased by the replacement of methoxyl at $\mathrm{X}$ (the para-substituent) by ethoxyl or phenyl. The lengthening of the side-chain $\mathrm{Y}$ in the order methyl, ethyl, and phenyl inhibits to an increasing extent the property of exhibiting the liquid crystalline condition. The property of circular polarisation is developed to a remarkable extent by the introduction of an active amyl group into position $\mathbf{R}$.

The ethyl $p$-azoalkylcinnamates and $p$-azoxyalkylcinnamates resemble the foregoing azomethine derivatives in respect of this property of assuming the crystalline liquid condition. ${ }^{19}$

The simpler azoxy-derivatives (azoxybenzene, p-azoxyphenetole, the three isomeric azoxytoluenes, and azoxyanisoles) can also exist in the anisotropic liquid condition, and it is stated that these modifications differ from the ordinary varieties in certain chemical properties. Among other anomalous reactions, they give the Liebermann nitrosocoloration, and are not transformed into hydroxyazo-compounds. ${ }^{20}$

\footnotetext{
18 T. Rotarski, Ber., 1908, 41, 1994 ; A., i, 640.

19 D. Vorlander, ibid., 2033 ; A., i, 641.

${ }^{20}$ T. Rotarski, $2 b i d ., 865 ; A$., i, 374.
} 
These differences are sufficiently remarkable to warrant a more extended investigation.

\section{Optical Activity.}

In recent measurements of the optical activity of organic compounds, the theoretical connexion with the degree of asymmetry of the molecule, as expressed by Guye's "asymmetry product," ${ }^{21}$ has been frequently referred to and discussed, without, however, any very definite conclusions having been yet reached. A recent physical investigation ${ }^{22}$ leads to the conclusion that the variation in the value of the expression with the temperature and the wave-length of the light used must be taken into account. The author states that if a substance containing a single asymmetric carbon atom could be found, the temperature of reversal of sign of which could be determined, a means would be provided of testing the validity of the modified Guye's equation, but this test has not yet been applied.

The difficulty of finding any simple formula for the relation has been further illustrated by the examination of a series of salts, all of which contained $p$-bromophenyl, methyl, and allyl, the remaining group being ethyl, n-propyl, isopropyl, or isoamyl. As in similar series examined previously, no simple relation was discovered. ${ }^{23}$ The influence of the constitution of the substituting groups may also be so great as to outweigh that of mass. ${ }^{24}$

The influence of the introduction of unsaturated groups into the molecule has also been further studied. ${ }^{25}$ The alkaloid salts of a number of acids were examined, and the rule that the change from the saturated to the ethylenic linking produces an increase in the rotatory power was confirmed. The triple linking, however, may give rise to a higher or a lower value in different cases, the direction depending mainly on the asymmetric part of the molecule. Neither could any rule be found for the comparative influence of cis-and transconfigurations. The presence of several unsaturated groups still further increases the optical activity, the relative nearness of the unsaturated linkings having an important effect. The investigation was extended to include sulphur derivatives in which the valency of the sulphur, and therefore the amount of its residual affinity, was variable. The progressively increasing unsaturation of the sulphur in the sulphone, $\mathrm{R}_{2} \mathrm{SO}_{2}$, the sulphoxide, $\mathrm{R}_{2} \mathrm{SO}$, and the sulphide, $\mathrm{R}_{2} \mathrm{~S}$, is accompanied by a small increase in the rotation, but the conjugation

21 Ann. Report, 1907, 178.

22 E. Bose, Physikal. Zeitsch., 1908, 9, 860 ; A., 1909, ii, 2.

23 H. O. Jones and J. R. Hill, Trans., 1908, 93, 295.

24 R. W. Everatt, ibid., 1225, 1789.

26 T. P. Hilditch, ibid., 700, 1388, 1618. 
of two bivalent sulphur atoms in the disulphide, RS·SR, produces a relatively enormous effect. The results obtained with alkaloid salts of aromatic sulphonic and sulphinic acids follow the same rule if the latter are assumed to contain sexavalent, and not quadrivalent, sulphur, an assumption for which there is chemical evidence. If both series of compounds contain sexavalent sulphur, the sulphonic acids will be the less saturated, owing to hydroxyl, possessing some residual affinity, replacing hydrogen: $\mathrm{R} \cdot \mathrm{SO}_{2} \cdot \mathrm{H} \rightarrow \mathrm{R} \cdot \mathrm{SO}_{2} \cdot \mathrm{OH}$.

No certain occurrence of optical activity has yet been observed in a compound in which the asymmetric carbon atom is not attached to other carbon atoms. Two compounds of very simple structure, chlorosulphoacetic acid, $\mathrm{SO}_{3} \mathrm{H} \cdot \mathrm{CHCl} \cdot \mathrm{CO}_{2} \mathrm{H}$, and chlorobromomethanesulphonic acid, $\mathrm{CHClBr} \cdot \mathrm{SO}_{3} \mathrm{H}$, one containing only two and the other only a single carbon atom, have been prepared and combined with various active bases, but without any resolution into optical isomerides being obtained. If isomerism in such a case is possible, the separation of the isomerides is evidently a very difficult one. ${ }^{26}$

The suggestion of van't Hoff, that enantiomorphous forms may exist of compounds containing no asymmetric atom, but deriving their asymmetry from the general structure of the molecule, as in allene derivatives,

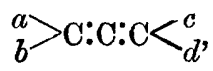

and that such isomerides should exhibit optical activity, is one of great theoretical interest, which has not yet been put to an experimental test. An attempt to prepare allene derivatives of the above type, capable of combining with active acids or bases, having proved unsuccessful, compounds have been selected in which symmetrical closed rings replace the double linkings, of which 1-methylcyclohexylidene4-acetic acid,

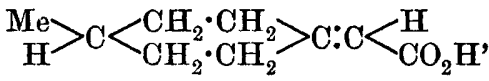

is a typical example. The synthesis of this acid ${ }^{27}$ has proved to be a difficult problem, and the product obtained is impure; the test of resolution has therefore not yet been applied. The problem is of such importance for stereochemical theory that it seems advisable to mention the investigation in this place, in spite of its incomplete state.

The problem of a complete asymmetric synthesis, that is, the artificial production of an optically active substance without the intervention of an optically active reagent, has been frequently attacked from

${ }^{26}$ W. J. Pope and J. Read, Trans., 1908, 93, 794.

27 W. H. Perkin, jun., and W. J. Pope, ibid., 1075. 
the physical as well as from the chemical side. The use of circularly polarised light has often been suggested and employed for this purpose, so far with entirely negative results. In the latest attempt in this direction ${ }^{28}$ the authors point out some of the conditions which must be fulfilled in order that such an attempt may have a prospect of success. The reaction by which the substance is produced must be one which is brought about by light. A reaction which proceeds independently of illumination is not likely to be affected by polarisation of the light falling on the reacting substance. A suitable reaction was found in the removal of carbon dioxide from substituted succinic, malonic, and cyanoacetic acids by light in the presence of uranium salts, as, for instance :

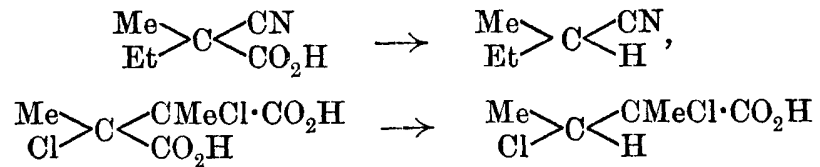

No optical activity of the resulting product was, however, observed when the light was polarised before entering the solution, and the attempt is therefore so far unsuccessful.

A remarkable series of observations is recorded with reference to the separation of active components from a $d l$-mixture. ${ }^{29} \quad$ A supersaturated solution containing, for instance, $d l$-sodium ammonium tartrate may be caused to crystallise by the addition of a crystal of the active modification of a tartrate isomorphous or isodimorphous with the dissolved salt, and the crystals separating will have the same sign as the crystal used for inoculation. This is not surprising when the similarity in crystalline structure is taken into account. It is further stated, however, that it is not necessary that the crystal used for inoculation should be optically active. The experiments were principally made with glycine, and when added to a supersaturated solution of $d l$-asparagine, deposition of active asparagine was brought about. It was impossible to predict whether the $d$ - or the $l$-form would separate, but the same crystal of glycine always brought about crystallisation of the same isomeride. It is suggested that glycine crystals are hemihedral. If these experiments should be confirmed, and are not found to be due to the presence of optically active substances in the glycine employed, a great advance will have been made in the artificial production of active compounds by an asymmetric synthesis.

Another line of attack which has been adopted by several workers,

${ }^{28}$ F. Henle and H. Haakh, Ber., 1908, 41, 4261 ; A., 1909, i, 6.

${ }^{29}$ I. Ostromisslensky, ibid., 3035 ; A., ii, 913. 
is that of preparing an asymmetric compound in an active solvent, the molecules of which might reasonably be expected to exert a directing influence on the course of the reaction. An attempt of this kind has now been made in the nitrogen series, but without success. Benzylmethylaniline was combined with allyl iodide in a number of optically active solvents, such as $d$-limonene, $l$-menthol, and $l$-menthyl chloromethyl ether, but in no case was an active ammonium iodide obtained. ${ }^{30}$

In the continued series of investigations of the influence of solvents on the optical activity of ethyl tartrate, Patterson and his co-workers have examined a large number of halogen and nitro-compounds. ${ }^{31}$ Amongst the halogenated solvents, such as alkyl iodides, chloroform, acetylene tetrabromide, etc., many exceptions were again found to the rule that specific rotation varies inversely with solution volume. With aromatic halogen derivatives, well-marked minina of rotation were observed at certain concentrations. The changes of rotation with temperature were also examined, and solutions in a-bromonaphthalene were found to have a maximum rotation at $94^{\circ}$, the case resembling that of dilute solutions of alkyl tartrates in water, the rotationtemperature curve of which also passes through a maximum. A wider range of activity was observed when aromatic nitro-compounds were used as solvents, the specific rotation at infinite dilution in $\alpha$-nitronaphthalene being about $+65^{\circ}$, and in $s$-trinitrobenzene about $-30^{\circ}$. The relation between the maximum rotation and the temperature at which it occurs is fairly independent of the nature of the solvent and of the concentration. As in the problem of the relation of activity to asymmetry, it is evident that in spite of the vast quantity of experimental material that has been accumulated, the complete theoretical explanation is far from having been attained.

Two forms of asymmetry have been observed in nitrogen compounds, the first, in substances containing tervalent nitrogen doubly linked with carbon or nitrogen, as in oximes and diazo-compounds; the second, in substances containing quinquevalent nitrogen. So far, activity has only been observed in the latter class when the five substituting groups are all different, although four different groups should suffice to produce asymmetry. A new class of active substances has now been found, in which two valencies of the nitrogen atom are united to the same, or similar, atoms. Methylethylaniline oxide, for example, has been resolved into two active components by conversion into the

30 E. Wedekind and O. Wedekind, Ber., 1908, 41, 456;A., i, 258.

31 T. S. Patterson and D. Thomson, Trans., 1908, 93, 355; T. S. Patterson and D. P. McDonald, ibid., 936 ; T. S. Patterson, ibid., 1836. 
$d$-camphorsulphonate. The solution of the active oxide, which is a very weak base, must contain

$$
\begin{array}{lll}
\mathrm{CH}_{3}- & \mathrm{CH}_{3}- \\
\mathrm{C}_{2} \mathrm{H}_{5} & \mathrm{C}_{6} \mathrm{H}_{5}
\end{array}>\mathrm{N}: \mathrm{O} \quad \text { or } \quad \begin{aligned}
& \mathrm{C}_{2} \mathrm{H}_{5} \\
& \mathrm{C}_{6} \mathrm{H}_{5}
\end{aligned}>\mathrm{N}<\mathrm{OH} ;
$$

in either case, the number of different groups united with the nitrogen atom is only four. If the compound present in the solution of the base has the second formula, the positions of the two hydroxyls cannot be identical, since the addition of hydrochloric acid produces a salt having the same activity as the base. It is concluded that four of the valencies of a quinquevalent nitrogen atom are directed, like those of a carbon atom, to the angles of a tetrahedron, the fifth (ionisable) valency being mobile. Isomerism would then occur whenever the groups attached by the four fixed valencies were different. ${ }^{32}$

Active piperidine derivatives having a large substituent in position 2 , and an alkyl attached to the nitrogen atom, have been found to yield two stereoisomeric quaternary salts with alkyl haloids, only a single product being obtained when the substituting group in position 2 is absent or small. This has been further confirmed by the examination of $\alpha$ - and $\beta$-pipecoline derivatives, benzyl haloids being added to the $l$-bases. In neither case were optical isomerides obtained. ${ }^{33}$

Turning now from the production of active substances to their resolution and racemisation, the preparation of the two active forms of benzoin has now been accomplished. l-Mandelic acid is converted into the amide, and this is combined with magnesium phenyl bromide, yielding l-benzoin. The $d$-isomeride is prepared in a similar way. With the exception of levulose, no keto-alcohol had previously been resolved into its optically active components. ${ }^{34}$

The autoracemisation of active ammonium salts in solution has been the subject of controversy, ${ }^{35}$ but it now appears certain from cryoscopic measurements and from comparative determinations of the velocity of dissociation and of change in rotation, that the observed alteration in rotation is due to the breaking up of the ammonium salt in solution into tertiary amine and alkyl halide.

A case of partial racemisation has been observed in the hydrogen tartrate of hydroquinaldine. ${ }^{36}$

The Walden inversion has been the subject of several investigations.

32 J. Meisenheimer, Ber., 1908, 41, 3966 ; A., 1909, i, 20.

33 M. Seholtz, ibid., 2005 ; A., i, 678.

${ }^{34}$ A. McKenzie and H. Wren, Trans., 1908, 93, 309.

${ }^{35}$ E. Wedekind, O. Wedekind, and F. Paschke, Ber., 1908, 41, 1029, $2659 ; A$, i, 334, 722; H. von Halban, ibid., $2417 ; A$., i, 627.

${ }^{36}$ A. Ladenburg and W. Herrmann, ibid., $966 ; A ., \mathrm{i}, 364$. 
The replacement of halogen by hydroxyl or methoxyl in phenylchloroacetic acid has been examined from this point of view, the results being expressed in the two following schemes:

I.

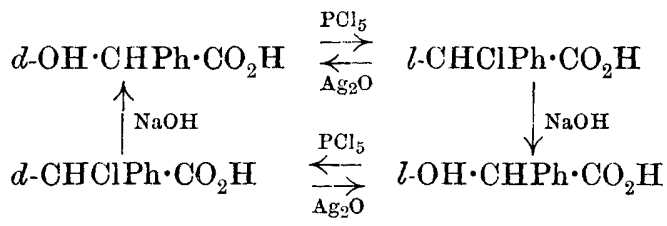

II.

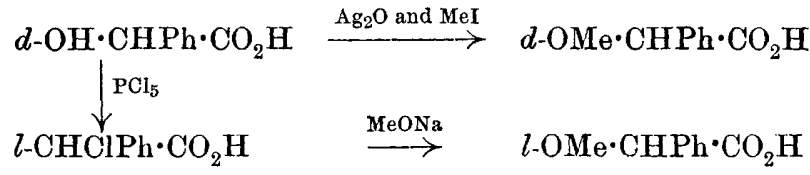

It appears from this that in the interconversion of the mandelic acids, sodium hydroxide behaves abnormally and silver oxide normally. ${ }^{37}$

E. Fischer has also continued his investigations on the same subject, ${ }^{38}$ and finds that valine ( $a$-aminoisovaleric acid) remains optically unchanged after conversion into the bromo-fatty acid and back again into the amino-compound. It is suspected, however, that this result is due rather to a double Walden inversion than to its absence. This exceptional behaviour is attributed to the influence of the isopropyl group. Active aminophenylacetic acid is racemised so rapidly by nitrosyl bromide or nitrous acid that pure active products could not be obtained.

It is oniy possible to refer to a few more papers dealing with stereoisomerism. A method of determining the configuration of $\alpha$-dioximes is furnished by the fact that of the possible isomerides, only the synmodification has the property of forming complex metallic dioximines. ${ }^{39}$ The method has been tested in a number of cases, and has been applied to several $a$-dioximes of previously unknown configuration.

No marked difference is to be found between the dielectric constants of $d-, l$, and $i$-modifications of asymmetric compounds. Ethyl racemate, however, has a much greater absorptive power for electric waves than the tartrate, and, since hydroxylic groups are the principal cause of such absorption, this suggests that the hydroxyls are mainly concerned in the formation of the racemic compound. ${ }^{40}$

The viscosity of a solution of a racemic salt is always less than that

37 A. MeKenzie and G. W. Clough, Trans., 1908, 93, 811.

38 E. Fischer and H. Scheibler, Ber., 1908, 41, 889, 2891 ; A., i, 324, 857 ; E. Fischer and $O$. Weichhold, ibid., $1286 ; A$., i, 419.

39 L. Tschugaeff, ibid., $1678 ; A$., i, 554.

${ }^{40}$ A. W. Stewart, Trans., 1908, 93, 1059. 
of the active components, but the difference is very small. The transition point of the racemate also appears as a break in the temperature-viscosity curve. ${ }^{41}$

\section{Some Reactions of the Cyclic Hydrocarbons and their Derivatives.}

1. Aromatic from Hydroaromatic Compounds. - The conversion of aromatic substances into hydroaromatic derivatives by hydrogen and a catalyst has already been mentioned. An interesting case of the converse change has recently been worked out, in which phenol has been produced from cyclohexanol in such a way that the intermediate products could be isolated, showing the gradual transition from the saturated to the aromatic ring.

cycloHexanone, obtained by the oxidising action of bromine or chlorine from the saturated alcohol, was brominated to 1-bromocyclohexanone. The elimination of hydrogen bromide led to $\Delta^{2}$-cyclohexenone; addition of bromine to this substance, followed by removal of bydrogen bromide from the resulting dibromide, finally gave phenol :

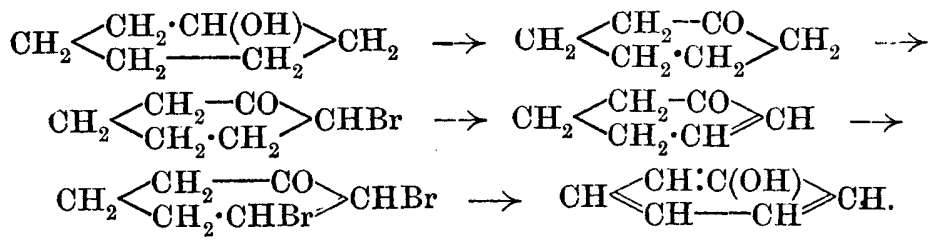

Ethyl cyclohexane-2-carboxylate is converted into salicylic acid by a precisely similar series of changes. ${ }^{42}$

2. Oxidation of Aromatic Substances.-Although the aromatic hydrocarbons (benzene, naphthalene, etc.) are not themselves oxidised to definite products by chromyl chloride yet, the corresponding aldehydes are readily obtained with this oxidising agent from the $m$ and $p$-nitrotoluenes and the three isomeric chlorotoluenes. In a similar manner, diphenylmethane and triphenylmethane are converted quantitatively into benzophenone and triphenylcarbinol respectively. ${ }^{43}$

Caro's acid has been successfully applied to the preparation of tertiary amine oxides ; tetramethyldiaminodiphenylmethane and hexamethyltriaminotriphenylmethane having been thus converted into tetramethyldiaminodiphenylmethane dioxide (I) and hexamethyltriaminotriphenylmethane trioxide (II) respectively.

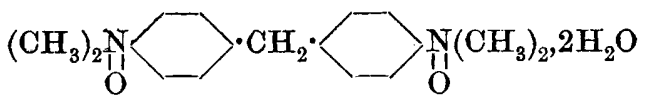

(I.)

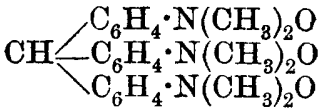

(II.)

41 A. E. Dunstan and F. B. Thole, Trans., 1908, 93, 1815.

12 A. Kötz and C. Götz, Annalen, 1907, 358, 183 ; A., i, 173.

43 H. D. Law and F. M. Perkin, Trans., 1908, 93, 1633. 
The reactions of these amine oxides are of interest ; sulphur dioxide and nitrous acid convert them respectively into the sulphonic acids and nitro-derivatives of the original tertiary bases. In these reactions the

$$
\mathrm{CH}_{2}\left[\mathrm{C}_{6} \mathrm{H}_{3}\left(\mathrm{NMe}_{2}\right) \cdot \mathrm{SO}_{3} \mathrm{H}\right]_{2} \quad \mathrm{CH}_{2}\left[\mathrm{C}_{6} \mathrm{H}_{3}\left(\mathrm{NO}_{2}\right) \cdot \mathrm{NMe}_{2}\right]_{2} \text {, }
$$

oxygen atoms of the di- and tri-oxides become involved, and the substituents take up ortho-positions with respect to the nitrogen atoms. ${ }^{44}$ The oxidation of acetyl-p-phenylenediamine by Caro's acid results in the formation of $p$-nitrosoacetanilide (green plates, m. p. $175^{\circ}$ ), which is transformed by water into its colourless, bimolecular polymeride (m. p. $\left.181^{\circ}\right) .45$

The technically important conversion of $p$-nitrotoluene and its derivatives into stilbene compounds has been further investigated, the results showing that the following scheme of condensation in two stages, accompanied at each stage by aerial oxidation, furnishes an explanation which is generally true of these condensations.

$$
\begin{aligned}
& 2 \mathrm{CH}_{3} \cdot \mathrm{C}_{6} \mathrm{H}_{4} \cdot \mathrm{NO}_{2} \underset{\text { 1st stage }}{\stackrel{\text { condensation }}{\longrightarrow}}
\end{aligned}
$$

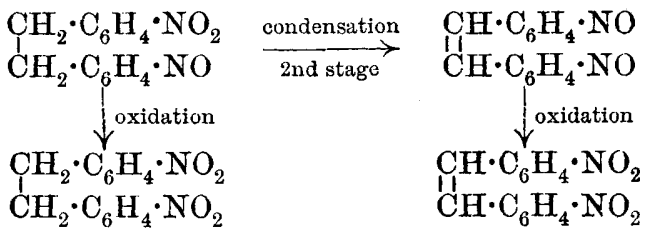

4-Nitro-o-xylene and 4-nitro-2-methoxy ${ }^{+}$luene with methyl-alcoholic potash and aerial oxidation gave chiefly $4: 4^{\prime}$-dinitro-2:2'-dimethylstilbene and $4: 4^{\prime}$-dinitro-2:2'-methoxystilbene. Similar changes occurred with 4-nitro-o-toluic acid and 2:4-dinitrotoluene, but in the former case sodium hypochlorite, and in the latter, iodine were employed as oxidising agents. ${ }^{46}$

3. Reduction of Aromatic Nitro-compounds.-A new phase in the reduction of nitro-groups has been observed by G. Heller and A. Sourlis, ${ }^{47}$ who also correct an earlier statement of Bamberger's, ${ }^{48}$ that his so-called "agnotobenzaldehyde" has the formula

$$
\mathrm{COH} \cdot \mathrm{C}_{6} \mathrm{H}_{4} \cdot \mathrm{N}(\mathrm{OH}) \cdot \mathrm{O} \cdot \mathrm{N}(\mathrm{OH}) \cdot \mathrm{C}_{6} \mathrm{H}_{4} \cdot \mathrm{COH} \text {. }
$$

This substance is really a molecular compound of $o$-nitrobenzaldehyde and $o$-hydroxylaminobenzaldehyde,

$$
\mathrm{COH} \cdot \mathrm{C}_{6} \mathrm{H}_{4} \cdot \mathrm{NO}_{2}, \mathrm{COH} \cdot \mathrm{C}_{6} \mathrm{H}_{4} \cdot \mathrm{NH} \cdot \mathrm{OH} \text {. }
$$

They find, however, that the reduction of o-nitromandelonitrile with

44 E. Bamberger and L. Rudolf, Ber, 1908, 41, 3290 ; A., i, 1011.

45 J. C. 'Cain, Trans., 1908, 93, 686.

46 A. G. Green and J. Baddiley, ibid., 1721.

47 Ber., 1908, 41, 373 ; A., i, 208.

48 Ibid., 1906, 39, 4252; A., 1907, i, 163. 
zinc dust leads to the formation of a molecular compound of hydroxylaminomandelonitrile and dihydroxylaminomandelonitrile, $\mathrm{CN} \cdot \mathrm{CH}(\mathrm{OH}) \cdot \mathrm{C}_{6} \mathrm{H}_{4} \cdot \mathrm{NH} \cdot \mathrm{OH}, \mathrm{CN} \cdot \mathrm{CH}(\mathrm{OH}) \cdot \mathrm{C}_{6} \mathrm{H}_{4} \cdot \mathrm{N}(\mathrm{OH})_{2}$.

This product on treatment with phenylhydrazine yields hydroxyisatinphenylhydrazone and the $\alpha$ - and $\beta$-phenylhydrazones of isatin.

The reduction of nitro-compounds by alcoholic ammonium sulphide, which was first practised by Zinin in 1842, has been further developed in recent years. In 1902 and subsequently, J. B. Cohen and others showed that hydroxylamino-derivatives were produced by the partial reduction of trinitrobenzene and trinitrotoluene with hydrogen sulphide in the presence of a small amount of ammonia. They also found that chloronitro-compounds and alkyl dinitrobenzoates likewise gave hydroxylamines under similar conditions. ${ }^{40}$ The fact that this change, $\mathrm{R} \cdot \mathrm{NO}_{2} \rightarrow \mathrm{R} \cdot \mathrm{NH} \cdot \mathrm{OH}$, occurs generally, has been further demonstrated by reducing the simpler nitro-compounds with alcoholic ammonium sulphide in the cold, when excellent yields of the corresponding arylhydroxylamines were obtained. For example, a-nitronaphthalene gives $a$-naphthylhydroxylamine, from which $a$-nitrosonaphthalene is easily produced by oxidation with silver oxide or lead peroxide in anhydrous solvents. ${ }^{50}$

It has generally been assumed that the azoxy-compounds formed during reduction by a condensation of the nitroso- and hydroxylaminoderivatives can only arise in neutral or alkaline solutions. But in certain cases this condensation may occur even in the presence of mineral acids. The reduction of certain substituted nitro- and dinitro-compounds has been systematically examined, the results showing that (1) condensation and reduction of the intermediate nitroso- and hydroxylamino-derivatives both proceed at a measurable rate whether the solution be acid, neutral, or alkaline; (2) condensation is induced by the presence of tervalent nitrogen in the free arylhydroxylamine, the quinquevalent nitrogen of the hydroxylamine salt being incapable of condensation. ${ }^{51}$

4. Formation of Aromatic Hydroxylic Compounds. - In practice the introduction of hydroxyl into the nucleus of an aromatic hydrocarbon requires several operations, although small amounts of nitrated phenols are produced during many nitrations. According to a recent patent, a mixture of benzene, strong nitric acid, and mercuric nitrate gives a fairly good yield of picric acid, together with smaller amounts of nitrobenzene and 0 -nitrophenol. ${ }^{52}$

The nitration process may be divided into two phases, in the second

49 Trans., 1902, 81, $26 ; 1905,87,1257$.

so R. Willstätter and H. Kubli, Ber., 1908, 41, 1936 ; A. i, 522.

51 B. Flürscheim and T. Simon, Trans., 1908, 93, 1463.

${ }^{52}$ R. Wolffenstein and O. Böters, D.R.-P. 194883 ; A., i, 629.

REP.-VOL. V. 
of which water is usually eliminated from the additive compound formed in the initial phase :

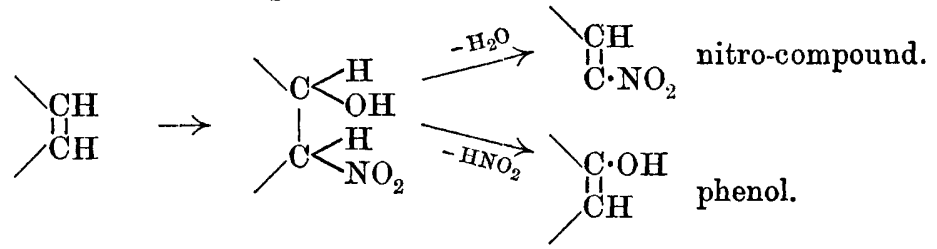

The alternative elimination of nitrous acid leads to the production of phenolic compounds.

The direct introduction of hydroxyl groups into the anthracene molecule has been effected, and alizarin, free from by-products, may be produced by heating anthraquinone with potassium chlorate and aqueous alkali hydroxide at $200^{\circ} .53$

Similarly, anthrarufin (1:5-dihydroxyanthraquinone) and chrysazin (1:8-dihydroxyanthraquinone) yield respectively the $1: 2: 5$ - and $1: 2: 8$-trihydroxyanthraquinones when they are heated at $180-185^{\circ}$ with sodium nitrate and aqueous alkalis, a mixture of potassium and sodium hydroxides giving the best result. ${ }^{54}$

\section{Ring Formation.}

The general tendency which undoubtedly exists for the formation of five- or six-membered rings in preference to those containing fewer or more components, is usually explained in terms of von Baeyer's strain hypothesis, to which reference was made in last year's Report (p. 138). The new cases of ring formation observed during the past year furnish further confirmation of the validity of this generalisation.

A striking illustration of the way in which the above tendency affects the properties of straight-chain compounds is afforded by a study of the aminoketones having the general formula

$$
\mathrm{C}_{6} \mathrm{H}_{5} \cdot \mathrm{CO} \cdot\left[\mathrm{CH}_{2}\right] x \cdot \mathrm{NH}_{2} \text {. }
$$

A general method has been devised for preparing these substances, which consists in converting the phthalimino-aliphatic acids into their chlorides, and then condensing these with benzene in the presence of aluminium chloride : ${ }^{55}$

$$
\begin{aligned}
& \mathrm{CO}_{2} \mathrm{H} \cdot\left[\mathrm{CH}_{2}\right]_{x} \cdot \mathrm{N}: \mathrm{C}_{8} \mathrm{H}_{4} \mathrm{O}_{2} \rightarrow \mathrm{COCl} \cdot\left[\mathrm{CH}_{2}\right]_{x} \cdot \mathrm{N}: \mathrm{C}_{8} \mathrm{H}_{4} \mathrm{O}_{2} \rightarrow \mathrm{CH}_{2} \rightarrow \\
& \mathrm{C}_{6} \mathrm{H}_{5} \cdot \mathrm{CO} \cdot\left[\mathrm{CH}_{2}\right]_{x} \cdot \mathrm{N}: \mathrm{C}_{8} \mathrm{H}_{4} \mathrm{O}_{2} \rightarrow \mathrm{C}_{6} \mathrm{H}_{5} \cdot \mathrm{CO} \cdot\left[\mathrm{CH}_{2}\right] \cdot \mathrm{NH}_{2}(\mathrm{I}) .
\end{aligned}
$$

Acid hydrolysis of the ketone leads to fission at the double linking,

${ }_{53}$ D.R.-P. 116526 ; A., i, 191.

${ }_{51}$ D.R.-P. 196980 and 195028 ; A., i, 807.

${ }^{55}$ S. Gabriel, Ber., 1907, 40, 2649 ; 1908, 41, 1127 ; A., 1907, i, $625 ; 1908$, i, 464. 
when phthalic acid and the salt of the aminoketone (I) are set free. It was at once seen that the stability of these compounds varied considerably with the value of $x$. The $\alpha$-aminoketones corresponding with $x=1$ are only known in the form of their salts. When liberated therefrom, they undergo simultaneously condensation and oxidation, so that a six-membered pyrazine ring is produced.

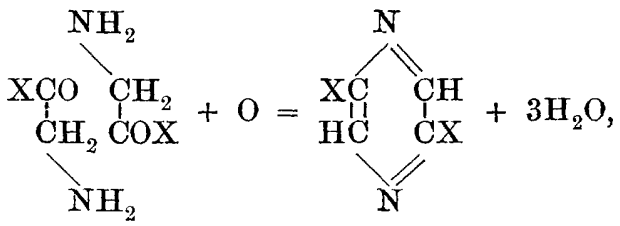

The $\beta$-aminoketones, such as diacetoneamine,

$$
\mathrm{CH}_{3} \cdot \mathrm{CO} \cdot \mathrm{CH}_{2} \cdot \mathrm{C}\left(\mathrm{CH}_{3}\right)_{2} \cdot \mathrm{NH}_{2} \text {, }
$$

are stable, and can be isolated without showing any tendency to undergo cyclic condensation into four- or eight-membered rings. The $\gamma$-aminoketones are so unstable that even in the form of their hydrochlorides, condensation occurs with the production of a fivemembered ring; thus phenyl $\gamma$-aminopropyl ketone gives rise to 2-phenylpyrroline :

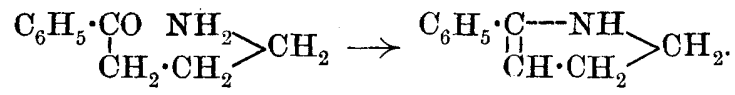

The $\delta$-aminoketones are as unstable as the $\gamma$-compounds. In preparing one of these, the following series of operations was carried out :

$$
\begin{aligned}
& \mathrm{C}_{8} \mathrm{H}_{4} \mathrm{O}_{2}: \mathrm{N} \cdot\left[\mathrm{CH}_{2}\right]_{3} \cdot \mathrm{CH}\left(\mathrm{CO}_{2} \cdot \mathrm{C}_{2} \mathrm{H}_{5}\right)_{2} \stackrel{\mathrm{HI}}{\longrightarrow} \mathrm{C}_{8} \mathrm{H}_{4} \mathrm{O}_{2}: \mathrm{N} \cdot\left[\mathrm{CH}_{2}\right]_{4} \cdot \mathrm{CO}_{2} \mathrm{H} \stackrel{\mathrm{PCl}_{5}}{\longrightarrow} \\
& \mathrm{C}_{8} \mathrm{H}_{4} \mathrm{O}_{2}: \mathrm{N} \cdot\left[\mathrm{CH}_{2}\right]_{4} \cdot \mathrm{COCl} \stackrel{\left(\mathrm{C}_{6} \mathrm{H}_{6}, \mathrm{AlCl}_{3}\right)}{\longrightarrow} \mathrm{C}_{8} \mathrm{H}_{4} \mathrm{O}_{2}: \mathrm{N} \cdot\left[\mathrm{CH}_{2}\right]_{4} \cdot \mathrm{CO} \cdot \mathrm{C}_{6} \mathrm{H}_{5} .
\end{aligned}
$$

Hydrolysis of the final product, $\delta$-phthaliminovalerophenone, gave rise, not to $\delta$-aminovalerophenone, but to 2 -phenyltetrahydropyridine, the six-membered cyclic condensation product :

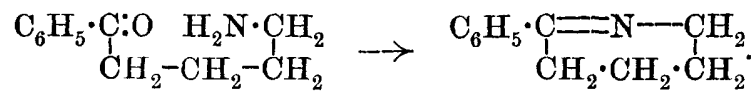

The $\epsilon$-aminoketones, for example, $\epsilon$-aminocaprophenone, which might give rise to seven-membered rings, are quite stable under conditions in which the $\gamma$-and $\delta$-aminoketones condense to pyrrole and pyridine derivatives respectively. ${ }^{56}$

The stability of $\beta$-substituted ketones disappears in the presence of a reagent capable of condensing so as to form a five-membered ring. Methyl $\beta$-chloroethyl ketone condenses in this way with hydroxylamine, phenylhydrazine, or any of the reagents used in detecting carbonyl oxygen.

56 S. Gabriel and J. Colman, Ber., 1908, 41, 2010, 2014 ; A., i, 648, 649. 
An isooxazoline, $\mathrm{N}<_{\mathrm{O}-\mathrm{C} \cdot \mathrm{CH}_{3} \cdot \mathrm{CH}_{3}}^{\mathrm{CH} \cdot \mathrm{CH}_{2}}$, is produced with hydroxylamine, whilst hydrazine and phenylhydrazine yield pyrazolines, ${ }^{57}$

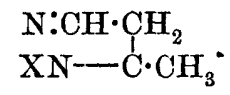

A methyl group situated in an aromatic nucleus generally preserves its inert paraffinoid character, but the tendency for ring formation may become sufficiently great to overcome this inertia, and the methane carbon atom then becomes involved in the formation of a new ring.

When the nitrosoacyl-o-toluidines are gently warmed in an anhydrous solvent, a condensation of this kind occurs and an indazole is produced. ${ }^{58}$

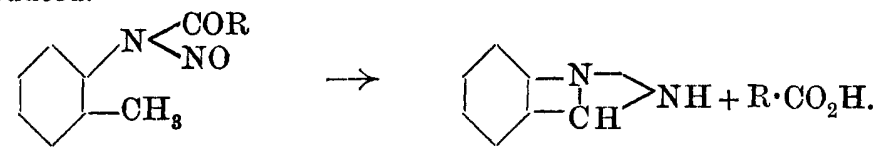

The intervention of a methyl substituent also occurs when a mixture of 2-methyl-1:2'-dianthraquinonylamine and lead oxide are added to aqueous potassium hydroxide at $170^{\circ}$.
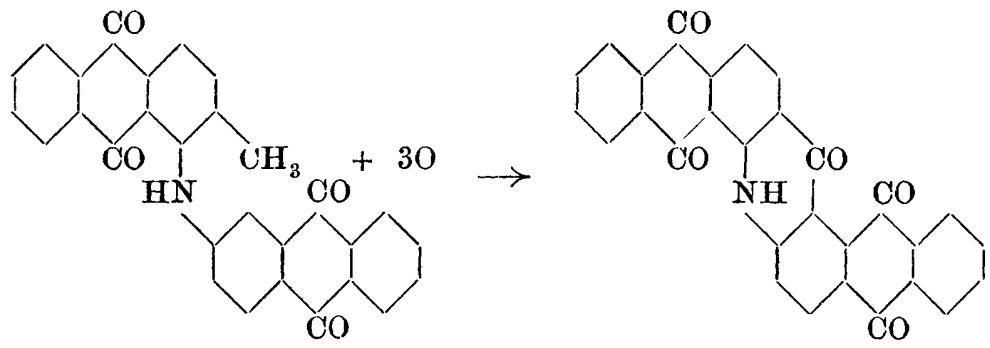

$a s$-Dianthraquinonyl-p-acridone thus produced is a red substance, which on reduction gives an oxidisable, violet leuco-derivative. ${ }^{59}$

Several ortho-acridones of the anthracene series have been obtained by the condensation of acetylmethyl-1-aminoanthraquinone and its derivatives.
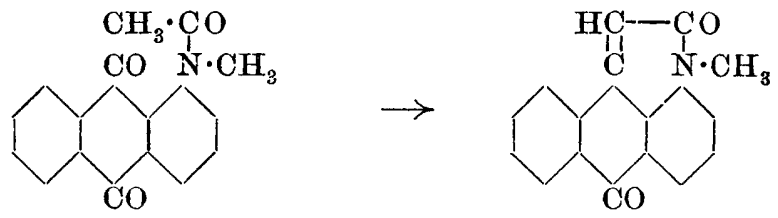

57 M. Maire, Bull. Soc. chim., 1908, [iv], 3, 272 ; A., i, 290.

${ }_{58}$ P. Jacobson and L. Huber, Ber., 1908, 41, 660 ; A., i, 298.

59 D.R.-P. 192436 ; A., i, 456. 
In these substances the methyl radicle is in an aliphatic group, but, nevertheless, the same tendency to the formation of six-membered rings underlies the condensation. ${ }^{60}$

$o$-Phenylenediacetonitrile (I), when warmed in alcoholic solution containing a trace of sodium ethoxide, undergoes molecular rearrangement into $\beta$-imino- $a$-cyanohydrindene (II) :

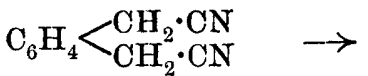

(I.)

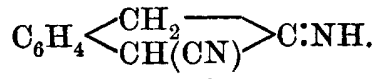

(II.)

This product gives all the reactions of an imino-derivative, but when the cyanogen group is replaced by $\mathrm{CO}_{2} \mathrm{H}, \mathrm{CO}_{2} \cdot \mathrm{C}_{2} \mathrm{H}_{5}$, or $\mathrm{CO} \cdot \mathrm{NH}_{2}$, then the structure changes to that of an aminoindene. The acid (III) does not lose its nitrogen until after carbon dioxide has been eliminated, when $\beta$-hydrindone (IV) is produced :

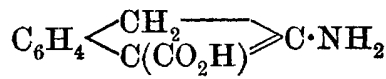

(III.)

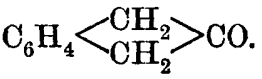

(IV.)

The above $\beta$-imino- $\alpha$-cyanohydrindene is hydrolysed by dilute acids into a-cyano- $\beta$-hydrindone $(V)$; this compound yields a phenylhydrazone and a $C$-methyl derivative (VI), but also reacts in its enolic form (VII) to give rise to acyl and o-alkyl derivatives :

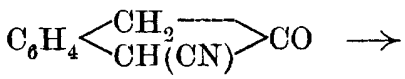

(V.)

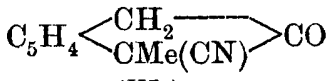

(VI.)<smiles>OC1CC2CCC(C1)C21c2ccccc21</smiles>

These results afford an interesting example of the formation of a five-membered ring, the structure of which is greatly influenced by the nature of its substituents. ${ }^{61}$

The interaction of the primary aromatic amines and $2: 3: 5$-trinitro4-acetylaminophenol, a substance containing a singularly mobile nitro-group in position 3 , leads to the production of iminazoles :<smiles></smiles>

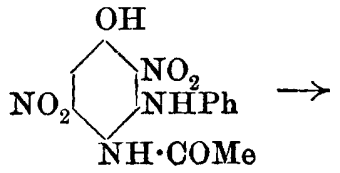

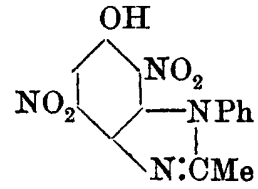

Dinitrohydroxy-1-phenylmethylbenziminazole.

In some cases the intermediate product can be isolated, but

60 D.R.-P. 192201 ; A., i, 456.

61 C. W. Moore and J, F. Thorpe, Trans., 1908, 93, 165. 
generally the ring formation occurs concurrently with the first condensation. ${ }^{62}$

The disruption of an unstable four-membered ring, and the subsequent formation of a more stable six-membered system, is illustrated by the condensation of primary amines and 4-nitroacetoanthranil :

$$
\begin{gathered}
\mathrm{NO}_{2} \cdot \mathrm{C}_{6} \mathrm{H}_{3}<\mathrm{CO} \cdot \mathrm{CO} \cdot \mathrm{CH}_{3}+\mathrm{RNH}_{2} \rightarrow \mathrm{NO}_{2} \cdot \mathrm{C}_{6} \mathrm{H}_{3}<\mathrm{CO} \cdot \mathrm{NHR} \cdot \mathrm{NH} \mathrm{CH}_{3} \rightarrow \\
\mathrm{NO}_{2} \cdot \mathrm{C}_{6} \mathrm{H}_{3}<\mathrm{CO} \cdot \mathrm{NR}=\mathrm{C} \cdot \mathrm{CH}_{3} .
\end{gathered}
$$

The process is general, for condensation occurred with extreme readiness with ammonia, methylamine, benzylamine, aniline and $\beta$-naphthylamine, and several other bases. ${ }^{63}$

The well-known Skraup reaction has been utilised in the production of technically important quinolines of the anthracene series. 1-Aminoanthraquinone, condensed with glycerol in the presence of sulphuric and nitrobenzenesulphonic acids, yields anthraquinonyl-1-quinoline,

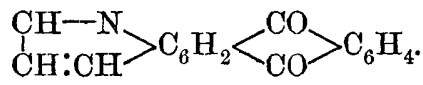

Anthraquinonyl-1:5-diquinoline is prepared in a similar manner from $1: 5$-diaminoanthraquinone : ${ }^{64}$

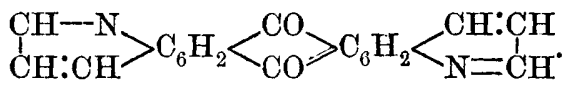

The Skraup synthesis, applied for the first time in the phenanthrene series, has led to the production of $9: 10$-phenanthraquinoline from 9 -aminophenanthrene, ${ }^{65}$

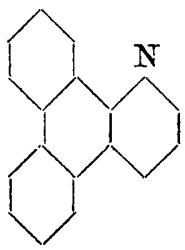

At the present time a special interest attaches to carbazole and its hydrogenated derivatives, owing to their possible relationship with the alkaloids of the strychnine group. Starting from the cyclohexanones, which are now readily procurable, a fairly general method has been

B2 R. Meldola and J. G. Hay, Trans, 1908, 93, 1659.

63 M. T. Bogert and W. Klaber, J. Amer. Chem. Soc., 1908, 30, $807 ;$ A., i, 466.

64 D.R.P. 189234 ; A., i, 365.

65 F. Herschmann, Ber, , 1908, 41, 1998 ; A., i, 683. 
ORGANIC CHEMISTRY.

worked out for the synthesis of tetrahydrocarbazole and its homologues:<smiles></smiles><smiles></smiles>

Tetrahydrocarbazole.

The aromatic hydrazones of these cyclic ketones undergo condensation when gently warmed with dilute acids. The reaction is general for all aromatic hydrazines containing one free ortho-position, but only takes place with simple saturated cyclic ketones, and not with those containing either unsaturated or bridged rings. ${ }^{66}$

Tetrahydrogenated acridines have been obtained from the cyclic ketones by the following methods.

1. Condensation with aromatic $o$-amino-aldehydes and ketones :<smiles>CCOCc1ccccc1N</smiles>

2. Condensation with isatin and alkali hydroxides:<smiles>C1CCOCC1</smiles><smiles>NC(=O)C1CCCCC1C(=O)O</smiles><smiles>O=C(O)c1c2ccccc2nc2ccccc12</smiles>

3. Condensation of the o-acylketohexamethylenes with aniline and its homologues. This process leads to a minture of a tetrahydroacridine with a tetrahydrophenanthridine :<smiles>COC1CCCC1=O</smiles><smiles>Nc1ccccc1</smiles><smiles>[CH]1[CH]C1</smiles><smiles></smiles><smiles>CCCCCCC(=O)O</smiles><smiles></smiles><smiles></smiles><smiles></smiles>

${ }^{66}$ W. Borsche, Annaten, 1908, 359, 49 ; A., i, 365. 
The foregoing hydroaromatic carbazoles and acridines can be transformed into the corresponding aromatic compounds by heating with lead oxide. 67

Diphenanthracridine (I) and phenophenanthracridine (II) have

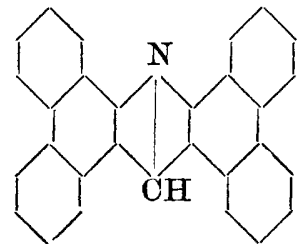

(I.)

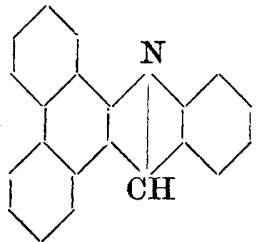

(II.)

been prepared, the first by condensing 9-aminophenanthrene with methylene halides, and the second, by treating the same base with $o$-nitrobenzyl chloride and stannous chloride. ${ }^{68}$

The foregoing cases of ring formation are all examples of the general tendency to the production of five- and six-membered cyclic systems. This rule is not, however, without important exceptions, and seven- and eight-membered rings do occasionally make their appearance. The cyclooctadienes, mentioned in connexion with the chemistry of the terpenes and indiarubber, contain a ring of eight carbon atoms.

The following remarkable series of reactions, published towards the close of 1907, illustrate the exceptional case of the conversion of a benzene nucleus into a seven-membered ring.

Reference has already been made, under the heading of aliphatic diazo-compounds, to the great variety of products obtainable from ethyl diazoacetate. One of the most remarkable properties of this ester is its reaction with benzene and its homologues. When gently warmed with one of these hydrocarbons, nitrogen is evolved, and the bivalent residue, $\mathrm{CO}_{2} \mathrm{Et} \cdot \mathrm{CH}<$, attaches itself to two contiguous carbon atoms of the aromatic nucleus with the formation of a bicyclic system, consisting, as a whole, of a seven-membered ring, but divided internally by a bridged linking into two cyclic components, one containing three, and the other six, members. The case of $m$-xylene was described in the last communication on this subject, and as it resembles those of toluene and benzene, it may be taken as an illustration of this condensation.

Inasmuch as the bicyclic structure is like that existing in carone, the initial product receives a name derived by transposition from that of the analogously constituted ketone. This methyl 1:3-dimethylnorcardienecarboxylate (I), so far, retains an aliphatic character, that

67 Borsche, Ber, 1908, 41, 2203 ; A., i, 682.

68 P. C. Austin, Trans,, 1908, 93, 1760. 
it yields the amide (II) on treatment with ammonia. Alkaline hydrolysis, however, converts it into a monocyclic acid (III), 3 :5-dimethylcyclo- $\Delta^{2: 3: 5}$-heptatriene-1-carboxylic acid. The amide gives rise to the isomeric 3:5-dimethylcyclo- $\Delta^{3: 5: 7}$-heptatriene-1-carboxylic acid (IV) when hydrolysed with alkalis, but under the influence of acids the heptatriene ring is transformed again into a benzene ring, and 3:5-dimethylphenyl-4-acetic acid $(V)$, isomeric with the two heptatrienecarboxylic acids, is produced. ${ }^{69}$
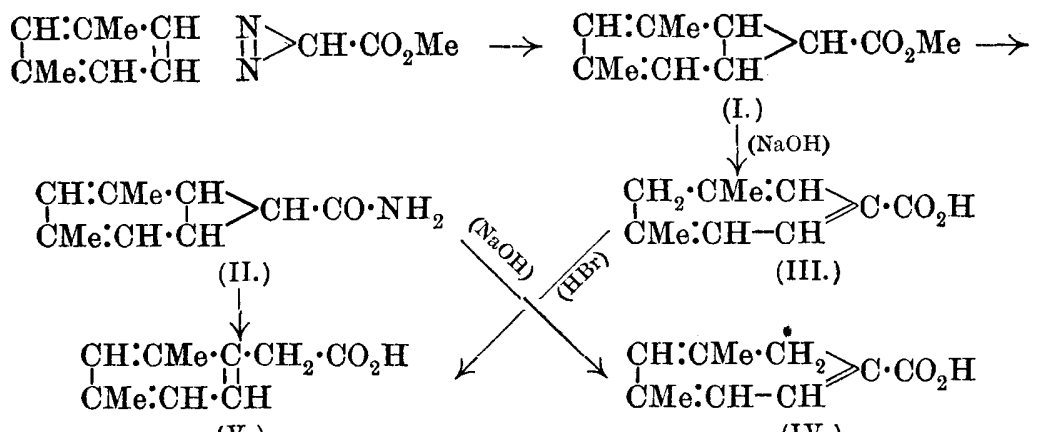

(V.)

(IV.)

\section{Mordant Colours as Heterocyclic Complexes.}

The theory that the colours produced on mordanted fabrics owe their existence to the formation of heterocyclic complexes in which the metallic oxide or hydroxide becomes a component of the ring, has been discussed by A. Werner and C. Liebermann. Both agree on the general principle that the peculiar properties of these lakes are due to a ring structure involving the metallic base. The great stability and sparing solubility of lakes, the remarkable differences between their colours and those of the ordinary salts containing the same metal, and the singular fact that in many cases the metal does not exhibit certain of its characteristic analytical reactions, all justify the theory of a heterocyclic constitution for these dyes.

Werner adduces many instances in which ring structure is possible only on the assumption that both the principal and secondary valencies of the metal are involved in ring formation.

Benzoylacetone and similar compounds are shown to behave as weak dyes on mordanted cotton. The lakes thus produced must be similar in structure to the closely allied metallic acetylacetonates, to which on account of their great stability a co-ordinated constitution is ascribed. Accordingly these lakes are also formulated as co-

69 E. Buchner and K. Delbrück, Annalen, 1907, 358, 1 ; A., i, 87. 
ordinated compounds (I), where $R$ is an alkyl or acyl radicle and $M$ is the metal.

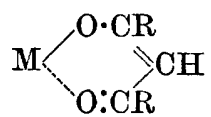

(I.)<smiles>c1ccccc1</smiles>

(II.)

This view of their constitution is justified by the fact that hydroxymethylenecamphor, a compound in which the keto-enolic structure is the stable form, also behaves as a mordant dye, the lakes of which must have the above formula (II).

Liebermann, on the other hand, assumes that in those cases where a carbonyl group is contiguous to the hydroxyl or isonitroso-radicle, it is only necessary to make the very reasonable assumption that this group reacts in its hydrated form (III and IV), and then the older theory becomes sufficiently comprehensive to include all cases of mordant dyeing without recourse to the hypothesis of supplementary valency.

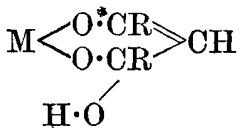

(III.)<smiles>OC1(O)[C@H]2C[C@@H]1[C@@H]2c1ccccc1</smiles>

(IV.)

Werner, in reply, points to the fact that the ordinary theory of valency does not account for the great difference in colour and stability between the lakes and the colourless salts of certain dibasic acids, many of which also possess a cyclic structure:

$$
\underset{\mathrm{Y}}{\mathrm{X}}>\mathrm{C}<\mathrm{O} \cdot \mathrm{O}>\mathrm{M} \text {. }
$$

According to Werner the production of a metallic heterocyclic complex leads to the development of colour and other properties peculiar to lakes only when both the supplementary and principal valencies of the metal are involved in the structure of the ring..$^{70}$

\section{Quinones.}

The interest attaching to the aromatic diketones and their derivatives is due to the fact that the existence of these compounds affords justification for the assumption so frequently made that the first phase in the interactions of aromatic substances and various reagents is the formation of an additive product in which the valencies of the aromatic nucleus have undergone a certain rearrangement. When the new arrangement persists in the final product, this substance is regarded as a quinone derivative or quinoid.

70 A. Werner, Ber., 1908, 41, 1062, 2383 ; A., i, 440 ; C. Liebermann, ibid., $1436 ; A .$, i, 441. 
In the simplest case of benzene, we may have the change from $\mathrm{C}_{6} \mathrm{H}_{4}{ }^{\mathrm{II}}$ to $p$ - or $o-\mathrm{C}_{6} \mathrm{H}_{4}{ }^{\mathrm{IV}}$.
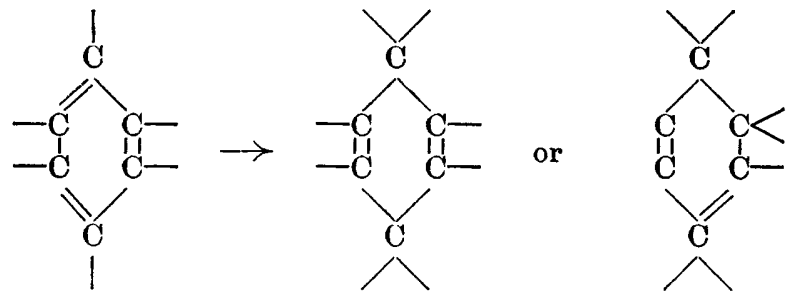

Corresponding with these two types of rearrangement there exist the long known $p$-benzoquinone and the more recently discovered $o$-benzoquinone.

At first only quinones of the ortho- and para-series were known, but lately the possibilities of quinonoid rearrangement have been considerably extended by Willstätter and his collaborators. In 1907 it was shown that 2:6-dihydroxynaphthalene could be oxidised so as to yield the corresponding $2: 6$-naphthaquinone, ${ }^{71}$<smiles></smiles><smiles>O=C1C=Cc2c(Cl)ccc1c2Cl</smiles>

whilst $1: 5$-dichloro-2 $: 6$-dihydroxynaphthalene furnishes $1: 5$-dichloro$2: 6$-naphthaquinone, a substance possessed of considerable stability.

In continuing the study of $o$-benzoquinone it has been found that when catechol is rapidly oxidised (15 seconds) with pure silver oxide in dry ether a colourless modification of the quinone can be isolated, This colourless variety, which is very unstable and changes quickly into the red modification, is also obtained when an ethereal solution of the latter is cooled. The two forms are therefore in equilibrium in solution. These isomerides are represented by the following formulæ, the colourless variety being regarded, not as a quinone, but as a benzene peroxide. ${ }^{72}$<smiles>O=C1C=CCCC1</smiles>

Red.

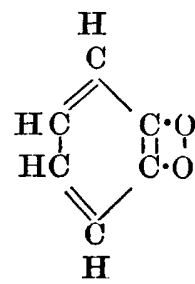

Colourless.

7 R. Willstätter and J. Parnas, Ber., 1907, 40, 3971 ; A., 1907, i, 1056.

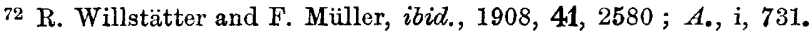




\section{4}

ANNUAL REPORTS ON THE PROGRESS OF CHEMISTRY.

The colour of $m$-nitroaniline and its derivatives was long ago ascribed by $\mathrm{H}$. E. Armstrong to the existence of a dynamic form having a meta-quinonoid structure, and more recently Baly has referred to the possibility of a meta-quinonoid rearrangement. These speculations have now been justified by the revision of the constitution of tribromoresoquinone, a yellowish-red substance originally discovered in 1872 by Liebermann and Dittler, who prepared it by removing two bromine atoms from tribromoresorcinol dibromide, and gave it the formula

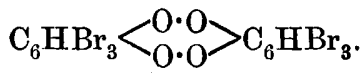

Molecular-weight determinations in boiling benzene have now shown that the substance has the simpler formula $\mathrm{C}_{6} \mathrm{HO}_{2} \mathrm{Br}_{3}$, and as it liberates iodine from potassium iodide, it is regarded as a metaquinone, namely, $2: 4: 6$-tribromo- $m$-benzoquinone, ${ }^{73}$<smiles>O=C1OC2(Br)[In]C1(Br)C(=O)C2Br</smiles>

This substance gives neither oxime nor hydrazone, for hydroxylamine and phenylhydrazine behave towards it as reducing agents and convert it into tetrabromodiresorcinol, $\mathrm{C}_{6} \mathrm{HBr}_{2}(\mathrm{OH})_{2} \cdot \mathrm{C}_{6} \mathrm{HBr}_{2}(\mathrm{OH})_{2}$.

One of the most characteristic reactions of quinones is the formation of intensely coloured additive compounds with their reduction products; quinhydrone produced by the combination of $p$-benzoquinone and quinol in molecular proportions being perhaps the best known example of this class of substances. That this property is not restricted to para-quinones is shown by the fact that tetrachloro-o-benzoquinone combines with tetrachlorocatechol to form octachloro-o-quinhydrone, $\mathrm{C}_{6} \mathrm{Cl}_{4} \mathrm{O}_{2}, \mathrm{C}_{6} \mathrm{H}_{2} \mathrm{Cl}_{4} \mathrm{O}_{2}, \frac{1}{2} \mathrm{H}_{2} \mathrm{O}$, a substance separating in lustrous, black needles. ${ }^{74}$ Willstätter proposes to call these additive compounds, which consist only partly of a quinonoid complex, meriquinoids, whilst the quinones themselves and their derivatives (imines, etc.) are termed holoquinoids. The formation of the meriquinoids is attributed to the residual affinity of the quinonoid oxygen atoms, or in the case of the quinoneimines to that of the imino-group. The intense colour of the additive product is considered to be due to an oscillation (isorropesis) of the quinone linking between the two

73 R. Meyer and K. Desamari, Ber., 1908, 41, 2437 ; A., i, 658.

${ }^{74}$ C. L. Jackson and P. W. Carleton, Amer. Chem. J., 1908, 39, 493 ; A., i, 427. 
components of the molecular compound. In this way the colour of the meriquinoids is referred to the same cause as that which is assumed by von Baeyer to be operative in the di- and tri-phenylmethane colouring matters, namely, the oscillation of the quinonoid condition between two or three aromatic nuclei.

These views on the colour of quinhydrones and meriquinoids are not accepted unreservedly by $F$. Kehrmann, ${ }^{75}$ who objects to the parallel drawn between quinoneimines and their meriquinoid salts, on the one hand, and the triphenylmethane-imine bases and their salts on the other. In the first case, the intensification of colour is due to the introduction of auxochromic groups $\left(\mathrm{NH}_{2}\right.$ or $\left.\mathrm{OH}\right)$ without any modification of the chromophore; in the second, the bases and their salts are quite different in constitution, and the variation of colour is due to this complete change in the configuration of the chromophore. The difference in stability between the ordinary quinhydrones and the meriquinoids (Wurster's salts, etc.) is merely one of degree, and there is no reason for assuming that these two types of partial quinoids differ essentially in constitution.

The coloured salts formerly obtained by C. Wurster ${ }^{76}$ on oxidising alkylated $p$-diamines are regarded as meriquinoids by Willstätter.

The red salt produced by the action of bromine on as-dimethyl-pphenylenediamine is meriquinonedimethyldi-imonium bromide,

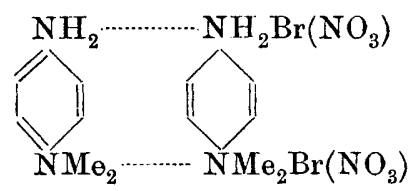

The nitrate has also been obtained, and the blue salt from tetramethyl- $p$-phenylenediamine contains a sulphate which is only one-third quinonoid,

$$
\mathrm{C}_{6} \mathrm{H}_{4}\left[\mathrm{NMe}_{2} \cdot \mathrm{HSO}_{4}\right]_{2}, 2 \mathrm{C}_{6} \mathrm{H}_{4}(\mathrm{NM} \Theta)_{2}, \mathrm{H}_{2} \mathrm{SO}_{4} .
$$

Benzidine gives rise to two meriquinonoid chromates, whilst both holo- and meri-quinoids have been obtained from tetramethylbenzidine. ${ }^{77}$

Further investigations on the oxidation products of benzidine, diphenyline, and tolidine have resulted in the production of diphenoquinonedichlorodi-imide, $\mathrm{NCl}: \mathrm{C}_{6} \mathrm{H}_{4}: \mathrm{C}_{6} \mathrm{H}_{4}: \mathrm{NCl}$, ditoluquinonedichloro-

75 Ber., 1908, 41, $2340 ; A ., \mathrm{i}, 698$.

76 Ibid., 1879, 12, 1803; 1887, 20, 2071.

77 R. Willstätter and J. Piccard, ibid., 1908, 41, 1458 and 3245 ; A., i, 475, 915 . 
di-imide, holo- and meri-dichloroditoluquinonedi-imonium chlorides, the last of these having the composition ${ }^{78}$

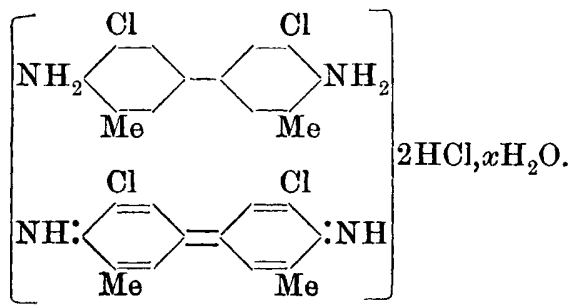

The action of alkali hydroxides on 1-phenylisoquinolinium methiodide and papaverinium methyl halides leads to the formation of 2-phenyl-a-naphthol and 6:7-dimethoxy-2-mp-dimethoxyphenyl- $\alpha$ naphthol, which on oxidation yield binuclear quinones having the appearance of indigotin. ${ }^{79}$

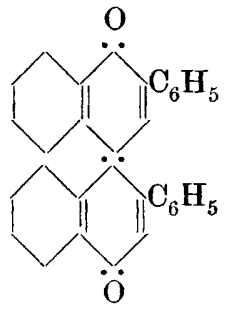

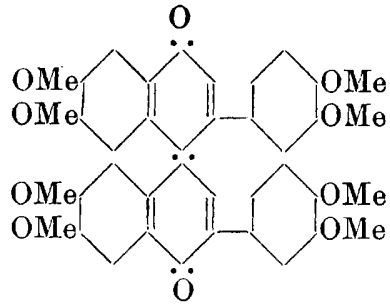

The residual affinity of quinones is also manifested by the formation of additive compounds with certain inorganic chlorides. The following are representative examples of this series: $p$-benzoquinone stannic chloride, $\mathrm{C}_{6} \mathrm{H}_{4} \mathrm{O}_{2}, \mathrm{SnCl}_{4}$ (red), a-naphthaquinone antimonic chloride, $\mathrm{C}_{10} \mathrm{H}_{6} \mathrm{O}_{2}, 2 \mathrm{SbCl}_{5}$ (red), $\beta$-naphthaquinone stannic chloride (green), phenanthraquinone mercuric chloride, $2 \mathrm{C}_{14} \mathrm{H}_{8} \mathrm{O}_{2}, \mathrm{HgCl}_{2}$ (red). ${ }^{80}$ Aromatic ketones behave similarly, and the following yellow compounds have been obtained, benzophenone antimonic chloride,

$$
\mathrm{CPh}_{2} \mathrm{O}, 2 \mathrm{SbCl}_{5} \text {, }
$$

and benzil stannic chloride, $(\mathrm{COPh})_{2}, \mathrm{SnCl}_{4}$.

F. Kehrmann refers the production of these compounds to the saltforming capacity of quinonoid oxygen, and points out that he had previously shown that phenanthraquinone and chrysoquinone are dibasic substances forming two series of salts. ${ }^{81}$

An ingenious use of the properties of phenyliminoquinones has been made in the study of the tri-, tetra-, penta-, hepta-, and octa-bromo-
78 W. Schlenk, Annalen, 1908, 363, 313 ; A., 1909, i, 36.
79 H. Decker, ibid., 362, 305 ; A., i, 806.
80 K. H. Meyer, Ber., 1908, 41, 2018 ; A., i, 731.
81 Ber., 1908, 41, 3396 ; A., i, 993. 
derivatives of $p$-hydroxydiphenylamine. In each case, oxidation with chromium trioxide gives rise to the corresponding quinoneanil (phenyliminoquinone), the colour of which becomes more intense as the proportion of bromine increases, the shades varying from scarlet to a purple so dark as to appear black.

These substances readily undergo hydrolysis, so that the number of bromine atoms present in each ring, and, in some cases, also their orientation, are readily ascertained : 82

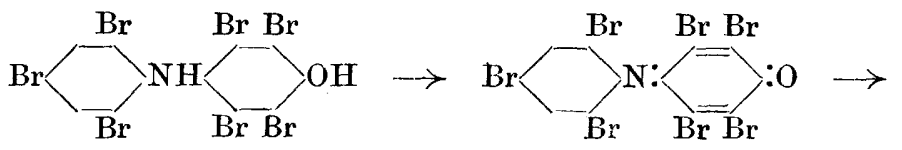<smiles>O=C1OC(=O)C(Br)=C1Br</smiles>

An extremely interesting synthesis of quinones from straight-chain compounds has been effected by a modification of the process for producing ethyl alkyloxalacetates. A mixture of ethyl oxalate and an ester of a monobasic fatty acid is treated with sodium instead of sodium ethoxide, when a hydroxyquinone derived from a $p$-dialkylbenzene is produced:

$$
\begin{aligned}
& \underset{\mathrm{CO}_{2} \mathrm{Et} \cdot \mathrm{CO}_{2} \mathrm{Et}}{\mathrm{R} \cdot \mathrm{CH}_{2} \cdot \mathrm{CO}_{2} \mathrm{Et}}+2 \mathrm{Na}=\underset{\mathrm{R} \cdot \mathrm{CH}_{2} \cdot \mathrm{CO}}{\mathrm{CO}_{2} \mathrm{Et} \cdot \mathrm{CO}}+2 \mathrm{NaOEt} .
\end{aligned}
$$

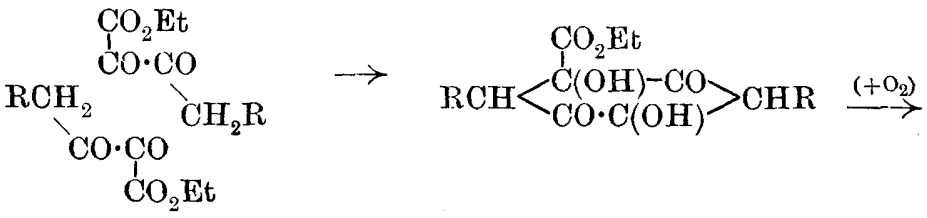

$$
\begin{aligned}
& \mathrm{RC}<_{\mathrm{CO}-\mathrm{C}(\mathrm{OH})}^{\mathrm{C}(\mathrm{OH}) \cdot \mathrm{CO}} \geqslant \mathrm{CR}+2 \mathrm{CO}_{2}+2 \mathrm{EtOH} \text {. }
\end{aligned}
$$

Atmospheric oxygen intervenes in the last step of this condensation, which takes place so readily that it may be employed as a lecture experiment to demonstrate the formatio of a coloured quinone from colourless, comparatively simple, aliphatic esters. In the foregoing scheme, $\mathbf{R}$ may be methyl, ethyl, isopropyl, $n$-butyl, phenyl, or benzyl. These hydroxyquinones are yellow, whereas their alkali salts are bluish-violet.

Equally noteworthy is the unique hydrolysis of these dihydroxydialkylbenzoquinones under the influence of boiling aqueous alkali

82 A. E. Smith and K. J. P. Orton, Trans., 1908, 93, 314. 
hydroxides, when the ring structure disappears with the production of symmetrically disubstituted succinic acids,

$$
\mathrm{CO}_{2} \mathrm{H} \cdot \mathrm{CHR} \cdot \mathrm{CH}\left(\mathrm{CH}_{2} \mathrm{R}\right) \cdot \mathrm{CO}_{2} \mathrm{H} \text {, }
$$

which are always obtained in their two stereoisomeric modifications, so that in some cases the reaction may with advantage be employed in the preparation of these isomerides. In this hydrolysis, the hydroxyquinones react in their tautomeric form :

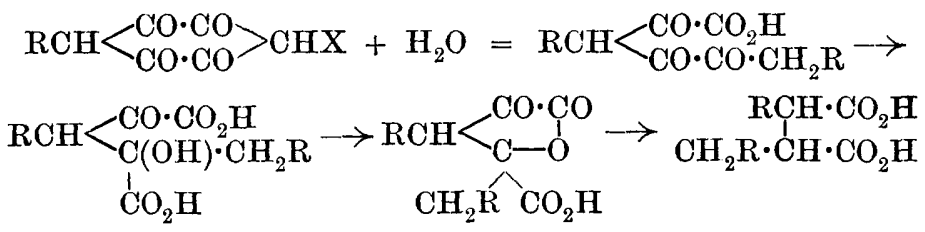

The triketocarboxylic acid containing an $a$-diketonic group undergoes the benzilic acid change to a dicarboxylic acid which condenses to a lactonecarboxylic acid ; this compound then takes up water and loses carbon dioxide to form the disubstituted succinic acid.

The penultimate product, the lactonecarboxylic acid, was in one instance prepared by an independent method and shown to undergo the last step in the hydrolysis under the influence of alkali hydroxides. ${ }^{83}$

In connexion with the production of quinones, reference may be made to the more recent of Zincke's long series of researches on the chlorination and bromination of phenols. ${ }^{84}$

Di-p-hydroxydiphenylmethylethylmethane yields a tetrabromoderivative, $\mathrm{HO} \cdot \mathrm{C}_{6} \mathrm{H}_{2} \mathrm{Br}_{2} \cdot \mathrm{CMeEt} \cdot \mathrm{C}_{6} \mathrm{H}_{2} \mathrm{Br}_{2} \cdot \mathrm{OH}$, which on further bromination is resolved into $s$-tribromophenol and the $\psi$-hexabromide of $p$-sec.-butylphenol; at $100^{\circ}$ a $\psi$-heptabromide is produced. These $\psi$-bromides, which unlike the less brominated phenols are insoluble in aqueous alkali hydroxides without decomposition, readily lose hydrogen bromide when treated with sodium acetate or sodium carbonate, and give rise to quinones:

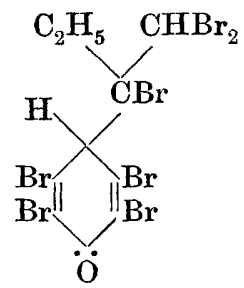

$\psi$-p-Tribromo-sec.-butyltetrabromophenol.

(Colourless hemiquinone.)

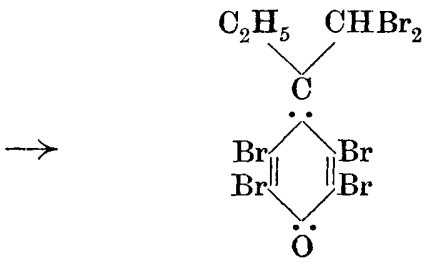

$p$-Dibromo-sec.-butylidenetetrabromoquinone.

(Yellow quinone.)

83 F. Fichter, Annalen, 1908, 361, $363 ;$ A., i, 658.

84 T. Zincke and J. Goldemann, ibid., 362, $201 ; A .$, i, 780 ; T. Zincke and E. Birschel, ibid., 221 ; A., i, 781. 
The tetrachloro- and tetrabromo-dihydroxybenzhydrols (I), when treated with hydrogen chloride and hydrogen bromide respectively, yield the $\psi$-pentachloro- and $\psi$-pentabromo-dibydroxydiphenylmethyl chloride and bromide (II). These halides, when shaken with aqueous acetone, lose hydrogen halide and furnish the tetrachloro- and tetrabromo-hydroxybenzylidenequinones (III).

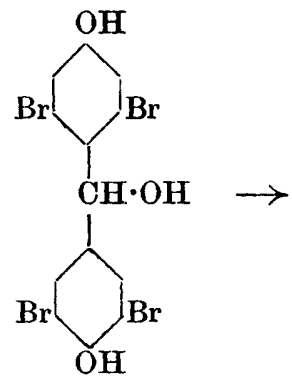

(I.)

Colourless benzenoid derivative.<smiles>O=C1C=CC(C(Br)C2CC(Br)CC2Br)C=C1Br</smiles>

(II.)

Colourless hemiquinone.<smiles></smiles>

(III.)

Yellow quinone.

These examples suffice to show the close relationship between the appearance of colour and the development of the complete quinonoid configuration. Of interest in this connexion is the preparation of coloured hydrocarbons of the quinodimethane series, of which the following synthesis is an example :

Benzoyltriphenylmethane, $\mathrm{COPh} \cdot \mathrm{C}_{6} \mathrm{H}_{4} \cdot \mathrm{CHPh}_{2}$, when subjected to the Grignard reaction with magnesium $\alpha$-naphthyl bromide, yields a substituted benzhydrol, $\mathrm{HO} \cdot \mathrm{CPh}\left(\mathrm{C}_{10} \mathrm{H}_{7}\right) \cdot \mathrm{C}_{6} \mathrm{H}_{4} \cdot \mathrm{CHPh}_{2}$, from which $p$-benzhydryldiphenyl- $\alpha$-naphthylmethyl chloride (I),

$$
\mathrm{Cl} \cdot \mathrm{CPh}\left(\mathrm{C}_{10} \mathrm{H}_{7}\right) \cdot \mathrm{C}_{6} \mathrm{H}_{4} \cdot \mathrm{CHPh}_{2} \text {, }
$$

is readily obtained by the action of hydrogen chloride. This chloride, when heated with quinoline, loses hydrogen chloride, giving rise to the orange-red hydrocarbon, triphenyl- $\alpha$-naphthylquinodimethane (II). This hydrocarbon absorbs halogen halide, regenerating the chloride (I). These changes constitute a reversible reaction, which may be represented as follows: ${ }^{85}$

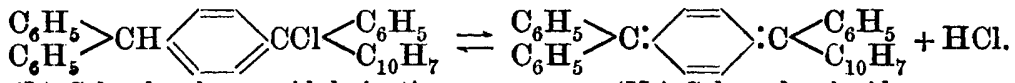

(I.) Colourless benzenoid derivative.

(II.) Coloured quinoid.

Recently several methods of oxidising aromatic hydrocarbons to quinones have been patented, based on the indirect employment of electrolytic methods. For example, manganic alum, produced electrolytically from an aqueous solution of manganous and ammonium

85 A. E. Tschitschibabin, Ber., 1908, 41, 2770 ; A., i, 872.

REP. - VOL. V. 
sulphates, is recommended for oxidising naphthalene, anthracene, and phenanthrene to their respective quinones. ${ }^{86}$

\section{Colour and Constitution.}

Contributions to the study of the relation of colour to structure have again been very numerous, and in several of these a comparison has been made between colour and fluorescence. Starting from the much-discussed case of nitroquinol dimethyl ether, an examination of a large number of coloured and fluorescent substances ${ }^{87}$ has shown that the colour of the light emitted in fluorescence is quite commonly dependent on the solvent employed. The fluorescent band of the solid substance lies furthest towards the nltra-violet, then follow the solutions in indifferent solvents, then those in dissociating solvents, the fluorescence of the vapour exposed to Tesla-radiation lying nearest to the red. This is true even of compounds in which it is impossible to assume a change of constitution to be brought about by dissociating solvents. Changes of colour in general run parallel with fluorescent changes. The theory of partial valencies is invoked in explanation of these facts. Considering the ordinary statical formulæ as representing an ideal constrained state of the molecule, the solid substance and its solutions in indifferent solvents are supposed to approach most nearly to this, whilst a greater freedom of the partial valencies is possible in dissociating solvents and in the state of vapour. Nitroquinol dimethyl ether is then written in the form (I), the

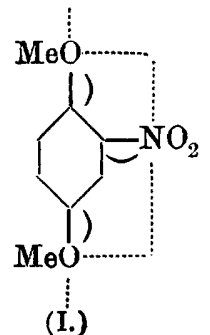

(I.)

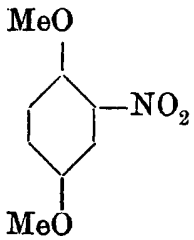

(II.)

formula (II) representing the ideal limiting condition. The paler the colour of the solution the more nearly the molecule approaches to the limiting condition, which is, however, never completely attained. $m$-Nitrodimethylaniline is a good example of a compound showing variable fluorescence. The results are unfavourable to the assumption of a quinonoid structure. The influence of solvents in modifying the direction of the lines of force which constitute the partial valencies is illustrated and discussed.

86 D.R.-P. 189178 ; A., i, 350.

87 H. Kauffmann, Ber., 1908, 41, 4396 ; A., 1909, i, 96. 
Somewhat different results have been reached by a very exhaustive study of the triphenylmethane (or ".tritane") series. ${ }^{88}$ It is shown that the parallel between colour and fluorescence must not be pressed too far. Simple ring compounds, such as benzene, are fluorescent, although the emitted light lies in the ultra-violet portion of the spectrum, and by substitution, or by the juxtaposition of rings, the oscillations causing fluorescence may be so far retarded as to enter the visible region. Thus anthracene has a distinct fluorescence. The production of colour occurs in a quite different way. The replacement of hydrogen in benzene by substituents, however heavy, is quite incapable of retarding the oscillations so as to bring the ultra-violet absorption of benzene into the visible region. The colour of benzene derivatives is brought about, not by the shifting of a previously existing ultra-violet band towards the red, but by the production of a new band or bands, and for this a definite arrangement of conjugated double linkings is required. The author considers the key to the problem to be given by a comparison of benzene with its isomeride, fulvene. In both compounds, the number of carbon and hydrogen atoms, and of double linkings is the same, and only the disposition of the latter is altered.<smiles>C1=CCCCCC1</smiles>

Benzene (colourless).<smiles>C#CC1C=CC=C1</smiles>

Fulvene (coloured).

From a comparison of a large number of coloured substances, the author concludes that there is only one true organic chromophore,

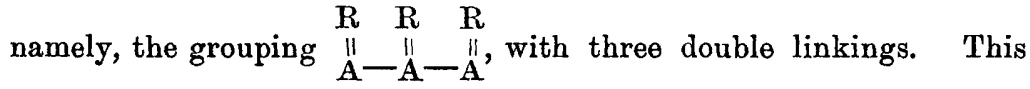
grouping is not, however, sufficient in itself to bring about colour, but requires some further condition (most frequently the closing of a ring) to produce visible colour. The reason for this is that the double linkings must first be brought into a definite relative position before the rhythmic oscillations which cause colour can be set up. It will be observed that nitroquinol dimethyl ether contains the required grouping, together with the ring:<smiles>COc1ccc(OC)c([N+](=O)[O-])c1</smiles>

\&8 H. von Liebig, Annalen, 1908, 360, 128 ; A., i, 445. 
Coloured solutions of such simple coloured substances as diacetyl must contain polymerised molecules in order to render the above grouping possible, an assumption for which there is good evidence.

Fluorescence is explained as due to a pulsating interchange of double linkings in rings, brought about by impinging light-waves. The tritane derivatives examined ranged from the colourless triphenylmethane, through compounds exhibiting both colour and fluorescence, to the penta- and hepta-acetyl derivatives of the complicated hydroxy tritanol ether,

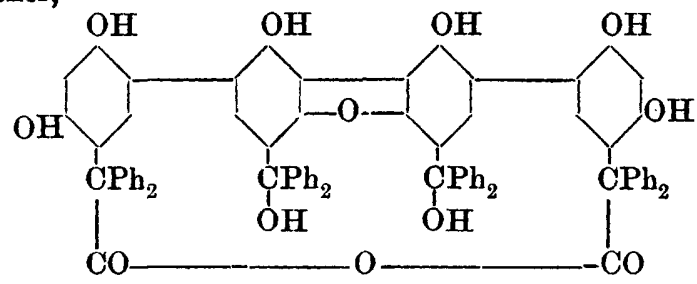

which exhibit colour, fluorescence, and pleochroism, a property hitherto only possessed by chlorophyll amongst colouring matters.

The picryl ethers of certain amidines have been noted as showing a remarkably strong fluorescence, although nitro-groups generally hinder the appearance of this property. ${ }^{89}$ The non-fluorescent 1 : 2-diphenyl-3-benzyloxyamidine yields a highly fluorescent ether, and the same is found to be true of other non-fluorescent imide bases. The essential grouping appears to be

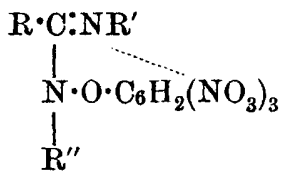

and that the residual affinity of the nitro-groups, acting in the direction of the imino-nitrogen atom, is connected with the property is suggested by the fact that the salts of the same imides with heavy metals, which are certainly internally complex, are highly coloured. The phenyl groups are not necessary, since picryl diguanide,

$$
\begin{aligned}
& \mathrm{NH}_{2} \cdot \mathrm{C}: \mathrm{NH} \\
& \mathrm{N} \cdot \mathrm{O} \cdot \mathrm{C}_{6} \mathrm{H}_{2}\left(\mathrm{NO}_{2}\right)_{3}, \\
& \mathrm{NH}_{2} \cdot \mathrm{C} \cdot \mathrm{NH}
\end{aligned}
$$

is also fluorescent. The effect is attributed to internal oscillations of linking in the molecule.

Pulsations of the ring-system of benzene were invoked to explain the absorption of benzene in the ultra-violet, ${ }^{90}$ it being shown that the

89 H. Ley, Ber., 1908, 41, 1637 ; A., i, 570.

90 E. C. C. Baly, W. H. Edwards, and A. W. Stewart, Trans., 1906, 89, 514. 
number of absorption bands corresponded with the number of distinct modes of deformation of the ring. This hypothesis has now been put to a severe test by the examination of compounds containing more than one ring. ${ }^{91}$ Naphthalene itself has three bands in the ultraviolet, one of which is attributed to the benzenoid ring, and the other two to the conjugation of this with the ethylenic linkings of the second ring. When this second ring is entirely reduced in $1: 2: 3: 4$ tetrahydronaphthalene, only the one benzenoid band is observed. In $1: 4: 5: 8$-tetrahydronaphthalene, the two rings are exactly alike, and the symmetrical arrangement resembles that of $p$-xylene, and the two spectra are consequently almost identical.

A similar spectrum is given by acenaphthene (I), whilst acenaphthylene (II) has, in 'addition, bands due to the influence of the double linking outside the ring, producing colour.

(I.)

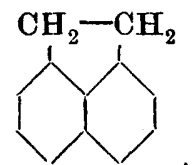

(II.)

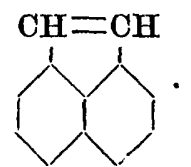

The complete absorption spectra of a number of compounds containing nitro- and nitroso-groups have been examined, and the position of the band is found to depend on the nature of the atom to which the group is attached.92 Dinitro-paraffins form both coloured and colourless solutions, the spectra of the former, and of the alkaline salts of these compounds, being unlike those of aci-mononitro-salts, $\mathrm{R} \cdot \mathrm{CH} \cdot \mathrm{NO}_{2} \mathrm{M}$. They are therefore assumed to contain an isomeric modification with quinonoid grouping, $\mathrm{R} \cdot \mathrm{C}<_{\mathrm{NO}(\mathrm{OM})}^{\mathrm{NO}}>0$, producing colour, in equilibrium with the colourless form. ${ }^{93}$

In continuation of the work on the strongly-coloured aci-ethers of nitrophenols, a dark violet aci-ether of hexanitrodiphenylamine has now been prepared ${ }^{94}$ from the violet silver salt. It is therefore assumed to have the quinonoid constitution,

$$
\mathrm{C}_{6} \mathrm{H}_{2}\left(\mathrm{NO}_{2}\right)_{3} \cdot \mathrm{N}: \mathrm{C}_{6} \mathrm{H}_{2}\left(\mathrm{NO}_{2}\right)_{2}: \mathrm{NO}_{2} \mathrm{Me}
$$

The fact that halogen-phenols, in which it is difficult to assume a quinonoid rearrangement, form both coloured and colourless silver salts ${ }^{95}$ points to the necessity of further investigation of this kind of isomerism, and an interesting case of the same kind has been recently discovered. ${ }^{96}$

91 E. C. C. Baly and W. B. Tuck, Trans., 1908, 93, 1902.

92 E. C. C. Baly and C. H. Desch, ibid, 1747.

93 E. P. Hedley, Ber., 1908, 41, 1195 ; A., i, 382.

94 A. Hantzsch and S. Opoloski, ibid., $1745 ; A$., i, 526.

95 Ann. Report, 1907, 114.

96 O. Dimroth and O. Dienstbach, Ber., 1908, 41, 4055; A., 1909, i, 62. 
4-Oximino-1-phenyl-5-triazolone, $\mathrm{NPh}<_{\mathrm{CO} \cdot \mathrm{C}}^{\mathrm{N}=\mathrm{N}} \mathrm{N} \cdot \mathrm{OH}$, forms three series of salts, yellow, red, and green, of which the red is usually th stable form, although the red silver salt is labile, and passes into the stable green modification. Further, the benzoyl and acetyl derivatives, which no longer contain a labile atom, also occur in red and yellow modifications, of which the latter is the stable form. That the case is one of chemical isomerism, and not merely of polymorphism, is shown by the fact that the red benzoyl derivative dissolves in chloroform to a deep red solution, which, however, immediately becomes yellow. Concentrated solutions are orange, and contain the two modifications in equilibrium.

Many aminoazo-compounds are known to form two series of differently coloured salts. The orange salts ${ }^{97}$ resemble azobenzene in colour and must have the azo-constitution,

$$
\mathrm{Ph} \cdot \mathrm{N}: \mathrm{N} \cdot \mathrm{C}_{6} \mathrm{H}_{4} \cdot \mathrm{NR}_{2} \mathrm{HX},
$$

whilst the violet salts are quinonoid, as, for example,

$\mathrm{Ph} \cdot \mathrm{NH} \cdot \mathrm{N}_{2} \mathrm{O}_{6} \mathrm{H}_{4}: \mathrm{NMe}_{2} \mathrm{Cl}$.

The solid orange salts are usually labile, and are converted into the violet salts on heating, or, in some cases, on rubbing.

The violet salts were proved to be unimolecular in solution. Indifferent solvents favour the violet modification, whilst the orange modification persists in alcohol, ether, or acetone. The solutions in concentrated sulphuric acid are all yellow, and resemble azobenzene.

The same colour relationships appear in the aminoazobenzenesulphonic acid series, and the colour-changes in helianthin and methylorange have therefore received a similar explanation,,$^{98}$ the intermediate formation of an internal azo-salt being assumed, as represented in the following scheme:

Helianthin.

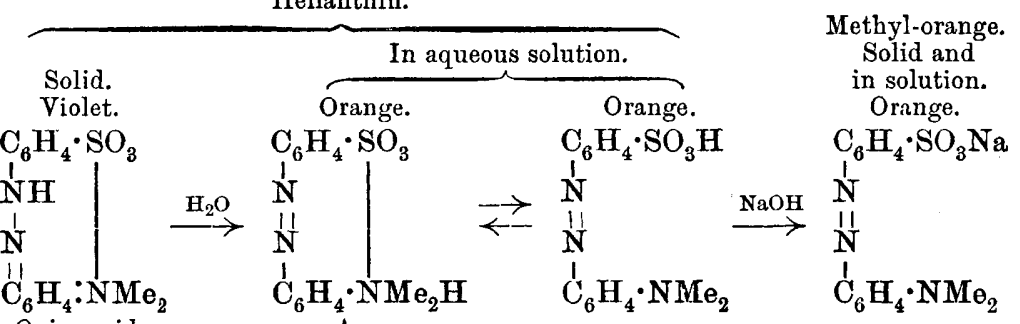

Quinonoid.

Azo.

Azomethines are of interest from their analogy to azo-compounds. Since the simplest azomethines and their ethers are colourless, whilst their hydrochlorides show an absorption band in the blue region of the

97 A. Hantzsch and F. Hilscher, Ber., 1908, 41, 1171 ; A., i, 484.

$9 s$ A. Hantzsch, ibid., 1187 ; A., i, 469. 
spectrum, it has been concluded ${ }^{99}$ that the latter are quinonoid oxonium salts, the simplest ethyl ether hydrochloride, for instance, having the formula $\mathrm{C}_{6} \mathrm{H}_{5} \cdot \mathrm{CH}_{2} \cdot \mathrm{N}: \mathrm{C}_{6} \mathrm{H}_{4}: 0<{ }_{\mathrm{Cl}}^{\mathrm{Et}}$.

A. recent observation ${ }^{1}$ is of interest as showing that the possession of residual affinity may suffice to give chromophoric properties to a group of compounds, even when no ethylenic linking is present. Iodochlorides, such as<smiles>CO[Al]1CCOCC1C</smiles>

are strongly coloured red. Hitherto all chromophores attached to the benzene ring have contained a double bond.

The investigations into the constitution of triphenylmethyl, which derive their interest mainly from their bearing on such problems as those just discussed, have added little to the knowledge summarised in last year's Report (p. 118). The hexaphenylethane formula seems well established for the solid substance. An attempt to prepare hexaphenylethane by heating triphenylmethyl triphenylacetate,

$$
\mathrm{CPh}_{3} \cdot \mathrm{CO}_{2} \cdot \mathrm{CPh}_{3},{ }^{2}
$$

yielded only an amorphous product, together with triphenylmethane. The product obtained from Gomberg's triphenylmethyl, and formerly supposed to be hexaphenylethane, ${ }^{3}$ is now ${ }^{4}$ proved to be $p$-benzhydryltetraphenylethane, $\mathrm{CHPh}_{2} \cdot \mathrm{C}_{6} \mathrm{H}_{4} \cdot \mathrm{CPh}_{3}$. by its synthesis from $p$-benzoyltriphenylmethane, which reacts with magnesium phengl bromide to form $p$-benzhydryltriphenylcarbinol ; condensation with aniline hydrochloride and elimination of the amino-grcup then gives Gomberg's compound, which is thus an isomeride, and not a polymeride, of triphenylmethyl. The preparation of the latter compound from the magnesium chloride has been improved, ${ }^{5}$ and the existence of isomeric modifications of magnesium triphenylmethyl chloride has been defended against the criticisms of Tschitschibabin. The existence of both a coloured and a colourless modification in solutions of triphenylmethyl is inferred from the disappearance of the yellow colour on shaking with air, the yellow modification being the more readily oxidised. ${ }^{6}$ On removing the peroxide by filtration, the colourless

99 F. G. Pope, Trans., 1908, 93, 532, 1914.

1 H. Kauffmann, Ber., 1908, 41, 4413; A., 1909, i, 95.

2 R. Anschiitz, Annalen, 1908, 359, 196 ; A., i, 331.

3 M. Gomberg, ibid., 1903, 36, 376 ; A., 1903, i, 244.

4 A. E. Tschitschibabin, Ber., J908, 41, 2421 ; A., i, 624.

5 J. Schmidlin, ibid., 1908, 41, 423, $426 ; A .$, i, 150.

6 Ibid., 2471 ; A., i, 623. 
filtrate again becomes yellow, an ethereal solution in equilibrium at the ordinary temperature containing about ten times as much of the colourless as of the coloured form. Lowering the temperature favours the production of the colourless modification. The theoretical explanation of these facts has made little progress since last year.

\section{Aromatic Diazo-compounds.}

In last year's Report reference was made to a new formula (II) for diazonium salts advocated by Cain, ${ }^{7}$ which was put forward to account

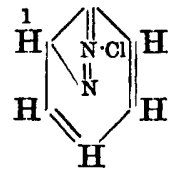

(I.)

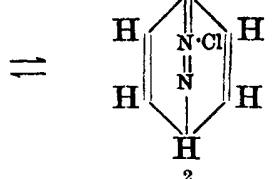

(II.)

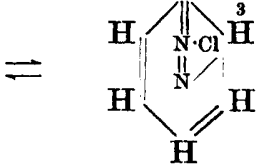

(III.)

for the following facts : (1) The property of giving rise to diazonium derivatives is confined to the aromatic primary amines, and is not possessed by the bases of the fatty series or fully saturated ring series; (2) the facility with which nitrogen is eliminated from diazonium salts suggests an unstable double linking $\searrow_{0}: N$, rather than the single linking $\geqslant \mathrm{C} \cdot \mathrm{N}$, assumed to be present in the Kekulé (IV) and Blomstrand (V) formulæ,

$$
\mathrm{C}_{6} \mathrm{H}_{5} \cdot \mathrm{N}: \mathrm{N} \cdot \mathrm{Cl}
$$

$$
\mathrm{C}_{6} \mathrm{H}_{5} \cdot \mathrm{NCl}: \mathrm{N} \text {. }
$$

(V.)

An ortho-quinonoid configuration would, however, afford an equally simple explanation of these facts, and accordingly it has recently been suggested that diazonium salts might appropriately be represented by a dynamic formula, in which the valency of the triad nitrogen atom in the foregoing static ortho- and para-quinonoid formulæ (I, II, III) is directed sucessively to the carbon atoms marked 1,2 , and 3 , but is not held continuously by any one of them. This extremely labile condition of the oscillating linking would account for the production of hydrazines rather than diamines on reduction. ${ }^{8}$

These views on the structure of diazonium salts have been vigorously attacked by Hantzsch, ${ }^{9}$ who contends that if diazonium salts are hemi-p-quinoids, as represented by Cain's formula, then on reduction they should yield $p$-diamines and not hydrazines. $\mathrm{He}$ also repudiates the suggestion of a. dynamic formulation, contending that

7 Ann. Report, 1907, 120.

8 G. T. Morgan and F. M. G. Micklethwait, Trans., 1908, 93, 617.

9 Ber., 1908, 41, 3532. 
this hypothesis, instead of obviating the difficulty of explaining the production of hydrazines rather than diamines, increases it twofold inasmuch as a mixture of ortho- and para-diamines should result from the reduction of such a compound. This view of the matter, however, involves the assumption that the properties of a substance with a dynamic structure are simply those of the tautomerides representing the extreme phases of the molecular oscillation. It is at least conceivable that the predominant properties of the compound might be those of the intermediate phase or phases. This conception, when applied to diazonium salts, furnishes a reason for the formation of hydrazines as the main products of reduction.

Cain, ${ }^{10}$ who has replied to Hantzsch's criticisms of his formula, points out that there is experimental evidence for the view that reducing agents would break the unstable linking, $>\mathrm{CH} \cdot \mathrm{N}$, rather than the more stable azo-bond, $-\mathrm{N}: \mathrm{N}-$. He also calls attention to Hantzsch's admission that the existence of aromatic diazonium salts and the non-formation of such derivatives of the aliphatic amines point to some interaction of the residual affinities of the aromatic nucleus with the unsaturated diazonium complex. He maintains that this connexion is more definitely expressed by his quinonoid formula than by the vague addition made by Hantzsch to the Blomstrand configuration formula and expressed by the dotted line in the following formula, $\mathrm{C}_{6} \mathrm{H}_{5} \cdot \mathrm{N}_{2} \mathrm{X}$.

Euler, ${ }^{11}$ who advocates another para-quinonoid formula for diazonium salts,

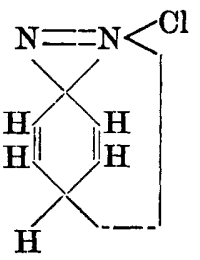

also lays stress on Hantzsch's admission of the imperfection of the Blomstrand formula (V.).

Although these controversial matters require further experimental evidence for their complete elucidation, yet this discussion has served the useful purpose of recalling attention to the important fact, so frequently overlooked, that the residual affinity of the aromatic nucleus is the determining factor both in the production of diazonium salts, and also in many other characteristic properties of aromatic compounds.

The study of the decomposition of diazonium salts in solutions of

10 Ber., 1908, 41, 4189 ; A., 1909, i, 70.

11 Ibid., 3979 ; A., 1909, i, 70. 
varying strengths and at different temperatures has led to the following results. ${ }^{12}$

1. Dry"diazonium chlorides give the maximum value for the velocity of decomposition in aqueous solutions. Freshly prepared specimens decompose more slowly, and contain apparently traces of a protecting substance, the nature of which has not been elucidated.

2. Diazonium chlorides and bromides in solutions of the same concentration decompose at the same rate.

3. Increase in the concentration results in a small rise in the velocity of decomposition, which is somewhat greater with the bromides than with the chlorides. The velocity increases as the decomposition progresses, probably owing to the formation of halogenated hydrocarbons by the action of the liberated hydrogen halide.

4. Diazonium iodides decompose more rapidly than the chlorides or bromides, even in very dilute solutions.

5. Increase of concentration has but little effect on the velocity of decomposition of $p$-nitrobenzenediazonium chloride, and only in very concentrated solutions is any acceleration noticed. Neither strong nor weak acids have any protecting influence.

6. The less basic is the diazonium hydroxide set free by hydrolysis the more rapidly is the diazonium acetate decomposed in aqueous solution. Sodium chloride has a protecting influence on $p$-nitrobenzenediazonium acetate.

7. Nitrous acid decomposes diazonium salts, not catalytically, but by actual participation in the decomposition.

The experimental data on which this last generalisation is based agree with those formerly obtained by Cain, ${ }^{13}$ and confirm his opinion that a solution of pure $p$-nitrobenzenediazonium chloride and another containing the same concentration of this salt with a trace of nitrous acid sufficient to give the starch-iodide test decompose with equal velocities under similar conditions of temperature. ${ }^{14}$

A study of the oxidation of primary aromatic hydrazines has led to a method of converting these substances quantitatively into the diazonium salts, from which they were obtained by reduction.

In the first place, the oxidation of these hydrazines with copper, silver, and mercuric oxides leads to the deposition of the corresponding metal, with the liberation of nitrogen and the formation of a hydrocarbon :

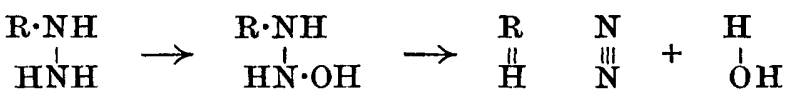

12 A. Hantzsch and K. J. Thompson, Ber., 1908, 41, 3519; A., i, 1021.

13 Ibid., 1905, 38, 2511; A., 1905, i, 724.

14 Ibid., 1908, 41, 4186; A., 1909, i, 70. 
Manganese and lead dioxides give similar results, and potassium permanganate and hydroxide furnish benzene, azobenzene, and diphenyl.

The oxidation proceeds most smoothly with alkaline potassium chromate, when a practically quantitative yield of nitrogen and hydrocarbon is produced..$^{15}$

Although the foregoing experiments give no indication of the formation of diazonium salts, yet it has been found possible to obtain these compounds in excellent yield by introducing chlorine or bromine into.an alcoholic solution of the hydrazine at temperatures below $-20^{\circ}$. This mode of procedure gives the solid diazonium salt, although a solution of the same can be obtained in glacial acetic acid by adding chlorine or bromine at $0^{\circ},{ }^{16}$

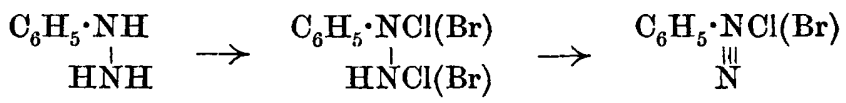

A more convenient method of obtaining the solid diazonium bromide is first to prepare its perbromide by adding bromide to the aqueous solution of the diazonium salt. The dry perbromide, when mixed with the corresponding hydrazine in cold alcohol, undergoes the following change: ${ }^{17}$

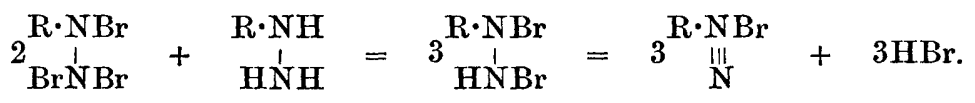

The ortho- and para-aminophenols can be diazotised to diazooxides,<smiles>c1ccccc1</smiles>

but the ortho-aminonaphthols, on treatment with nitrous acid in the presence of mineral acids, undergo oxidation to $\beta$-naphthaquinone.

It has been found that these aminonaphthols and their sulphonic acids can be diazotised readily, providing that mineral acids are absent. A solution of 1-amino- $\beta$-naphthol-4-sulphonic acid, sodium nitrite, and sodium chloride slowly deposits the cyclic diazo-derivative, $\mathrm{NaSO}_{3} \cdot \mathrm{C}_{10} \mathrm{H}_{6}<\mathrm{O}_{2}^{\mathrm{N}_{2}}$, and this result is also obtained by treating the sulphonic acid at $40-50^{\circ}$ with sodium nitrite, zinc sulphate, and zinc hydroxide; other metallic salts may be used instead of zinc sulphate. ${ }^{18}$

Although diazo-oxides can be obtained from ortho-, para-, and periaminophenols, diazoimines can be prepared only from ortho- and peri-

15 F. D. Chattaway, Trans., 1908, 93, 270, ${ }_{16}$ Ibid., 852. $\quad 17$ Ibid., 958.

${ }^{18}$ D.R.-P. 189179,195228 , and 195322; A., i, 231, 842. 
diamines. The unsubstituted para-diamines do not give rise to diazoimines, although certain of their arylsulphonyl and aryl derivatives have been found to yield $p$-diazoimides and $p$-diazoimines of varying degrees of stability.

The simplest compound of this group is the explosive phenyl-pphenylenediazoimine ${ }^{19}$ (I) obtained by adding ammonia to the diazonium salt of $p$-aminodiphenylamine, $\mathrm{NH}_{2} \cdot \mathrm{C}_{6} \mathrm{H}_{4} \cdot \mathrm{NH} \cdot \mathrm{C}_{6} \mathrm{H}_{5}$. A series of increasingly stable $p$-diazoimines has been produced by gradually introducing nitro-groups into the phenyl nucleus of this base, so that when the trinitrophenyl (picryl) derivative is reached a $p$-diazoimine (IV) is produced, which is as stable as the $p$-diazoimides (V) obtained from the arylsulphonyl-p-diamines and mentioned in earlier reports. ${ }^{20}$

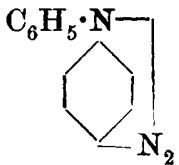

(I.)

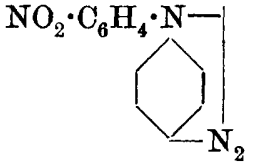

(II.)

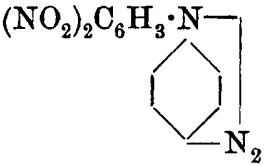

(III.)

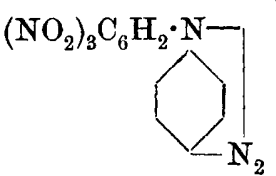

(IV.)

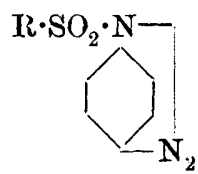

(V.)

In the foregoing diagram these derivatives of the still unknown $p$-diazoiminobenzene are arranged in the order of their stability, which increases as the acidity of the substituent group becomes more pronounced. In spite of the great difference in stability, the members of this series all exhibit the two properties which are characteristic of $p$-diazoimino-derivatives. They combine additively with $\beta$-naphthol, and change quantitatively into the corresponding diazonium salt on treatment with cold concentrated mineral acids. ${ }^{21}$

\section{Hydrazones and Hydrozyazo-compounds.}

In considering the diazonium salts, special stress was laid on the fact that these are known only in the aromatic series. The compounds now under discussion may be either entirely aromatic or mixed aliphatic-aromatic derivatives.

Several important investigations on these substances have been published during the last year, and at last it seems likely that some agreement will be reached in regard to their constitution.

19 Annalen, 1888, 243, 282, and Ber., 1902, 35, 895.

20 Ann. Report, 1906, 124 and 151.

21 G. T. Morgan and F. M. G. Micklethwait, Trans., 1908, 93, 602. 
The coupling of a diazonium salt with a phenol gives rise to an aromatic hydroxyazo-compound, whilst an aliphatic-aromatic azoderivative results from the condensation of the diazonium salt with an aliphatic substance containing the group $\cdot \mathrm{CH}_{2} \cdot \mathrm{CO} \cdot$

It is in the first place necessary to consider the constitution of the aliphatic and aromatic compounds concerned in these condensations.

Aliphatic compounds containing the above group tend to conserve this ketonic configuration, even although in certain reactions the dynamic enolic form comes into play.

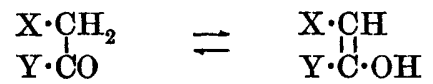

Stable ketonic form. Labile enolic form.

In the aliphatic series the ketonic form is the more stable.

The converse holds with the phenols. Although it is frequently necessary to assume the intervention of the dynamic ketonic (quinonoid) form, this in the aromatic series is the labile condition, and whenever possible the phenol or its condensation product reverts to the stable hydroxylic (benzenoid) configuration.

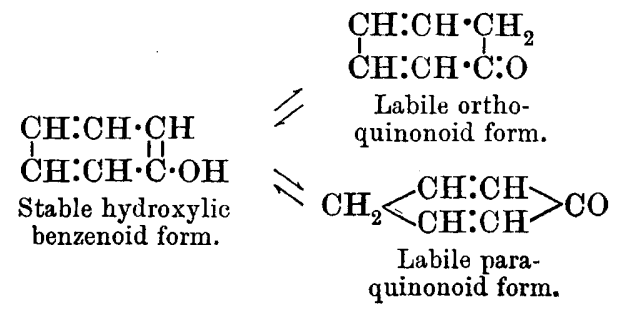

Recent experimental evidence is almost unanimous in demonstrating that these properties of the aliphatic diketones and aromatic hydroxyderivatives are shared by the mixed and aromatic azo-compounds respectively, the aliphatic-aromatic derivatives tending always to acquire the hydrazone configuration, whilst the purely aromatic derivatives assume almost invariably the hydroxyazo-structure.

Aliphatic series :

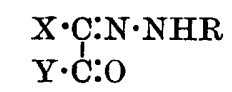

Stable hydrazo-form.

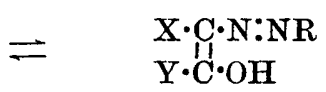

Labile azo-enolic form.

Aromatic series :

\section{$\begin{array}{ll}\mathrm{CH}: \mathrm{CH} \cdot \mathrm{C} \cdot \mathrm{N}: \mathrm{NR} & \Rightarrow \quad \mathrm{CH}: \mathrm{CH} \cdot \mathrm{C}: \mathrm{N} \cdot \mathrm{NHR} \\ \mathrm{CH}: \mathrm{CH} \cdot \mathrm{C} \cdot \mathrm{OH} & \mathrm{CH}: \mathrm{CH} \cdot \mathrm{C}: \mathrm{O}\end{array}$}

Stable $o$-hydroxyazo-form.

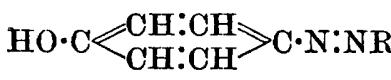

Stable $p$-hydroxyazo-form.
Labile $o$-hydrazone.

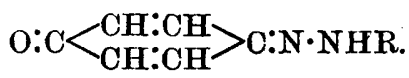

Labile $p$-hydrazone. 
An investigation of the mechanism of the coupling of diazonium salts and aliphatic ketones has been carried out with tribenzoylmethane, which reacts in its enolic form, since the first product is a diazo-oxide (I) containing the diazo-complex attached to the enolic oxygen. This is proved by the ease with which the diazo-group can be removed merely by treatment with $\beta$-naphthol or $\alpha$-naphthylamine,

This diazo-oxide passes successively into two isomerides, the first, a red azo-compound (II), and the last and most stable, a colourless hydrazone (III).
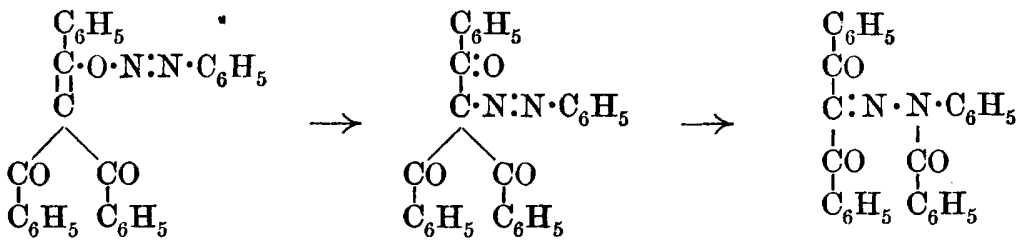

I. Yellow diazo-oxide.

II. Red azo-compound.

III. White acyl hydrazone.

On hydrolysis, these three isomerides give the same products, namely, ethyl benzoate and the hydrazone (IV).

$$
\begin{aligned}
& \mathrm{C}_{6} \mathrm{H}_{5} \cdot \stackrel{\text { CO }}{:}: \mathrm{N} \cdot \mathrm{NH} \cdot \mathrm{C}_{6} \mathrm{H}_{5} \\
& \mathrm{C}_{6} \mathrm{H}_{5} \cdot \mathrm{CO} \\
& \text { IV. Yellow hydrazone. }
\end{aligned}
$$

These results show that in the aliphatic series the final stable product is a hydrazone rather than an azo-compound.

When a very reactive group, such as nitroxyl, is present, the transformation of diazo-oxide into azo-compound and hydrazine derivative may occur simultaneously.

$\omega$-Dinitrotoluene, $\mathrm{C}_{6} \mathrm{H}_{5} \cdot \mathrm{CH}\left(\mathrm{NO}_{2}\right)_{2}$, and its homologues couple with diazonium salt in alkaline solutions, the first product being a diazooxide (I). This substance readily changes into two isomerides, a red azo-compound (II) and a white hydrazine derivative (III). In the initial coupling, the dinitro-compound is used in the form of its alkali salt, $\mathrm{C}_{6} \mathrm{H}_{5} \cdot \mathrm{C}\left(\mathrm{NO}_{2}\right): \mathrm{NO} \cdot \mathrm{OK}$.
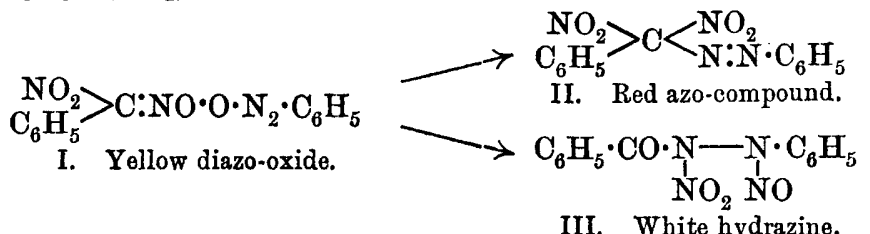

The constitution of the hydrazine derivative is shown by the action of water, which hydrolyses it first into nitric acid and nitrosobenzoyl-

${ }^{22}$ O. Dimroth and M. Hartmann, Ber., 1908, 41, 4012, A., 1909, i, 66. 
phenylhydrazine, $\mathrm{C}_{6} \mathrm{H}_{5} \cdot \mathrm{CO} \cdot \mathrm{NH} \cdot \mathrm{N}(\mathrm{NO}) \cdot \mathrm{C}_{6} \mathrm{H}_{5}$, this compound being finally decomposed into nitrous acid and $s$-benzoylphenylhydrazine. ${ }^{23}$

In the aromatic series the first product, the $O$-azo-derivative, or diazo-oxide, has also been isolated in a few cases where the velocity of transformation into the $C$-azo-derivative has been lessened by the presence of substituents in the reactive para-position. $p$-Bromobenzenediazonium chloride and $p$-nitrophenol couple to give $p$-bromobenzenediazo-4-oxynitrobenzene, $\mathrm{C}_{6} \mathrm{H}_{4} \mathrm{Br} \cdot \mathrm{N}: \mathrm{N} \cdot \mathrm{O} \cdot \mathrm{C}_{6} \mathrm{H}_{4} \cdot \mathrm{NO}_{2}$, which at $80^{\circ}$ becomes transformed into its isomeride, the red $p$-bromobenzene-2-azo4-nitrophenol, $\mathrm{C}_{6} \mathrm{H}_{4} \mathrm{Br} \cdot \mathrm{N}: \mathrm{N} \cdot \mathrm{C}_{6} \mathrm{H}_{3}\left(\mathrm{NO}_{2}\right) \cdot \mathrm{OH}$.

Auwers ${ }^{24}$ is inclined to regard these intermediate $O$-azo-derivatives as diazonium oxides, but inasmuch as they are produced only in the absence of acids stronger than acetic acid, it seems preferable to regard them as diazo-oxides, $R \cdot N: N \cdot O Y$, analogous to the diazo-amines, $\mathrm{R} \cdot \mathrm{N}: \mathrm{N} \cdot \mathrm{NHY}$, which are formed under similar conditions and undergo the same change into $C$-azo-derivatives.

In $1907 \mathrm{~W}$. Borsche succeeded in condensing o-nitrophenylhydrazine and 2:4-dinitrophenylhydrazine with $p$-benzoquinone and its homologues; the products were identical with the hydroxyazo-derivatives prepared by coupling $o$-nitrobenzenediazonium and $2: 4$-dinitrobenzenediazonium chlorides with phenol and its homologues. ${ }^{25}$

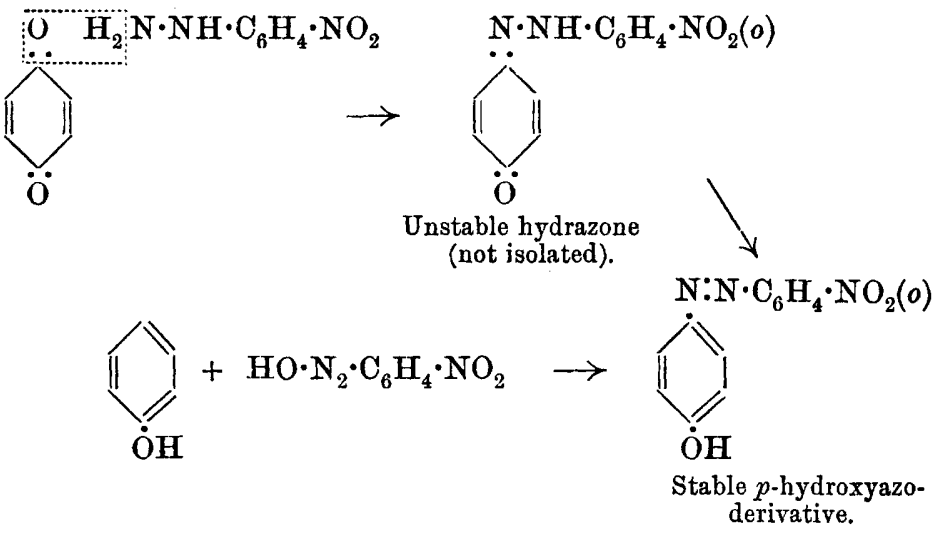

These condensations are of great interest, because the products are admittedly $p$-hydroxyazo-derivatives, formed by a process which ought to give rise to $p$-quinonehydrazones were it not for this tendency of the aromatic hydroxyl derivatives to conserve their hydroxylic structure.

${ }^{23}$ G. Ponzio and G. Charrier, Atti R. Accad. Sci. Torino, 1908, 43, 303 ; Gazzetta, 1908, 38, i, $526 ;$ A., i, 482.

${ }^{24}$ Ber., 1908, 41, 4304; $A$., 1909, i, 67.

${ }^{25}$ Borsche, Annalen, 1907, 357, 171; A., i, 66. 
When a $p$-quinoneoxime is employed instead of the $p$-quinone itself in the foregoing condensation, then the primary product can be isolated.
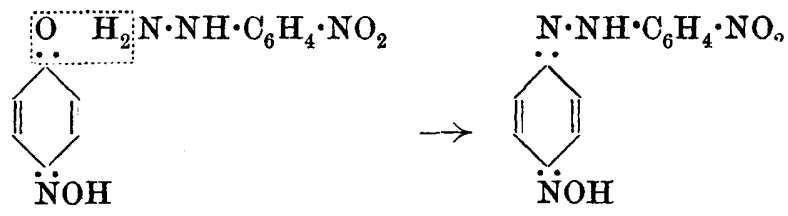

Stable $p$-quinoneoximehydrazone. ${ }^{26}$

In this case the phenolic $\mathrm{OH}$ is replaced by $\mathrm{NOH}$, so that the striving of the aromatic residue $>\mathrm{C}\langle\mathrm{C}: \mathrm{O}$ to become $-\mathrm{C} \backslash \mathrm{C} \cdot \mathrm{OH}$ is non-existent.

To the foregoing evidence may be added the closely related transformation of $p$-benzoquinonebenzoylphenylhydrazone into benzeneazo-p-phenyl benzoate under the influence of cold potassium hydroxide, already referred to in last year's Report (p. 126).

The production of $\beta$-benzeneazo-a-naphthyl benzoate from as-benzoylphenylhydrazine and $\beta$-benzoquinone simply means that the orthoquinonehydrazones are even less stable than the paraquinonehydrazones and pass spontaneously into ortho-azo-derivatives.

The reduction of this $\beta$-benzeneazo- $\alpha$-naphthyl benzoate has been compared with that of its isomeride, $\alpha$-benzeneazo- $\beta$-naphthyl benzoate; the former gave benzanilide, aniline, and $N$-benzoyl-2amino-a-naphthol, whilst the latter yielded benzanilide, aniline, and $N$-benzoyl-1-amino- $\beta$-naphthol. ${ }^{27}$ The corresponding acetates behave similarly on reduction.

The reduction of benzene-o-azo-p-tolyl benzoate leads to the hydrazoderivative, which, on heating in acetic acid, regenerates the azoderivative and yields simultaneously $N$-benzoyl-o-amino-p-cresol and aniline : 28

$$
\begin{aligned}
\mathrm{CH}_{3} \cdot \mathrm{C}_{6} \mathrm{H}_{4}<_{\mathrm{OBz}}^{\mathrm{N}: \mathrm{NPh}} \rightleftarrows \mathrm{CH}_{3} \cdot \mathrm{C}_{6} \mathrm{H}_{4}<_{\mathrm{OBz}}^{\mathrm{NH} \cdot \mathrm{NHPh}} \rightarrow \\
\mathrm{CH}_{3} \cdot \mathrm{C}_{6} \mathrm{H}_{4}<\mathrm{OH}+\mathrm{NHBz}
\end{aligned}
$$

Benzanilide was never obtained in this reduction.

Bearing in view the fact that acyl groups readily shift from oxygen to nitrogen in aminophenols, Auwers considers that the foregoing

26 There is evidence that this compound can assume the dynamic azo-form, $\mathrm{NO}_{2} \cdot \mathrm{C}_{6} \mathrm{H}_{4} \cdot \mathrm{N}: \mathrm{N} \cdot \mathrm{C}_{6} \mathrm{H}_{4} \cdot \mathrm{NH} \cdot \mathrm{OH}$, in certain of its reactions, as, for exarnple, oxidation (loc. cit., p. 148).

27 Ber., 1908, 41, 403 ; A., i, 228.

${ }^{28}$ K. Auwers and M. Eckardt, Annalen, 1908, 359, $336 ; A .$, i, 480. 
results favour the assumption that these esters are really azoderivatives and not o-quinoneacylhydrazones.

Mercuric acetate was shown by Dimroth to condense with phenols and aromatic amines, entering the unsubstituted para- and orthopositions with reference to the oxygen and nitrogen atoms respectively. On this account it has been employed in the study of hydroxyazocompounds, for, as will be seen from the following formulæ, the number of mercuriacetate groups introduced into the azo-compound should be a criterion of its constitution :

I.

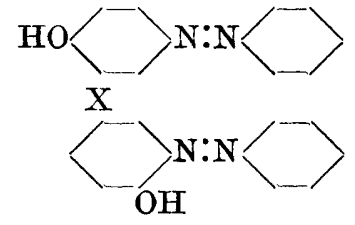

$p$ - and $o$-Hydroxyazo-derivatives. or

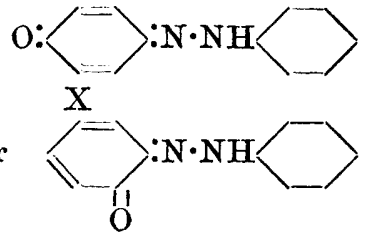

Considered as an azo-derivative, the para-compound (I) should condense with not more than two mercuriacetate groups, whilst as hydrazone it should form a tri-substituted mercuriacetate. The ortho-compound (II), in its hydrazo-form, should also take up three mercuriacetate groups, but as an azo-derivative it should only condense with one molecule of mercuric acetate. In every case examined, the result corresponded with the hydroxyazo-structure, both in the ortho- and para-series. ${ }^{29}$

These results, like the other chemical evidence already cited, are all in favour of the view that the constitution of both ortho- and parahydroxyazo-derivatives is what their usual designations imply, and that these substances have not in ordinary circumstances a hydrazone structure.

The spectroscopic evidence, as interpreted by Tuck, is, to a certain extent, against this view and in favour of the assumption that the ortho-hydroxyazo-compounds and their acyl derivatives have the quinonehydrazone constitution. Both Auwers and C. Smith, however, take exception to the comparisons instituted between the absorption curves, the former referring to the difference between the curve for benzoquinonebenzoylphenylhydrazone and those for a set of azoderivatives, whilst the latter asserts that the curve for benzeneazo- $p$ tolyl benzoate, presumably a hydrazone, resembles that of benzeneazophenol, admittedly an azo-compound, more than that of the foregoing quinonehydrazone.

From the chemical evidence now available, it is permissible to deduce the general rule that a hydroxyazo-compound will be an azo-

29 C. Smith and A. D. Mitchell, Trans., 1908, 93, 842.

REP. - VOL. V. 
derivative or a hydrazone according as to whether its oxygenated generator is an enol or a ketone respectively.

The case of 2-pyridone (IV) is of interest in this connexion, for this substance, which differs from the phenols in not giving the ferric chloride and nitrosoamine colorations and in not yielding acetyl and nitroso-derivatives, nevertheless forms an azo-compound, 5-benzeneazo-2-pyridone (II or III), with benzenediazonium chloride. The orientation of the substituents in this compound is established by the following series of operations, starting with 6-hydroxynicotinic acid (I), a substance of known constitution : 30

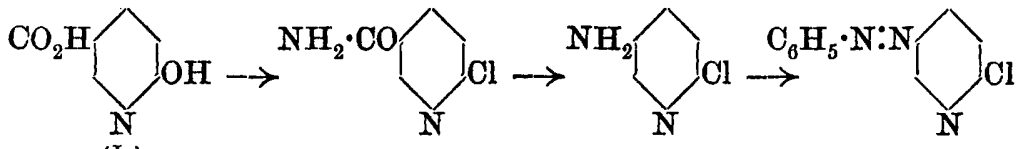

(I.)

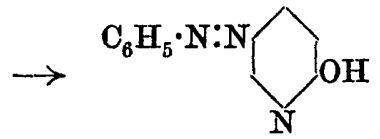

(II.)

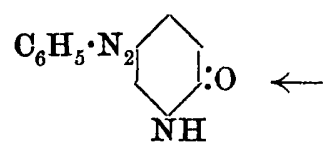

(III.)<smiles>O=C1CCCCN1</smiles>

(IV.)

This azo-derivative and the isomeric benzeneazo-3-hydroxypyridine merit further examination from the point of view of the constitution of hydroxyazo-compounds.

Although the balance of chemical evidence is in favour of the view that all aromatic hydroxyazo-derivatives have the azo-structure, the question of the nature of their salts with the mineral acids next arises. Some years ago Hewitt showed that, on nitration, benzeneazophenol itself behaves in accordance with its hydroxyazo-constitution, ${ }^{31}$ and in this respect differed from its sulphate, which behaves as if it were a quinonehydrazone.

More recently it has been found that benzeneazophenol and its ethoxy-derivative, benzeneazophenetole, both admittedly azocompounds, have similar absorption spectra in concentrated hydrochloric acid.32 Accordingly the formula for the salts of benzeneazophenol must be applicable to the salts of benzeneazophenetole, and at the same time should account for the chemical properties of benzeneazophenol sulphate. After discussing several formulæ, Fox and Hewitt, who have prepared and examined spectroscopically the salts of a series of azophenols and their ethyl ethers, decide on the following structure :

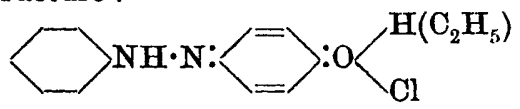

30 W. H. Mills and S. T. Widdows, Trans., 1908, 93, 1373.

31 Trans., 1900, 77, $99 . \quad 32$ Tuck, ibid., 1907, 91, 450. 
The compounds having this constitution are characterised spectroscopically by strong and persistent absorption in the yellow and green and chemically by behaving towards substituting agents as quinonehydrazones. ${ }^{33}$

\section{Heterocyclic Rings containing Oxygen.}

The Coumarin Group-The coumarin condensation with malic acid or ethyl acetoacetate and the substituted phenols has been studied, the results showing that phenols containing alkyl, hydrbxyl, or dialkylamino-groups in the positions indicated below give good yields of the corresponding coumarins.
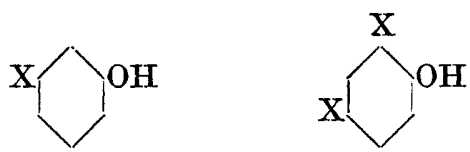

Chlorine, as a substituent in these positions, has a similar effect, but to a less appreciable extent. The introduction of nitro-, carboxy-, or carbethoxy-groups prevents condensation. ${ }^{34}$

The condensation is affected considerably by the strength of the sulphuric acid employed; when 73 per cent. acid is used, a satisfactory yield of 4-methylcoumarin may be obtained from phenol and ethyl acetoacetate, otherwise the amount produced is very small..$^{35}$

One of the most interesting, and still only partly explained, reactions of coumarin is its hydrolysis into coumarinic and o-coumaric acids. When treated with sodium ethoxide, coumarin and 7-methylcoumarin yield respectively ethyl o-coumarate and ethyl 4-methyl-o-coumarate. But under these conditions, 4:7-dimethylcoumarin, which contains one methyl group in the lactonic ring gives rise to more complex products, namely, 3-[2:5-dimethylhydrocoumarilyl]-4:7-dimethylcoumarin and 1-[2:5-dimethylhydrocoumarilyl]-2:5-dimethyldihydrocoumarone (II) respectively. A molecular proportion of the $\beta$-4-dimethylcoumaric acid produced by hydrolysis condenses with unaltered 4:7-dimethylcoumarin, and the product then undergoes rearrangement ${ }^{36}$ and a coumaryl ring is produced $(\mathrm{I})$. The second product is formed from the first by hydrolysis and loss of carbon dioxide.

The interaction of 4:6-dimethylcoumarin and sodium ethoxide leads to the production of similar products differing from compounds (I) and (II) only in the position of the methyl substituent in the benzene ring.

The reduction of coumarin with zinc dust and alkali hydroxide

33 Fox and Hewitt, Trans, , 1908, 93, 333.

34 A. Clayton, ibid., 2018.

35 F. Peters and H. Simonis, Ber., 1908, 41, 830 ; A., i, 339.

${ }^{36}$ K. Fries and W. Klostermann, Annalen, 1908, 362, 1 ; A., i, 820. 


\section{8}

ANNUAL REPORTS ON THE PROGRESS OF CHEMISTRY.

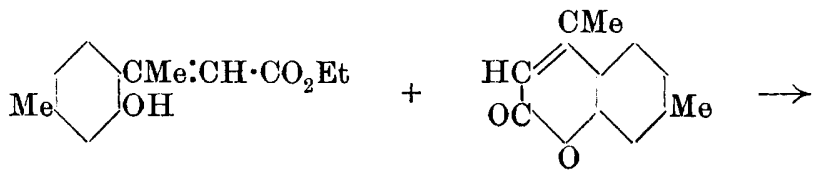

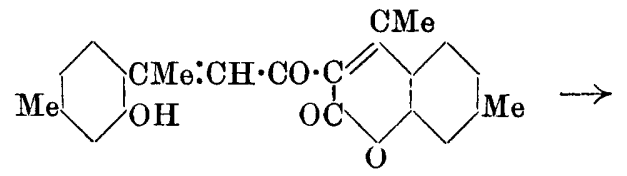

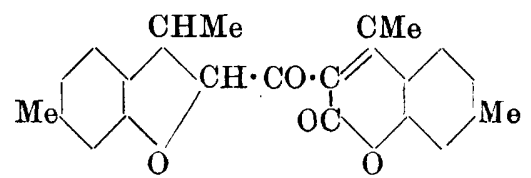

(I.)

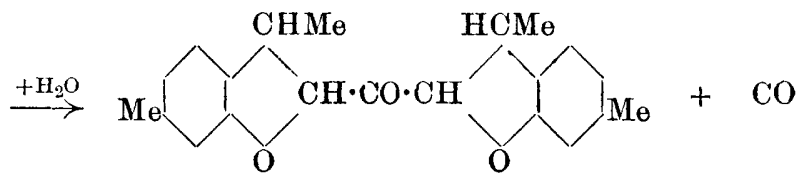

(II.)

leads to melilotic acid as the main product, and, in addition, to two by-products, which are stereoisomeric $\alpha$ - and $\beta$-tetrahydrodicoumaric acids, the isomerism of which resembles that of the symmetrically di-substituted succinic acids, and persists even when they are condensed into tetrahydrodicoumarins.

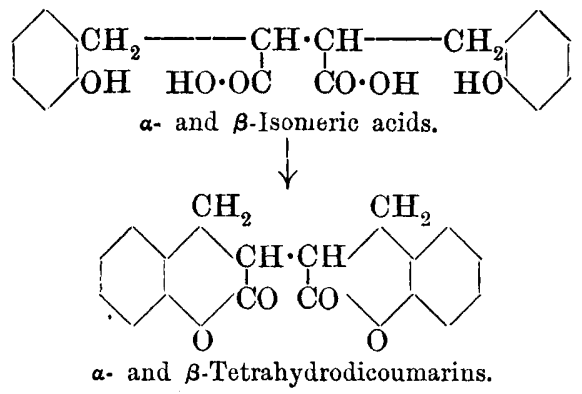

4 : 7-Dimethylcoumarin behaves differently on reduction, and gives rise to three products : 2-hydroxy-4-methylphenyldimethylcarbinol (I) (hydroxythymol), 2-hydroxy- $\alpha$-4-dimethylstyrene (II), and thymol (III).

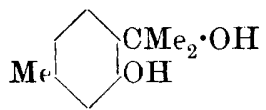

(I.)

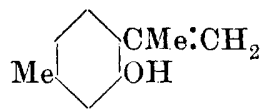

(II.)<smiles>CC1CCC(C)C1O</smiles>

(IIl.) 
The second product also exists in a polymeric bimolecular form. These vinylphenols and their polymerides may be produced by distilling o-coumaric acid and its homologues under reduced pressure. The simplest member of the series, $o$-vinylphenol (o-hydroxystyrene), prepared from o-coumaric acid itself, readily polymerises. The bimolecular form is insoluble in alkali hydroxides, and becomes depolymerised when distilled under the ordinary pressure, although under $15 \mathrm{~mm}$. it passes over unchanged. ${ }^{37}$

As the coumarins are colourless, and do not condense with either hydroxylamine or phenylhydrazine, whilst the thiocoumarins are yellow and yield oximes and phenylhydrazones, it has been suggested that coumarin has the modified structure (I), whilst thiocoumarin retains the configuration (II) generally attributed to coumarin : ${ }^{38}$

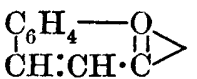

(I.)

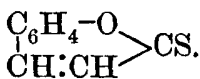

(II:)

\section{The Flavone Group.}

The residue $\cdot \mathrm{C}: \mathrm{C} \cdot \mathrm{CO} \cdot$ is often associated with the development of colour, and it may occur in compounds in four different ways; both $\cdot \mathrm{C}: \mathrm{C} \cdot$ and $\cdot \mathrm{CO} \cdot$ may be present in a ring, or both may occur in a chain, or one may be in the ring and the other in the chain. As the case of the ethyl linking in the ring ("cyclostatic") and the carboxyl group in the chain ("streptostatic") has not been studied, 1-hydroxybenzoylcoumarone, a compound having the required structure, has been synthesised from coumarilic chloride and phenol by the action of aluminium chloride,

$$
\mathrm{C}_{6} \mathrm{H}_{4}<_{\mathrm{CH}}^{-} \geqslant \mathrm{C} \cdot \mathrm{CO} \cdot \mathrm{C}_{6} \mathrm{H}_{4} \cdot \mathrm{OH} \text { (pale yellow). }
$$

The colour is absent from the alkyl derivatives. The methyl compound is synthesised in the following manner: salicylaldehyde and $p$-methoxybenzophenone give 2-hydroxy-4'-methoxychalkone, $\mathrm{OH} \cdot \mathrm{C}_{6} \mathrm{H}_{4} \cdot \mathrm{CH}: \mathrm{CH} \cdot \mathrm{CO} \cdot \mathrm{C}_{6} \mathrm{H}_{4} \cdot \mathrm{OMe}$, a yellow substance containing both chromophores in the streptostatic condition.

The acetate of this compound yields a dibromide, which on heating with alcoholic potash furnishes the required compound, 1-methoxybenzoylcoumarone, ${ }^{39}$

$$
\mathrm{C}_{6} \mathrm{H}_{4}<\mathrm{CH}_{\mathrm{CH}}^{-} \geqslant \mathrm{C} \cdot \mathrm{CO} \cdot \mathrm{C}_{6} \mathrm{H}_{4} \cdot \mathrm{OMe} \text { (colourless). }
$$

37 K. Fries and G. Fickewirth, Ber., 1908, 41, 367 ; A., i, 160.

38 A. Clayton, Trans., 1908, 93, 524.

39 F. Zwayer and S. von Kostanecki, Ber., 1908, 41, $1335 ; A$., i, 443. 
The two chromophores are cyclostatic in the allied group of flavones, the hydroxy-derivatives of which exhibit colour, whereas their alkyl and acyl derivatives are colourless.

A series of flavones have been synthesised from orcacetophenone dimethyl ether and the isomeric isoorcacetophenone dimethyl ether, these ethers being produced by condensing acetyl chloride and orcinol dimethyl ether. One example of this synthesis will suffice to indicate the general method. Orcacetophenone is condensed with methyl $o$-methoxybenzoate, yielding $2: 6: 2$ '-trimethoxy-4-methylbenzoylacetophenone (I); this intermediate product, when boiled with concentrated hydriodic acid, condenses into $1: 2^{\prime}$-dihydroxy-3-methylflavone (II) (greenish-yellow). ${ }^{40}$

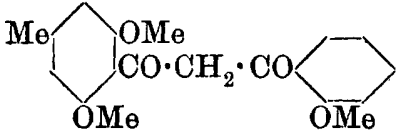

(I.)

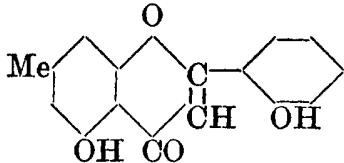

(II.)

Brazilin, Haematoxylin, and their Derivatives.

The culminating point in a long series of researches on brazilin and hæmatoxylin has been reached this year with the demonstration of the constitution of these two substances and of the colouring matters, brazilein and hæmatein, into which they are converted by oxidising agents.

Brazilein and hæmatein are respectively the colouring matters of brazil-wood and logwood, both of which find extensive application in dyeing; they stand in the same relationship to brazilin and hæmatoxylin as $p$-benzoquinone does to quinol.

As in both cases the quinol derivative is more amenable to chemical treatment than the quinonoid substance, the problem of ascertaining the constitution of these substances has mainly been worked out with brazilin and hæmatoxylin. The former of these substances contains three, and the latter four, hydroxyl groups, and it was found advisable to protect these by methylation before systematically breaking down the compounds by oxidation.

Trimethylbrazilin yields on treatment with potassium permanganate a number of acidic substances, all of which are of great importance in tracing out a skeleton formula for the parent substance. The following are two pairs of these oxidation products.<smiles>CO[C@H]1CC[C@@H](O)[C@@H]1O</smiles>

2-Carboxy-5-methoxyphenoxyacetic acid.

40 J. Tambor, Ber., 1908, 41, 787, 793 ; A., i, 349, 358.

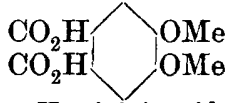

$m$-Hemipinic acid. 
ORGANIC CHEMISTRY.

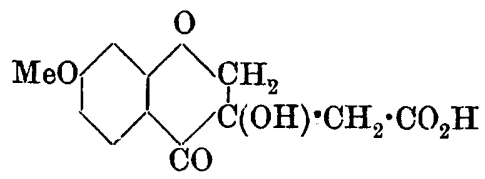

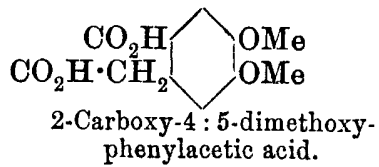

Brazilic acid.

Bearing in mind that the empirical formula of trimethylbrazilin is $\mathrm{C}_{19} \mathrm{H}_{20} \mathrm{O}_{5}$, a careful consideration of the oxidation products led to the graphical formula for trimethylbrazilin (I) :

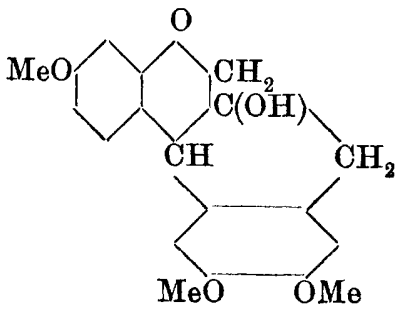

I.

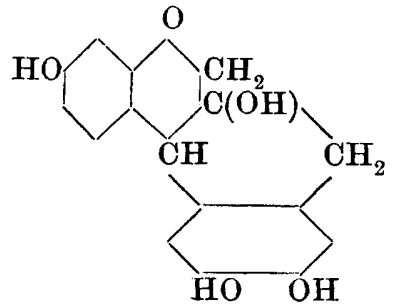

II. Brazilin.

It will be seen that this constitution agrees with the formation of the foregoing oxidation products. In confirming this formula, all the more important degradation products of trimethylbrazilin have been synthesised with the exception of brazilic acid.

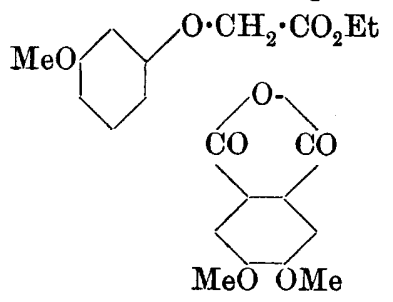

Ethyl methoxyphenoxyacetate and $m$-hemipinic anhydride.

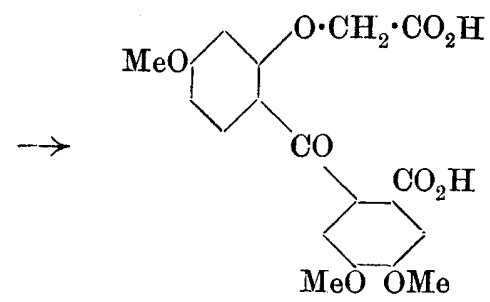

I.

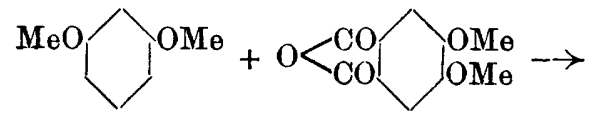<smiles>COC(=O)CC1CCC(O)CC1COC(=O)OC</smiles>

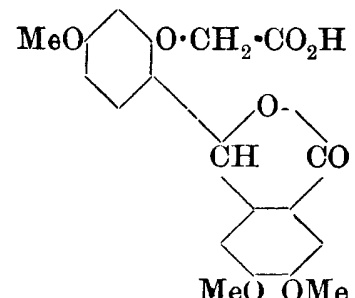<smiles>COC1CCC(C)C1O</smiles>

$\overleftarrow{\mathrm{CH}_{2} \mathrm{Cl} \cdot \mathrm{CO}_{2} \mathrm{H}}$ and $\mathrm{KOH}$

$\mathrm{MeO}$ OMe

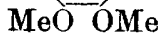

II. 
Of these syntheses, one of the most important is that of brazilinic acid (I), an oxidation product of trimethylbrazilin, which on reduction changes into the lactone (II) of dihydrobrazilinic acid. Both these substances have been synthesised in the manner indicated on p. 151 .

A similiar synthesis, using $m$-hemipinic anhydride with pyrogallol trimethyl ether instead of the foregoing resorcinol dimethyl ether, led by a precisely comparable series of reactions to the lactone (III) of dihydrohæmatoxylinic acid :

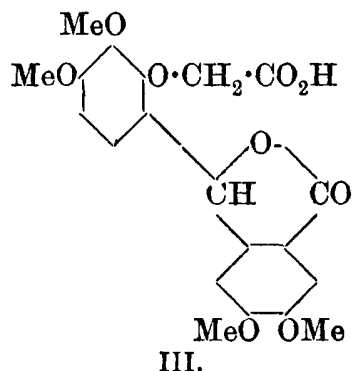

a result which proves that hæmatoxylinic acid and hæmatoxylin must be represented respectively by formulæ IV and V.41
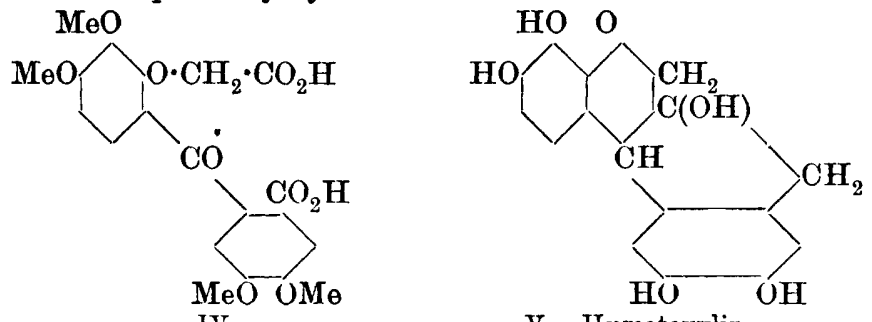

IV.

V. Hæmatoxylin.

Brazilein has the empirical formula $\mathrm{C}_{14} \mathrm{H}_{12} \mathrm{O}_{5}, 2 \mathrm{H}_{2} \mathrm{O}$, losing water at $130-140^{\circ}$. On methylation it yields trimethylbrazilein (II) and tetramethyldihydrobrazileinol, the former of these on treatment with dilute aqueous potassium hydroxide becomes hydrated to trimethylbrazileinol (I); the tetramethyl derivative has the configuration (I) with methoxyl in place of the lower hydroxyl :
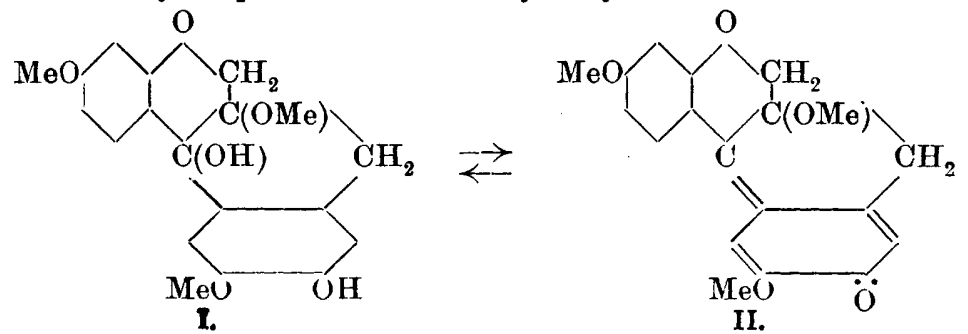

41 W. H. Perkin, jun., and R. Robinson, Trans., 1908, 93, 489. 
The trimethyldihydrobrazileinol is reconverted into trimethylbrazilein on heating, this reversible change being quite comparable with the change of trihydroxytriphenylcarbinol (III) into aurin (IV), and vice versa.

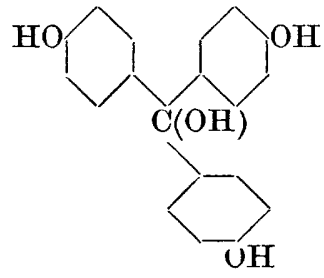

III.

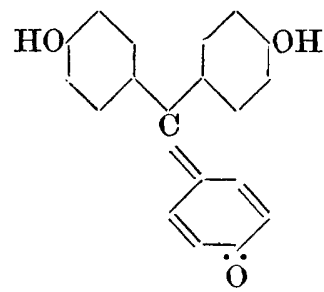

IV.

The close relationship existing between brazilin and hæmatoxylin indicates that hæmatein is hydroxybrazilein. The behaviour of hæmatein on methylation fully justifies this hypothesis. The colouring matter is converted into tetramethylhæmatein (II) and pentamethyldihydrohæmateinol ; the former of these, when digested with dilute potassium hydroxide, is hydrated to tetramethyldihydrohæmateinol (I), a change which is reversed on heating:
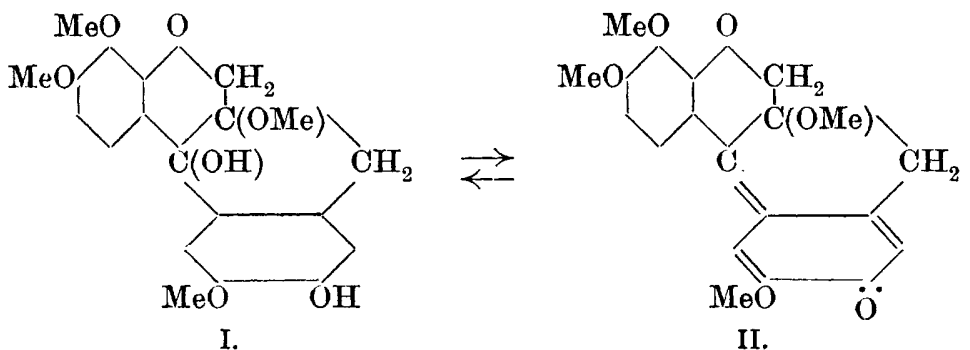

These reactions, together with more confirmatory evidence, lead to the following formulæ for brazilein (I) and hæmatein (II) : 42

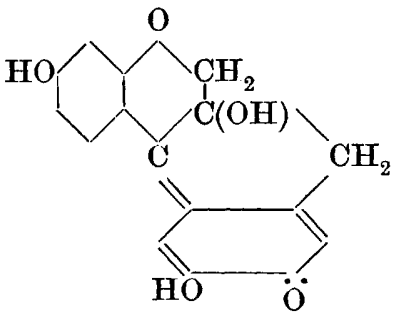

I.

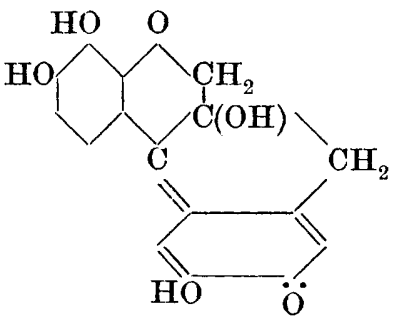

II.

The synthesis of brazan, a substance obtained from brazilin, has ${ }_{42}$ P. Engels, W. H. Perkin, jun., and R. Rohinson, Trans., 1908, 93, 1115. 


\section{4}

ANNUAL REPORTS ON THE PROGRESS OF CHEMISTRY.

been effected in the following manner from resorcinol and $2: 3$-dichloronaphthaquinone : 43<smiles>OC1CCCCC1</smiles><smiles>CCC1COC2(OCl)CCC1O2</smiles><smiles>OCC1CCC2OC3OC4CCCCC4C3OC12</smiles><smiles>COCC1OC2C3CCCCC3OC2C2CCCCC12</smiles><smiles>C[13CH](C)CCO</smiles>
$\underset{\text { with zinc }}{\stackrel{\text { Distillation }}{\longrightarrow}}$<smiles>O=C1CC23CCCCC2C2CC4CCCCC4CC1C23</smiles>
Brazan (o-phenylene$\beta \beta$-naphthylene oxide).

\section{Pyranol Salts.}

In connexion with the experiments on brazilin and hæmatoxylin, the synthesis and coustitution of certain pyranol salts have been studied. As a typical example of these compounds, one may take the product obtained by condensing either resorcinol and benzoylacetaldehyde or $\beta$-resorcylaldehyde and acetophenone. The hydrochloride of this pyranol contains an additional molecule of water, and may be represented by the following formulæ:<smiles>OCC1C(O)C2CCCCC2C1Cl</smiles>

I.

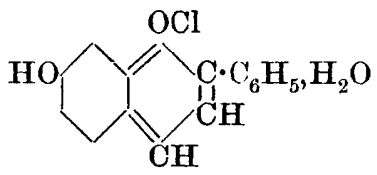

II.

The balance of evidence is in favour of the second formula, which represents the salt as 7-hydroxy-2-phenylbenzopyranol(1:4)anhydrohydrochloride with one molecule of water of crystallisation. All the hydrochlorides examined could be formulated in this way, excepting that some contained even more water of crystallisation.

The platinichloride of the above pyranol was obtained in both

43 S. von Kostanecki and V. Lampe, Ber., 1908, 41, 2373 ; A., i, 671. 
hydrated and anhydrous (III) forms, and all the ferrichlorides described were free from water.

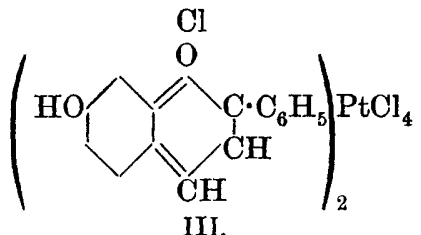

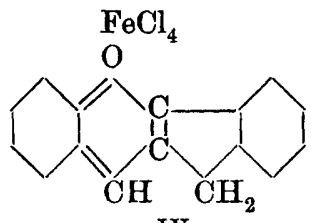

Formula (IV), for example, represents the anhydroferrichloride of $2: 3$-indenobenzopyranol( $1: 4)$, the free base having the structure indicated by $(\mathrm{V})$ :<smiles>CC(O)=C1C2CCCCC2C(C)C12OC1CCCCC12</smiles>

$\mathrm{V}$.<smiles>OC12CCCCC1C1CC3=C2C2CCCCC2CC3C1</smiles>

$\mathrm{CH} \cdot \mathrm{OH}$

VI.

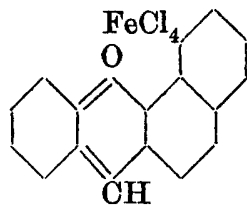

VII.

The ortho-quinonoid formula is adopted for these salts because they are coloured, and in every way comparable with those of naphthaxanthhydrol. Formulæ (VI) and (VII) represent respectively this substance and its anhydroferrichloride. It will be seen that the heterocyclic nuclei of $2: 3$-indenobenzopyranol( $1: 4)$ and naphthaxanthhydrol are similarly constituted (V and VI), and their salts, for example, the anhydroferrichlorides (IV and VII), are formed in a similar manner with elimination of water. Now the naphthaxanthhydrol anhydroferrichloride must be formulated as an ortho-quinoid whether the double linkings are represented as in (VII) or whether they are turned towards the naphthalene nucleus. Accordingly, it may fairly be assumed that the same ortho-quinonoid structure exists in the salts of $2: 3$-indenobenzopyranol $(1: 4)$.

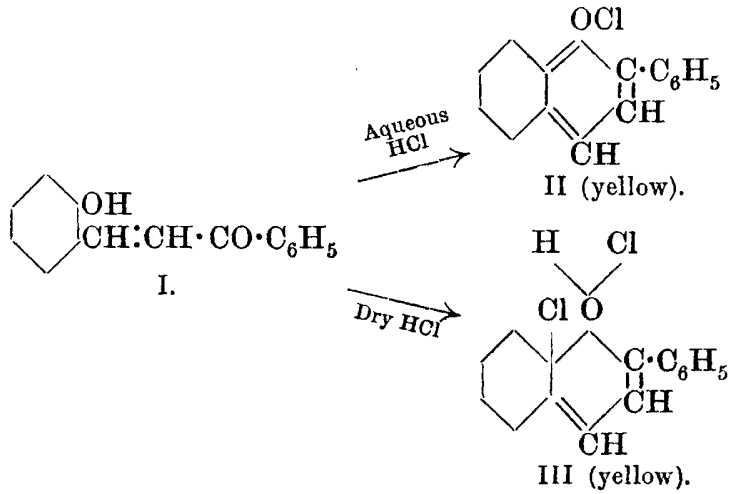


The action of hydrogen chloride on 2-hydroxybenzylideneacetophenone (I) under different conditions affords a noteworthy example of ring formation with production of oxonium salts. Hot concentrated hydrochloric acid acting on the ketone in glacial acetic acid produces 2-phenylbenzopyranol anhydrohydrochloride (II), a very soluble salt isolated in the form of its platinichloride, $\left(\mathrm{C}_{15} \mathrm{H}_{11} \mathrm{OCl}\right)_{2} \mathrm{PtCl}_{4}$.

Dry hydrogen chloride and the ketone interacting in ethereal solution give rise to the dichloride (III) (the hydrochloride of 2-phenylbenzopyranol anhydrohydrochloride).

The original memoir should be consulted for further examples of these interesting pyranol salts, and for a fuller exposition of the arguments adduced in favour of their constitutional formulæ. ${ }^{44}$

A closely allied series of oxonium salts has been produced from disalicylideneacetone $(I)$; this substance when treated with alcoholic hydrochloric acid undergoes condensation to a red oxonium chloride (II), which furnishes a brick-red ferrichloride, $\mathrm{C}_{17} \mathrm{H}_{13} \mathrm{O}_{2} \cdot \mathrm{FeCl}_{4}$. Dilute aqueous sodium hydroxide converts the 2-o-hydroxystyrylbenzopyrylium chloride (II) into the sodium salt, 2-o-hydroxystyrylbenzopyranol-2 (III), from which, however, the free carbinol could not be isolated, as dilute acids induce further condensation with the formation of a substance containing two heterocyclic nuclei. This so-called dibenzospiropyran (IV) is hydrolysed by strong acids to the oxonium salt, and by alcoholic soda to the original disalicylideneacetone $(J) . .^{45}$

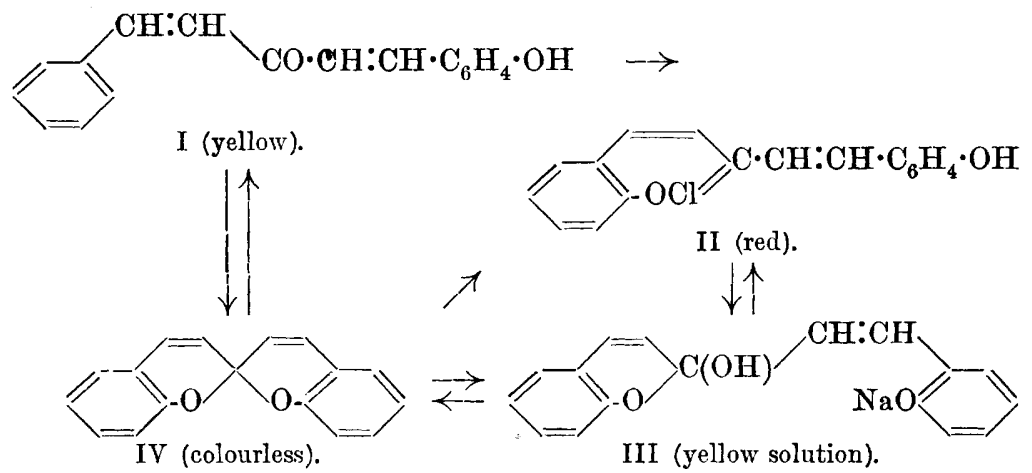

Indigotin and Indigoid Dyes.

The investigations recently carried out on the dyes of the indigo group fall chiefly under four headings: (1) improvements in the phenylglycine synthesis of indigotin, (2) the production of halogenated

${ }_{44}$ W. H. Perkin, jun., R. Robinson, and M. R. Turner, Trans., 1908, 93, 1085.

45 H. Decker and H. Felser, Ber., 1908, 41, 2997 ; A., i, 906. 
indigotins, (3) the synthesis of indigoid dyes containing sulphur, (4) the synthesis of more complex dyes, chiefly of the anthracene series, which are capable of employment in the hyposulphite vat.

1. Modifications in the process of synthesising indoxyl by heating phenylglycine with alkalis have formed the subject of many recent patents. The addition of magnesium powder to the fused mixture of phenylglycine with sodium and potassium hydroxides and barium oxide more than doubles the yield of indigotin subsequently precipitated by aerial oxidation from aqueous solutions of the melt. Fusion under greatly reduced pressure at $200-230^{\circ}$ gives an 80 to 90 per cent. yield of indigotin. ${ }^{46}$

2. A well-defined chloroindigotin, $\mathrm{C}_{16} \mathrm{H}_{9} \mathrm{O}_{2} \mathrm{~N}_{2} \mathrm{Cl}$, has been prepared by direct chlorination of indigotin suspended in hot nitrobenzene. Bromination in the same medium has led to the formation of a tri- and two tetra-bromoindigotins, and more highly halogenated indigotins have been produced, containing both chlorine and bromine. The substitution of hydrogen by halogen in indigotin increases the brilliancy and fastness of the dye, and it is noteworthy that the leuco-derivatives of these halogenated indigotins differ from indigowhite in being coloured, the shade varying from yellow to brown. ${ }^{47}$

The sulphonic acids of the halogenated indigotins have also been prepared; their tinctorial properties differ considerably from those of indigo carmine. ${ }^{48}$

3. 2-Hydroxythionaphthen, an important compound in the synthesis of thioindigoid dyes, is obtained, together with its carboxylic acid,

$$
\mathrm{C}_{6} \mathrm{H}_{4}<\mathrm{S}(\mathrm{OH})>\mathrm{CH} \quad \text { or } \quad \mathrm{C}_{6} \mathrm{H}_{4}<\mathrm{CO}>\mathrm{CH}_{2} \text {, }
$$

by condensing chloroacetic and thiosalicylic acids or their esters in alkaline solutions and then heating the intermediate product, carbmethoxy-o-thiobenzoic acid, $\mathrm{CO}_{2} \mathrm{H} \cdot \mathrm{C}_{6} \mathrm{H}_{4} \cdot \mathrm{S} \cdot \mathrm{CH}_{2} \cdot \mathrm{CO}_{2} \mathrm{H}$, with sodium hydroxide at $180^{\circ}$. Oxidation of 2-hydroxythionaphthen, or its carboxylic acid, results in the formation of a red colouring matter, thioindigotin or $2: 2^{\prime}$-bisthionaphthenindigotin, ${ }^{49}$

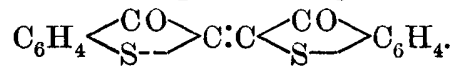

Thionaphthen (I), the parent substance of this group of dyes, is now readily obtained by reducing the synthetical 2-hydroxythionaphthen with zinc and glacial acetic acid :

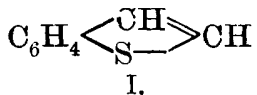

I.

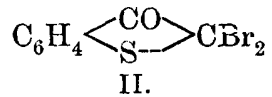

II.

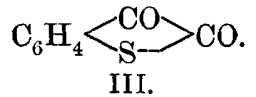

III.

46 L. Lilienfeld, D.R.-P. 189021, 195352 ; A., i, 371, 797.

47 D.R.-P. 193438, 193970, 193971, 195085, 195291 ; A., i, 468, 695, 798.

43 C. G. Schwalbe and H. Jochheim, Ber., 1908, 41, 3798 ; A., i, 1019.

49 D.R.-P. 192075, 194237, 194254 ; A., i, 451, 672. 
2-Hydroxythionaphthen yields 1:1-dibromo-2-ketodihydrothionaphthen (II), and this, on treatment with lead acetate, gives rise to the intensely yellow thionaphthenquinone (III). Like hydroxythionaphthen, the dibromide and the quinone are employed in the synthesis of thioindigoid dyes. ${ }^{50}$

The interaction of thionyl choride, and various styrene derivatives, at $180-270^{\circ}$, leads to the formation of thionaphthen compounds, $\alpha \beta$-dibromostyrene giving rise to hexachlorothionaphthen,

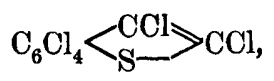

a substance containing only carbon, chlorine, and sulphur. ${ }^{51}$

The condensation of 2-hydroxynaphthen and thionaphthenquinone furnishes thioindirubin, $2: 3$-bisthionaphthenindigotin, ${ }^{52}$

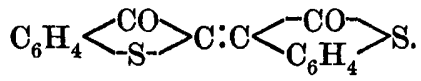

Dyes containing indigotin and thionaphthen nuclei have been synthesised. Isatin and hydroxythionaphthen give rise to thioindigoscarlet, 2-thionaphthen-3-indole-indigotin,

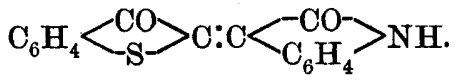

The isomerides, 2-thionaphthen-2-indole-indigotin and 3-thionaphthen-2-indole-indigotin, are obtained from indoxyl with thionaphthen dibromide and thionaphthenquinone respectively.

The application of peri-carboxymethylthionaphthoic acid,

$$
\mathrm{CO}_{2} \mathrm{H} \cdot \mathrm{CH}_{2} \cdot \stackrel{1}{\mathrm{~S}} \cdot \mathrm{C}_{10} \mathrm{H}_{6} \cdot \stackrel{8}{\mathrm{CO}} \mathrm{O}_{2} \mathrm{H}
$$

in the preparation of blue thioindigoid dyes has been patented. ${ }^{53}$

4. Certain complex anthracene derivatives containing nitrogen have the property of yielding colouring matters suitable for the hyposulphite dye vat. ${ }^{54}$

Flavanthren, which possesses this property, may be conveniently considered at this stage. This yellow colouring matter is remarkable because it yields a series of reduction products, most of which are more intensely coloured than the original substance. The progressive reduction of flavanthren indicates the formation of seven reduction products, five of which have actually been isolated.

50 A. Rezdzik, P. Friedländer, and P. Koeniger, Ber., 1908, 41, 227 ; A., i, 200.

51 G. Barger and A. J. Ewins, Trans., 1908, 93, 2086.

52 P. Friedländer, Monatsh., 1908, 29, 359, 375;A., i, 673.

${ }^{53}$ D.R.-P. 198050 ; A., i, 797.

54 D.R.-P. $197554 ; A ., \mathrm{i}, 807$. 


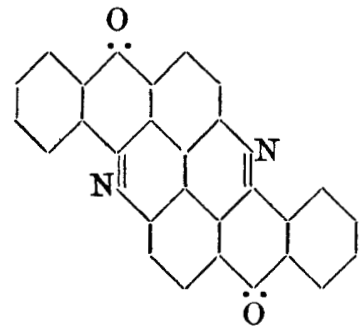

Flavanthren (yellow).

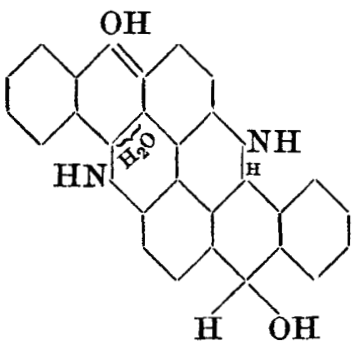

a-Hexahydroflavanthren hydrate (blue).

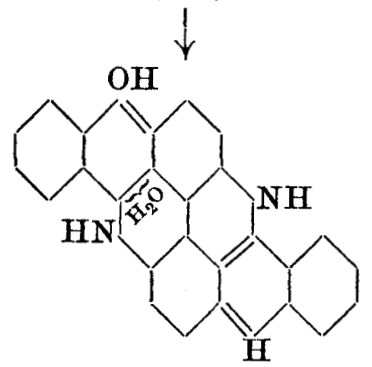

Flavanthrinol hydrate (blue).

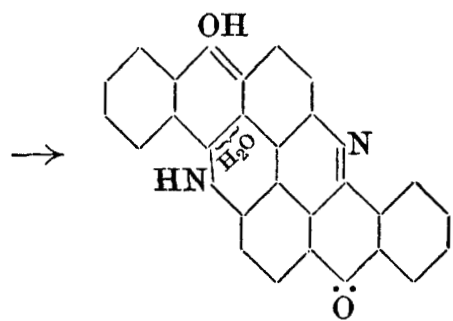

Dihydroflavanthren hydrate (blue).<smiles>[V][V]</smiles>

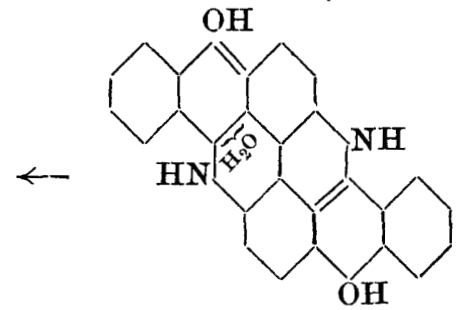

$a$-Tetrahydroflavanthren hydrate (not isolated, brown solution).

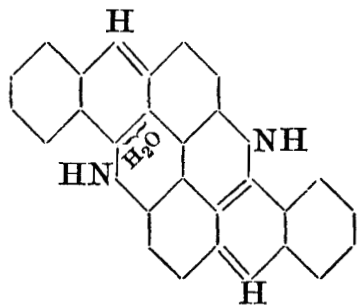

Flavanthrine hydrate (greenish-brown).

The foregoing diagram represents, according to Scholl, the successive stages in the reduction of flavanthren. The products thus isolated contain water of hydration, which is assumed to be attached to two carbons united by a double linking in one of heterocyclic rings. Dihydroflavanthren (green), a-hexahydroflavanthren (blue), flavanthrinol (blue), and flavanthrine (brown) have, however, all been obtained in the anhydrous condition by expelling the water at $150-200^{\circ}$. This dehydration is not accompanied by any marked change in colour. The di-, $a$-tetra-, and $a$-hexa-hydroflavanthren hydrates are obtained by alkaline reducing agents, flavanthrinol is formed by heating a-hexahydroflavanthren hydrate, and flavanthrine hydrate is produced by reducing flavanthren or the foregoing hexahydro-hydrate 
with red phosphorus and hydriodic acid at $210^{\circ}$. At $170^{\circ}$, flavanthren, when reduced, gives rise to another tetrahydroflavanthren, to which in solution the following constitution $(I)$ is ascribed, although when precipitated it probably exists in the ketonic form (II). This $\beta$-tetrahydroflavanthron cannot be hydrated, for it already contains two hydrogen atoms in the position occupied by water in the other reduction products.

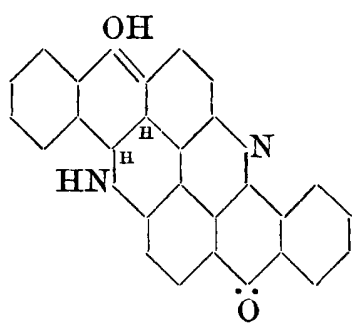

I. B-Tetrahydroflavanthren red in solution (enol).
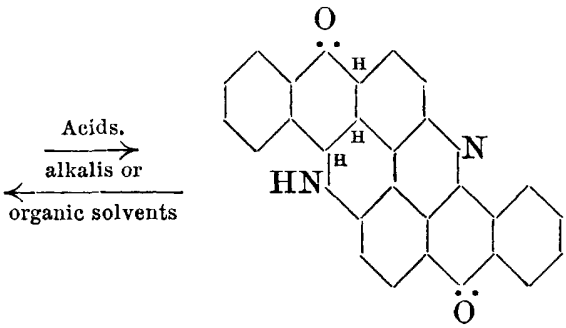

II. Green precipitated ketonic form.

This production of intensely coloured reduction products from a faintly coloured substance is a striking example of the rule that the partial conversion of the chromophores of a colouring matter into auxochromic groups brings about an intensification of the colour. The partial reduction of yellow picric acid to dark brown picramic acid is a case in point. This generalisation accounts for the colour of the intermediate reduction products of flavanthren. The colour of the final product, flavanthrine, like that of meso- and $\beta$-anthramines, may be referred to the fact that they are all derivatives of anthracene, a hydrocarbon which must be regarded as having a chromophoric orthoquinonoid constitution. ${ }^{55}$

\section{Oxazine Group.}

The oxazine dye produced by the condensation of nitrosodimethylaniline and methyl gallate is termed "prune" (I), and an interesting series of derivatives may be obtained from it by the action of aniline and similar aromatic amines. Pruneanilide was formerly supposed to be an additive compound of the oxazine and aniline, but it has now been shown to be a substituted derivative, the dye and aniline condensing in molecular proportions while the hydrogen which should be displaced is employed in reducing another molecule of prune to its leuco-derivative. Actually, the yield of pruneanilide was doubled by blowing air through the mixture. A similar result was obtained with cœlestin blue B [the oxazine (II) from nitrosodimethylaniline and gallamide],

${ }_{55}$ R. Scholl, Ber., 1908, 41, 2304, 2534 ; A., i, 696, 740. 
the yield of anilide being considerably increased by the introduction of air.

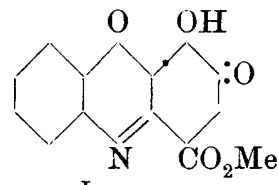

I.<smiles>NC(=O)C1=NC2CCCCC2C(=O)C1O</smiles>

II.

The constitution of pruneanilide has been demonstrated by condensing nitrosodimethylaniline and methyl dibromogallate,

$$
\mathrm{C}_{6} \mathrm{Br}_{2}(\mathrm{OH})_{3} \cdot \mathrm{CO}_{2} \mathrm{Me} \text {, }
$$

when bromoprune is produced, which must have the following constitution (III). When this bromoprune is heated with an alcoholic solution of aniline, pruneanilide results. Accordingly the anilinoresidue occupies the position adjacent to the quinonic oxygen (IV). The anilide of celestin blue $\mathrm{B}$ has a similar constitution. ${ }^{56}$<smiles>COC(Br)(Br)C1=NC2CCCCC2C(=O)C1O</smiles><smiles>COC(=O)C1=C2C3CCCCC3C(=O)C2(O)C(=O)N1c1ccccc1</smiles>

\section{The Azine Group.}

The relationship between azines and quinoxalines (" ethopyrazines ") is well illustrated by the conversion of the two isomeric $\alpha \beta$-dinaphthazines into bases of the quinoxaline series. $s$ - $\alpha \beta$-Dinaphthazine is first
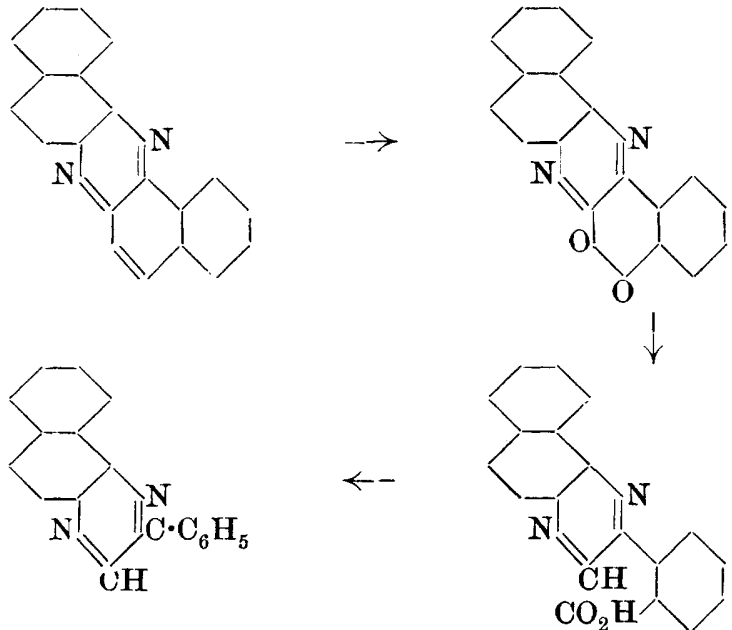

se E. Grandmougin and E. Bodmer, Ber., 1908, 41, 604 ; A., i, 289. REP.-VOL. V. 
oxidised by chromium trioxide into diketo-s- $\alpha \beta$-dinaphthazine. This substance, when heated with concentrated sodium hydroxide, gives rise to 2-phenylnaphthaquinoxalinecarboxylic acid, which, on heating, loses carbon dioxide, and yields 2-phenylnaphthaquinoxaline ("2-phenylnaphthapyrazine"). as.a $\beta$-Dinaphthazine is converted into 3-phenyl naphthaquinoxaline by a precisely similar series of changes. ${ }^{57}$

The prasindones are a group of hydroxyazonium bases containing a hydroxyl group in the para-position with respect to the azonium nitrogen. In some cases, water is eliminated from the azonium and phenolic hydroxyls, so that the base exists in the form of an anhydride. An attempt to prepare the simplest member of this series has not been successful. o-Aminodiphenylamine has been condensed with 3-amino4-hydroxy-o-benzoquinone, and the following series of changes has been realised, but it was not found possible to isolate the base corresponding with the final product : the prasindone nitrate.

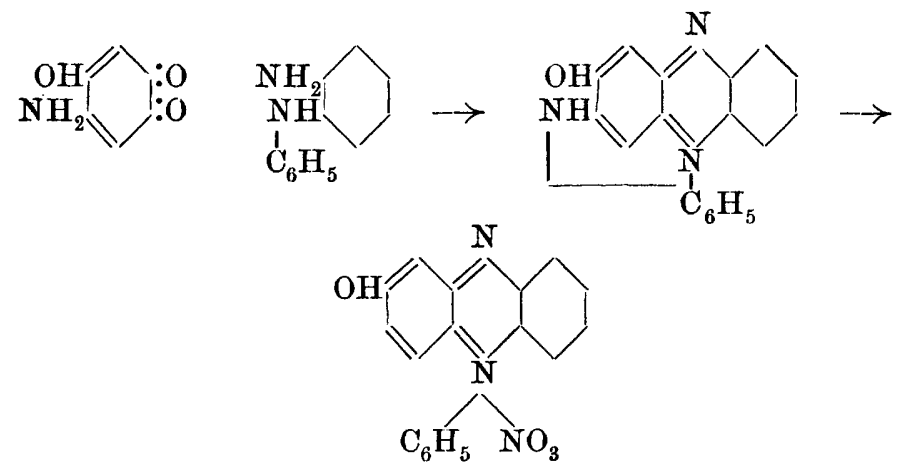

When 2-anilino-1-aminonaphthalene was substituted for o-aminodiphenylamine in the foregoing condensation, the synthesis was carried a stage further, but in this case the prasindone hydrate, although actually isolated, could not be dehydrated. ${ }^{58}$
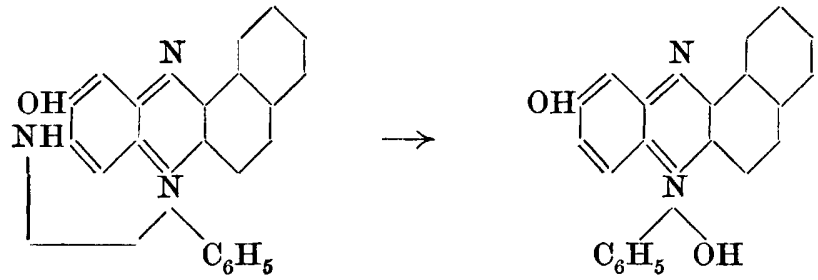

Further evidence in favour of Kehrmann's betaine formula for isorosindone (I) has been obtained by converting it into the chloride of

${ }^{57}$ O. Fischer and E. Schindler, Ber., 1908, 41, $390 ; A$., i, 221.

${ }^{62}$ F. Kehrmann and R. Schwarzenbach, ibid., $472 ; A$., i, 297. 
its acetyl derivative (IV) by two distinct processes. In one the compound is simultaneously reduced and acetylated by zinc dust and acetic anhydride, the product, a diacetyl leuco-derivative (II), being then oxidised to the chloride. In the other process the isorosindone is treated with acetic anhydride alone, when the acetate (III) of its acetyl derivative is directly produced, and can be converted into the corresponding chloride. ${ }^{59}$

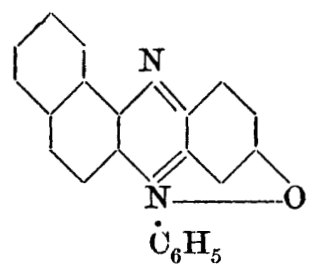

(I.)

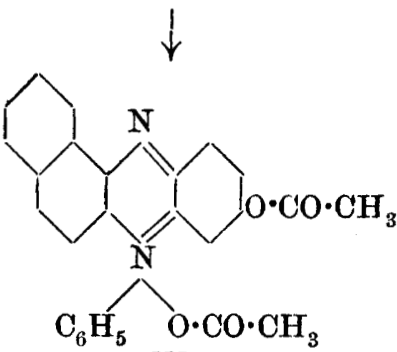

(III.)

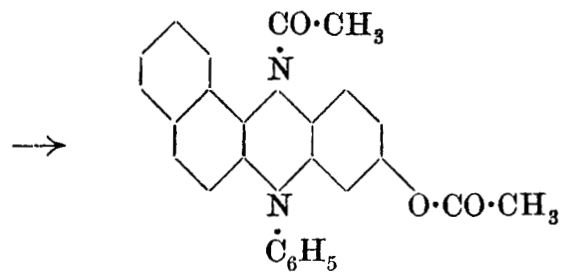

(II.)

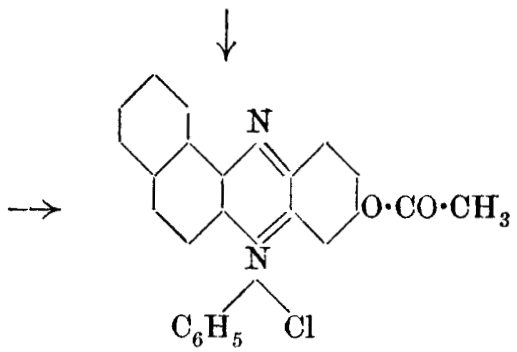

(IV.)

Carboxonium dyes with a structure somewhat similar to the preceding substances have quite recently been obtained by condensing $m$-acetylaminophenol and benzotrichloride in nitrobenzene at $16^{\circ}$. One of these is acetylaminophenylfluorone $(I)$, to which an orthoquinonoid structure is ascribed. The non-acetylated base is of great

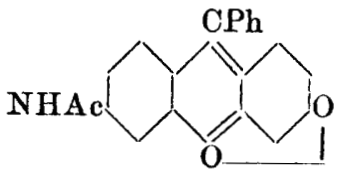

(I.)

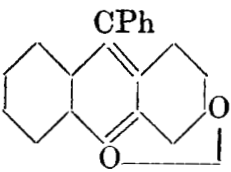

(II.)

interest, as on eliminating the amino-group, phenylfuorone (II) is obtained, which is the chromogen of fluorescein. Hydroxyphenylfluorone (III), produced by replacing the amino-group by hydroxyl, is identical with resorcinolbenzein, and is remarkably like fluorescein, which, as its

59 F. Kehrmann and K. L. Stern, Ber., 1908, 41, 12 ; A., i, 220. 
carboxylic acid, should, if Kehrmann's formulation be accepted, have the formula (IV).

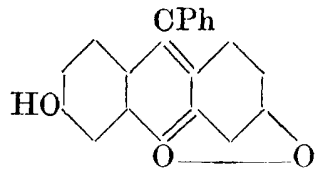

(III.)

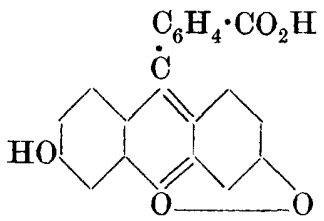

(IV,)

The other condensation product is diacetylaminophenorosamine chloride $(V)$, which yields an unstable colour base changing rapidly into a colourless, stable form. Hydrolysis leads to the simplest rosamine, the salt of which is represented by (VI). ${ }^{60}$

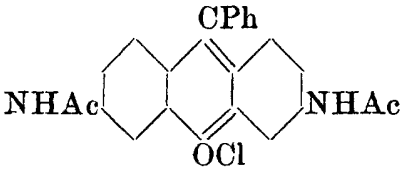

(V.)

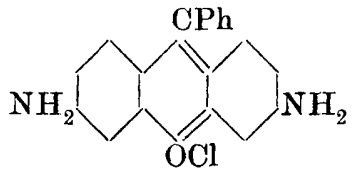

(VI.)

The Rosaniline Group.

The researches of Baeyer and Villiger have shown that many bases of the triphenylmethane group exist in two forms, one colourless and the other coloured. There is little doubt that the colourless bases have the carbinol formula, $\mathrm{HO} \cdot \mathrm{C}\left(\mathrm{C}_{6} \mathrm{H}_{4} \mathrm{NR}_{2}\right)_{3}$, but some uncertainty still exists as to the nature of the coloured amines. In many cases the coloured amine is the dehydrated imino-base, which has only been obtained pure when the amino-groups are phenylated, as in

$$
\mathrm{C}_{6} \mathrm{H}_{5} \mathrm{~N}: \mathrm{C}_{6} \mathrm{H}_{4}: \mathrm{C}\left(\mathrm{C}_{6} \mathrm{H}_{4} \cdot \mathrm{NH} \cdot \mathrm{C}_{6} \mathrm{H}_{5}\right)_{2} \text {. }
$$

The methylated rosanilines have as yet only been isolated in the colourless carbinol form, and although the observations of Hantzsch and Osswald indicate that isomeric quinoneimonium bases of this series may exist, these substances have not been obtained in a state of purity.

Naphtho-blue, $\mathrm{NMe}_{2} \mathrm{Cl}: \mathrm{C}_{10} \mathrm{H}_{6}: \mathrm{C}\left(\mathrm{C}_{8} \mathrm{H}_{4} \cdot \mathrm{NMe}_{2}\right)_{2}$, has yielded its base in two isomeric forms, the colourless carbinol (I) (m. p. 155 ) and the dark green, quaternary ammonium hydroxide (II) (m. p. $261^{\circ}$ ), which may possibly have the alternative pseudo-ammonium formula (III).

$$
\begin{aligned}
& \mathrm{C}_{6} \mathrm{H}_{4} \cdot \mathrm{N}\left(\mathrm{CH}_{3}\right)_{2} \\
& \begin{array}{c}
\mathrm{HO} \cdot \mathrm{C}_{1} \cdot \mathrm{C}_{10} \mathrm{H}_{6} \cdot \mathrm{N}\left(\mathrm{CH}_{3}\right)_{2} \\
\mathrm{C}_{6} \mathrm{H}_{4} \cdot \mathrm{N}\left(\mathrm{CH}_{3}\right)_{2}
\end{array}
\end{aligned}
$$

$$
\begin{aligned}
& \mathrm{C}_{6} \mathrm{H}_{4} \cdot \mathrm{N}\left(\mathrm{CH}_{3}\right)_{2} \\
& \mathrm{C}_{4}: \mathrm{C}_{10} \mathrm{H}_{6}: \mathrm{N}\left(\mathrm{CH}_{3}\right)_{2} \cdot \mathrm{OH} \\
& \mathrm{C}_{6} \mathrm{H}_{4} \cdot \mathrm{N}\left(\mathrm{CH}_{3}\right)_{2}
\end{aligned}
$$

60 F. Kehrmann and O. Dengler, Ber., 1908, 41, 3440; A., i, 1002. 


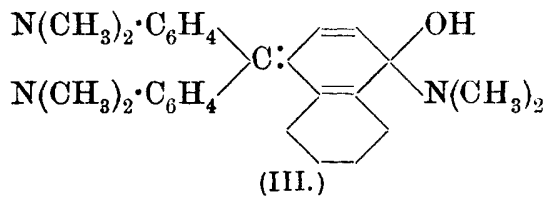

Victoria-blue $\mathrm{R}, \mathrm{NHEtCl}: \mathrm{C}_{10} \mathrm{H}_{6}: \mathrm{C}\left(\mathrm{C}_{6} \mathrm{H}_{4} \cdot \mathrm{NMe}_{2}\right)_{2}$, has also given rise to a coloured as well as a colourless base, but these substances are not isomeric. The colourless compound is the carbinol (I) (m. p. $170^{\circ}$ ), but the coloured substance is the anhydrous imino-base (II) (m. p. $\left.192^{\circ}\right)$.

$$
\begin{aligned}
& \mathrm{C}_{6} \mathrm{H}_{4} \cdot \mathrm{N}\left(\mathrm{CH}_{3}\right)_{2} \\
& \begin{array}{c}
\mathrm{HO} \cdot \mathrm{C}_{\mathrm{C}} \cdot \mathrm{C}_{10} \mathrm{H}_{6} \cdot \mathrm{NH} \cdot \mathrm{C}_{2} \mathrm{H}_{5} \\
\mathrm{C}_{6} \mathrm{H}_{4} \cdot \mathrm{N}\left(\mathrm{CH}_{3}\right)_{2}
\end{array}
\end{aligned}
$$

(I.)

$$
\begin{aligned}
& \mathrm{C}_{6} \mathrm{H}_{4} \cdot \mathrm{N}\left(\mathrm{CH}_{3}\right)_{2} \\
& \mathrm{C}: \mathrm{C}_{10} \mathrm{H}_{6}: \mathrm{N} \cdot \mathrm{C}_{2} \mathrm{H}_{5} \\
& \mathrm{C}_{6} \mathrm{H}_{4} \cdot \mathrm{N}\left(\mathrm{CH}_{3}\right)_{2}
\end{aligned}
$$

The composition of these two pairs of diphenylnaphthylmethane bases has been confirmed in each case by complete analyses, ${ }^{61}$ which show that the substances were obtained in a fairly pure state.

The corresponding diphenylnaphthylmethane colouring matter, containing methyl instead of ethyl in the foregoing formulæ, gives rise also to the corresponding colourless carbinol and the coloured imino-base.

All attempts to isolate the quinonoid form of the bases from crystalviolet, malachite green, and $o$-chloromalachite green were unsuccessful ; although the coloured bases could be seen in solution, they were too unstable to be anailysed. ${ }^{62}$

\section{Cyclic Sulphur Compounds.}

One of the nitration products of thiodiphenylamine is the dinitrosulphoxide (I), which has been taken as the starting point in the synthesis of $S$-phenylphenazothionium hydroxide and its salts. When condensed with phenol or phenetole in concentrated sulphuric acid, the sulphoxide gives rise to the sulphate of a phenazothionium base, the chloride of which is represented by formula (II).

$S$-Phenetyl-3 : 3 '-dinitrophenazothionium chloride undergoes hydrolysis to the base $S$-phenetyl-3:3'-dinitrophenazothionium hydroxide (III), but when treated with aqueous alkali hydroxide the anhydride (IV) (anhydro-S'-phenetyl-3:3'-dinitrophenazothionium) is set free.

61 E. Noelting and K. Philipp, Ber, 1908, 41, 579 ; A., i, 295.

52 Ibid., 3908 ; A., 1909, i, 61 . 


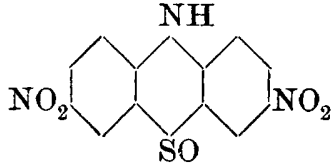

(I.)<smiles>CCOCCOCCO</smiles>

IV. Reddish-brown anhydride.

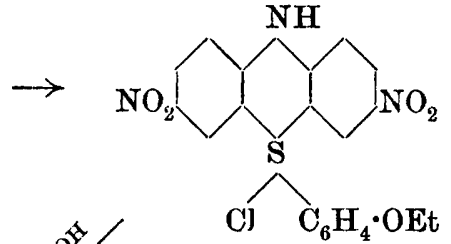

II. Green salt.

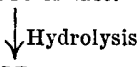
$\mathrm{N}$

$\mathrm{HO}_{2} \mathrm{~N}$

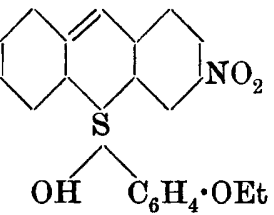

III. Crimson hydroxide.

The chloride (II) has been reduced to a diamine, which, on oxidation, gives rise to $S$-phenetyl-3: $3^{\prime}$-diaminophenazothionium chloride (V).

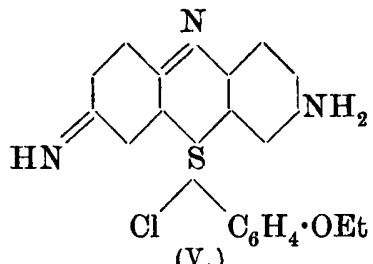

Corresponding phenazothionium salts have been produced containing hydroxyphenyl in the place of phenetyl. ${ }^{63}$

Thiopyrine, the sulphur analogue of antipyrine, is regarded by Michaelis as having the formula (I). It has now for the first time been converted into 1-phenyl-3-methyl-5-thiopyrazolone (IV) in the manner indicated in the following diagram :<smiles>Cc1cc2cccn2n1C</smiles>

(I.)

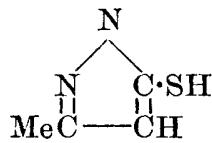
(IV.)

\section{Hydrolysis}
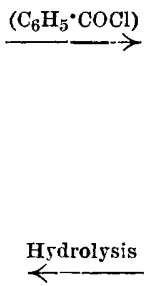

63 S. Smiles and T. P. Hilditch, Trans., 1908, 93, 145, 1687. 
The presence of the thiol group SH is indicated by the mode in which the thiopyrazolone undergoes oxidation. Alkaline hydrogen peroxide gives rise to the sulphonic acid, whilst nitrous acid or iodine in potassium iodide solution leads to the disulphide. Nevertheless, 1-phenyl-3-methyl-5-thiopyrazolone also reacts in its thiocarboxyl form, and, like phenylmethylpyrazolone, it condenses with aldehydes and ketones. ${ }^{64}$

\section{Alkaloids.}

Damascenine, the alkaloid from Nigella, has been investigated, and its constitution established. Boiling with alkalis converts it into an isomeride, damascenic acid, which by a series of steps yields 2-amino3-hydroxybenzoic acid, proving it to be 2-methylamino-3-methoxybenzoic acid (I). The alkaloid, being devoid of acid properties, appears to be a betaine (II).

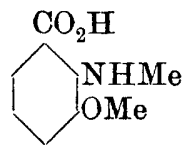

(I.)

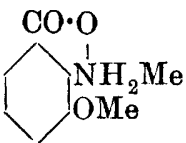

(II.)

Methyldamascenine, present in the same plant, proves to be the methyl ester of damascenic acid. An attempt to synthesise the alkaloid, starting from methylanthranilic acid, failed owing to the impossibility of introducing methoxyl or hydroxyl in place of the amino-group in position 3 , the diazonium compound changing into a stable azimino-compound.65

Atropine may be synthesised by a method giving a much better yield than does the condensation of tropine with tropic acid, by acetylation of tropic acid, conversion into the chloride, condensation with tropine hydrochloride, and elimination of the acetyl group, the last process taking place spontaneously when the acetyltropine is allowed to remain a short time in aqueous solution. On the other hand, when an attempt is made to replace the chlorine in $\beta$-chlorohydratropyltropine by hydroxyl, an intramolecular change takes place, hydrogen chloride being transferred, and cpoatropine hydrochloride is obtained :

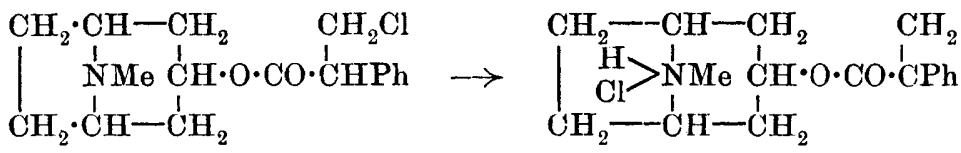

This apoatropine synthesis is a general one for tropeines, starting from $a$-, $\beta$-, or $\gamma$-halogenated propionic or $n$-but,yric acids. ${ }^{66}$

64 A. Michaelis, Annalen, 1008, 361, 251;A., i, 688.

${ }^{65}$ O. Keller, Arch. Pharm., 1908, 246, 1 ; A., i, 283.

${ }_{66}^{6}$ R. Wolffenstein and L. Mamlock, Ber., 1908, 41, 723; R. Wolffenstein and J. Rolle, itid., 733; A., i, 281, 282. 
A contribution to the study of cinchonine has been made in the form of an examination of cinchoninone, the ketone obtained by oxidation of the alkaloid. This ketone is amphoteric, and also exhibits enol-keto-tautomerism, yielding both an oxime and an $O$-benzoyl derivative. By the action of nitrous acid, cinchonic acid and an oxime are obtained, the latter yielding Koenig's meroquinenine on hydrolysis. This leads to formulæ ( $\mathrm{I}$ and II) for cinchoninone and cinchonine respectively : ${ }^{67}$

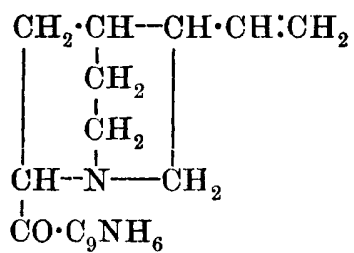

(I.)

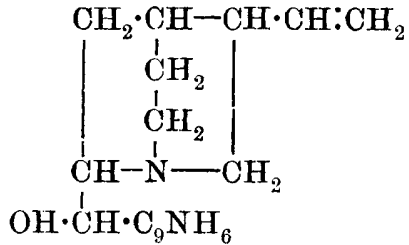

(II.)

Although little progress has been made towards establishing the constitution of the strychnos alkaloids, nevertheless crystalline acids have now been obtained by oxidation, the composition of which indicates that both alkaloids contain a secondary alcohol grouping. ${ }^{68}$

When papaverinium alkyl salts are treated with very dilute alkalis, the liberated papaverinium hydroxides undergo condensation to phenolbetaines. Thus $N$-methylpapaverinium methosulphate yields the phenolbetaine,

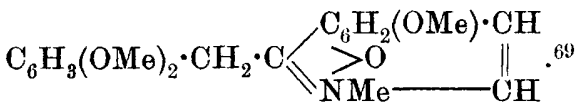

In the morphine group of alkaloids, a synthesis of a compound obtained in the partial breaking down of morphine has been effected for the first time. Morpholquinone is known to be 3:4-dihydroxyphenanthraquinone, and this may be prepared from 3-nitrophenanthraquinone by reduction, diazotisation, and conversion into the 3-hydroxycompound, nitration in the 4-position, a repetition of the reduction and diazotisation giving morpholquinone. ${ }^{70}$

$\psi$-apoCodeine is the 3-methyl ether of apomorphine, and thus stands in the same relation to apomorphine as codeine does to morphine. ${ }^{71}$

Much work has also been carried out on the constitution of

67 P. Rabe, Bor., 1908, 41, 62; A., i, 100.

68 H. Lenchs, ibid., 1711 ; A., i, 563.

69 H. Decker and G. Dunant, Annalen, 1908, 358, 288 ; A., i, 204.

70 J. Schmidt and J. Söll, Ber., 1908, 41, 3696; A., i, 995.

71 L. Knorr and F. Paabe, ibid., $3050 ; A$., i, 908. 
sparteine ${ }^{72}$ by means of a study of the reactions of $a$-methylsparteine. When degraded by Hofmann's reaction, methylsparteine yields methylhemisparteilene,

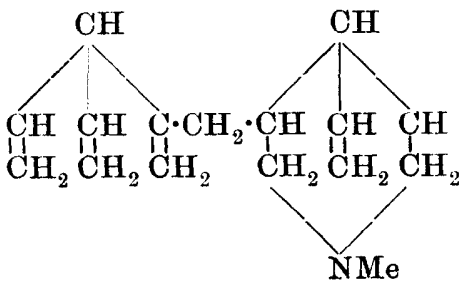

The methylsparteines behave as unsaturated bases, having a methyl group attached to nitrogen. The isosparteine into which they may be converted is a ditertiary base, which does not reduce acid permanganate. The conversion may be carried out by heating a-methylsparteine di-iodide with water at $125^{\circ}$, when isomeric change to isosparteine methiodide takes place.

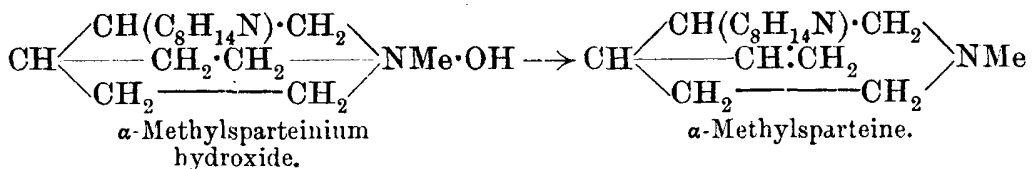

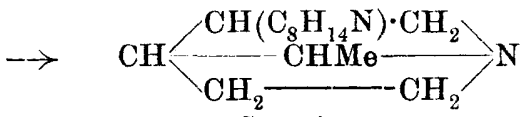

isoSparteine.

The reverse change may be carried out by heating a-methylisosparteinium hydroxide in a vacuum, when it gives $\alpha$-methylsparteine. The latter compound takes up two atoms of iodine to form the methiodide of an iodo-base, which behaves as if it were an iodoisosparteine,

$$
\mathrm{CH}\left\langle\frac{\mathrm{CH}\left(\mathrm{C}_{8} \mathrm{H}_{14} \mathrm{~N}\right) \cdot \mathrm{C}_{\mathrm{H}_{2}}}{\mathrm{CH}\left(\mathrm{CH}_{2} \mathrm{I}\right)}{\stackrel{\mathrm{CH}_{2}}{\mathrm{CH}_{2}}}^{-}{ }^{\mathrm{NMeI}}\right.
$$

but it is possible that its formation is due to the isomerisation of the a-methylsparteine under the influence of bydrogen iodide.

Jateorrhizine and columbamine, alkaloids from columba root, have been further investigated, ${ }^{73}$ and the monomethyl ether of columbamine is found to be identical with the dimethyl ether of jateorrhizine. The acid obtained on oxidation of this ether is a trimethoxy-o-

$7^{2}$ C. Moureu and A. Valeur, Compt. rend., 1907, 145, 815, 929, 1184, 1343 ; 1908, 146, 79 ; 147, 127 ; Bull. Soc. ehim., 1903, [iv], 3, 674; A., i, 43, 44, 103, $206,563,736,1006$.

${ }^{73}$ K. Feist, Arch. Pharm., 1907, 245, $586 ;$ A., i, 100. 
phthalic acid, but it has not yet been determined whether the methoxyl groups have the $3: 4: 5$ - or $3: 4: 6$-position. A third alkaloid, palmatine, closely resembling berberine, is also present in the root, but its relation to the other two is unknown.

\section{Polypeptides.}

The progress in the building up of polypeptide molecules has been exceedingly rapid during the past year. Perhaps the most important step that has been made is that of introducing tyrosine groups into the molecule. The tyrosine group is of such frequent occurrence in natural proteins that this advance was necessary before compounds showing the reactions of the true proteins could be prepared, especially as the difference between the naturally occurring and the synthetic polypeptides is now recognised as consisting less in the number of amino-acid groups present than in the conjunction, in natural substances, of groups of several different kinds.

The usual method of synthesis is not applicable when an aminohydroxy-acid, such as tyrosine, is employed, because of the action of phosphorus pentachloride on the hydroxyl group. This may be protected by the introduction of the carbomethoxyl group, which resists the action of phosphorus pentachloride and acyl chlorides, and is readily removed afterwards by hydrolysis. The protecting group is introduced by means of methyl chlorocarbonate. The products are, however, inactive. ${ }^{74}$

A tetrapeptide was isolated last year from silk, and was shown to consist of two glycine groups and one group each of $d$-alanine and $l$-tyrosine. Several attempts to synthesise this substance have been made, but in every case the product was found to differ from the natural polypeptide in not being precipitated by ammonium sulphate, or in only being precipitated from very concentrated solutions. Such compounds, isomeric with the tetrapeptide sought after, have been prepared by the action of $l$-tyrosine ester on chloroacetyl-d-alanylglycine, and by coupling glycine- $d$-alanine anbydride with chloroacetyltyrosyl chloride methyl carbonate, followed by hydrolysis. The glycyltyrosylglycyl- $d$-alanine obtained in the second case is probably a mixture of stereoisomerides. ${ }^{75}$ Various tyrosine polypeptides, derived from glycine, $d$-alanine, and $l$-leucine, were also not precipitated by ammonium sulphate. ${ }^{76}$

The 3:5-di-iodo-l-tyrosine group has also been introduced, on account of its occurrence in the proteins of coral. Glycyldi-iodotyro-

74 E. Fischer, Sitzungsber. K. Akad. Wiss. Berlin, 1908, 542 ; A., i, 544.

75 E. Fischer, Ber., 1908, 41, 850, $2860 ; A$, i, 324, 887.

76 E. Abderhalden and A. Hirszowski, ibid., $2840 ; A$., i, 887 . 
sine has been synthesised, ${ }^{77}$ starting from the action of iodine on tyrosine.

Various dipeptides have been prepared containing the $d$-valine group, which are of interest, not only in connexion with polypeptide synthesis, but also for the study of the Walden inversion. ${ }^{78}$ More complex groups have also been introduced, notably the $\alpha$-aminostearyl group ${ }^{79}$ and $\beta$-amino-acid residues, such as those of $\beta$-aminobutyric acid and $\alpha$-methylisoserine. ${ }^{80}$

It is found that glycine ethyl ester, like ethyl oxalate, may be reduced with sodium amalgam, the final product, after treatment with alcoholic hydrogen chloride, being aminoacetal.$^{81}$ The appiication of a similar method of reduction to polypeptides gives unsatisfactory yields, but the corresponding aminoacetals are readily prepared by the condensation of aminoacetal with chloroacyl chlorides and treatment of the products with ammonia.

The presence of histidine in many natural proteins, and the existence of proline (pyrrolidine-2-carboxylic acid) in the products of the hydrolysis of gelatin, have led Fischer and his pupils to include these groups also in the synthetic scheme, and methods of synthesis have therefure been devised for the purpose of preparing the materials. ${ }^{82}$

$l$-Leucyl- $l$-histidine is stable towards concentrated hydrochloric acid, and since both $l$-leucine and $l$-histidine are present in oxyhæmoglobin, the dipeptide was sought for, but unsuccessfully, in the products of hydrolysis of that substance.

The use of hydrofluoric acid has been recommended for the hydrolysis of proteins, as causing less secondary reactions than any other acid. ${ }^{83}$

\section{Synthetical Therapeutic Agents.}

Considerable activity is being shown in the production of local anæsthetics of the "novocaine" type. This substance itself is the hydrochloride of diethylaminoethyl $p$-aminobenzoate,

$$
\mathrm{NH}_{2} \cdot \mathrm{C}_{6} \mathrm{H}_{4} \cdot \mathrm{CO}_{2} \cdot \mathrm{C}_{2} \mathrm{H}_{4} \cdot \mathrm{N}\left(\mathrm{C}_{2} \mathrm{H}_{5}\right)_{2}, \mathrm{HCl} \text {. }
$$

A series of similarly constituted compounds has been prepared, and their physiological action has been ascertained. Some of these substances have pronounced local anæsthetic properties, but are not

77 E. Abderbalden and M. Guggenheim, Ber., 1908, 41, 1237 ; A., i, 420.

78 E. Fischer and H. Scheibler, Annalen, 1908, 363, $136 ; A$., i, 957.

79 E. Fischer and W. Kropp, ibid., 362, 338 ; A., i, 773.

80 F. W. Kay, ibid., $348 ; A$., i, 773.

81 E. Fiseher, Ber., 1908, 41, $1019 ; A$., i, 323.

82 E. Fischer and A. Krämer, ibid., 2728 ; E. Fischer and L. H. Cone, Annalen, 1908, 363, 107 ; E. Fischer and G. Reif, ibid., $118 ; A .$, i, 858, 1004, 1007.

${ }^{83}$ L. Hugounenq and A. Morel, Compt. rend., 1908, 146, 1291 ; A., i, 706. 


\section{2}

suitable for use in medicine, owing either to their high general toxicity or to the local irritation produced by their injection. ${ }^{84}$

In view of these results, it is open to doubt whether the many compounds recently described in patents are, in general, of much therapeutic value.

The hydrochlorides of the dialkylaminoalkyl benzoates, such as $\mathrm{C}_{6} \mathrm{H}_{4} \cdot \mathrm{CO}_{2} \cdot \mathrm{CH}_{2} \cdot \mathrm{CH}_{2} \cdot \mathrm{NEt}_{2}, \mathrm{HCl}$, are stated to be useful anæsthetics, ${ }^{85}$ whilst the alkyluminoalkyl aminocinnamates (for example,

$$
\mathrm{NH}_{2} \cdot \mathrm{C}_{6} \mathrm{H}_{4} \cdot \mathrm{CH}: \mathrm{CH} \cdot \mathrm{CO}_{2} \cdot \mathrm{CH}_{2} \cdot \mathrm{CH}_{2} \cdot \mathrm{NEt}_{2} \text { ) }
$$

are said to surpass the alkylaminoalkyl benzoates in this respect. ${ }^{86}$

It is claimed that the alkylaminoalkyl salicylates unite these anæsthetic properties with those of salicylic acid..$^{87}$

Salicylic acid and its acetyl derivative ("aspirin") have certain undesirable physiological properties, which are said to be favourably modified in the recently-described 'anhydrides of acylsalicylic acids. Of these products, acetylsalicylic anhydride, $\mathrm{O}\left(\mathrm{CO} \cdot \mathrm{C}_{6} \mathrm{H}_{4} \cdot \mathrm{O} \cdot \mathrm{CO} \cdot \mathrm{CH}_{3}\right)_{2}$, and cinnamoylsalicylic anhydride, $\mathrm{O}\left(\mathrm{CO} \cdot \mathrm{C}_{6} \mathrm{H}_{4} \cdot \mathrm{O} \cdot \mathrm{CO} \cdot \mathrm{CH}: \mathrm{CH} \cdot \mathrm{C}_{6} \mathrm{H}_{5}\right)_{2}$, appear to be the most promising. ${ }^{88}$

The recent commercially successful synthesis of the powerful hæmostatic adrenaline by the Farbwerke vorm. Meister, Lucius, and Brining has stimulated research in this direction. An interesting series of observations on the conversion of catechol methylene ethers into cyclic carbonates by the action of thionyl chloride may be mentioned at this stage. ${ }^{89}$

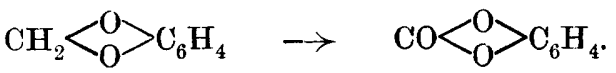

The benzoylaminoacetylcatechol others,

$$
\text { . } \mathrm{C}_{6} \mathrm{H}_{4} \cdot \mathrm{CO} \cdot \mathrm{NH} \cdot \mathrm{CH}_{2} \cdot \mathrm{CO} \cdot \mathrm{C}_{6} \mathrm{H}_{3}(\mathrm{OR})_{2} \text {, }
$$

when hydrolysed with aqueous acids under pressure, yield amino-

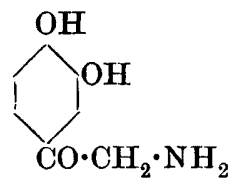

acetylcatechol, which is stated to have powerful hæmostatic properties like the active principles of the suprarenal capsules. ${ }^{90}$

The root of Canadian hemp (Apocynum cannabinum) retards the heart in systole. Apocynin, one of its physiologically active con-

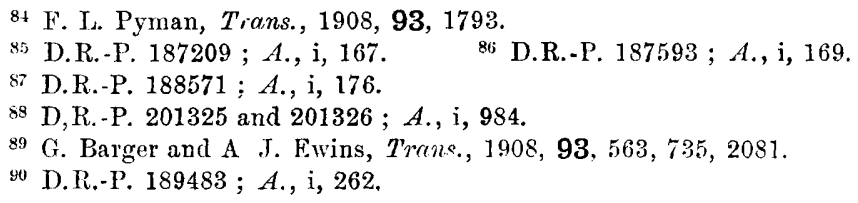


stituents, has been examined, and shown to be identical with acetovanillone. This conclusion has been confirmed by the synthesis of apocynin from vanillin. ${ }^{91}$

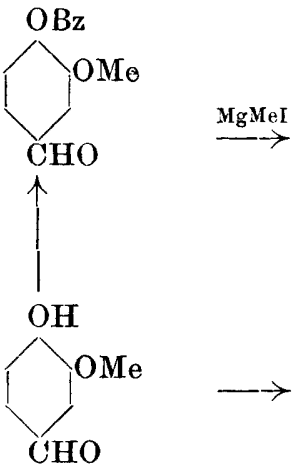

Vanillin.

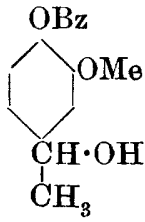

Benzoylapocynol.<smiles>CC(O)C1CCC(O)C(O)C1</smiles>

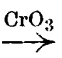

$\stackrel{\mathrm{Na}+\mathrm{EtOH}}{\leftarrow}$

Apocynol.

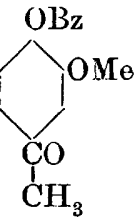

Benzoylapocyuin.

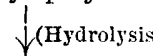<smiles>O</smiles><smiles>CCC1CCCOC1</smiles>

Apocynin.

5 : 5-Diethylbarbituric acid ("veronal") and its homologues still receive much attention, and new methods of preparation form the subjects of many patents. Practically quantitative yields of these acids may be obtained by treating with nitrous acid the dialkylmalonylguanidines produced by condensing ethyl dialkylmalonates with guanidine. ${ }^{92}$ A detailed study of the dialkylmalonic acids has brought to light the interesting fact that complex anhydrides of these substances may be produced by treating the acid chlorides with aqueous pyridine. The duodecimolecular anhydride of diethylmalonic acid has in ethylene dibromide or benzene a complexity corresponding with the formula $\left[\begin{array}{l}\mathrm{O}_{2} \mathrm{H}_{5} \\ \mathrm{C}_{2} \mathrm{H}_{5}\end{array} \mathrm{C}_{\mathrm{CO}}>\mathrm{CO}\right]_{12}$. In nitrobenzene the degree of association is diminished to that of an octamolecular anhydride. ${ }^{93}$

\section{Organic Derivatives of Arsenic.}

The last few years have witnessed a great revival of interest in the study of organic derivatives of arsenic, owing to the circumstance that certain of these substances have proved efficacious in the therapeutics of diseases of protozoic origin.

Sodium $p$-aminophenylarsonate ("atoxyl") and its acetyl derivative have been successfully employed in the treatment of trypanosomiasis (sleeping sickness). The former of these substances was discovered by

91 H. Finnemore, Trans., 1908, 93, 1513, 1520 .

92 D.R.-P. $189076 ; A$., i, 370.

93 A. Einhorn, Annalen, 1908, 359, $145 ; A .$, i, 312. 
Béchamp in 1863, but its true nature was discovered only in 1907 by Ehrlich and Bertheim.

$p$-Aminophenylarsonic acid, $\mathrm{NH}_{2} \cdot \mathrm{C}_{6} \mathrm{H}_{4} \cdot \mathrm{AsO}(\mathrm{OH})_{2}$, is the chief product of the interaction of aniline and aniline arsenate at $180^{\circ}$, but Pyman and Reynolds have recently demonstrated that a small amount ( 2 or 3 per cent.) of bis- $p$-aminophenylarsinic acid $(\mathrm{I})$ is simultaneously produced. $^{94}$

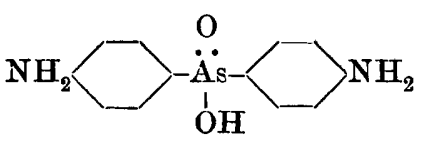

(I.)

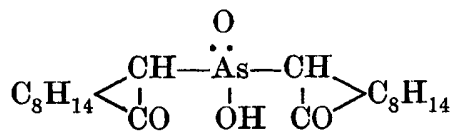

(II.)

These investigators have also prepared the corresponding bis-2aminotolyl-5-arsinic acid, so that the reaction is probably a general one. These compounds are the aromatic analogues of cacodylic acid, $\mathrm{AsMe}_{2} \mathrm{O} \cdot \mathrm{OH}$. The camphor analogue, dicamphorylarsinic acid (II), has recently been isolated from the products of the action of arsenious chloride on sodium camphor. ${ }^{95}$

The use of arsenious chloride for the introduction of arsenic into aromatic compounds was first studied by Michaelis and his collaborators. The dimethylaminophenylarsine oxide,

$$
\mathrm{NMe}_{2} \cdot \mathrm{C}_{6} \mathrm{H}_{4} \cdot \mathrm{AsO} \text {, }
$$

obtained from the chloride and dimethylaniline, has now been oxidised to dimethyl- $p$-aminophenylarsonic acid (dimethylatoxyl) by alkaline hydrogen peroxide. ${ }^{96}$

Aminoarsonic acids can be obtained from all primary aromatic amines having an unsubstituted para-position, and by means of the diazo-reaction the corresponding hydroxy-arsonic acids have been prepared. ${ }^{97}$

Phenylarsonic acid gives a nitrophenylarsonic acid, which, on reduction, yields an aminophenylarsonic acid isomeric with the atoxyl acid. The isomeride is probably a meta-derivative; unlike atoxyl, it retains its arsenic on boiling with hydriodic acid. In the para-series the arsenic is replaced by iodine. ${ }^{98}$

The arsenic in these compounds is not removed by boiling with aqueous alkali hydroxides, but when fused with these reagents it is eliminated as alkali arsenate.

The alkyl esters of arsenious acid, $\mathrm{As}(\mathrm{OEt})_{3}$, etc., may be obtained by heating arsenious oxide with the primary alcohols in the presence

94 Trans., 1908, 93, 1180.

95 G. T. Morgan and F. M. G. Micklethwait, ibid., 2144,

96 A. Michaelis, Ber., 1908, 41, 1514; A., i, 590.

97 L. Benda and R. Kahn, ibid., 1672, 3859 ; $A$., i, 591.

${ }^{98}$ A. Bertheim, ibid., $1455 ; A$., i, 590. 
of an insoluble dehydrating agent (for example, dry copper sulphate)..$^{99}$

When arsenious oxide is added to an ethereal solution of magnesium phenyl bromide, it is found to undergo the Grignard reaction, with the production, after about thirty minutes, of diphenylarsine oxide, $\left[\mathrm{As}\left(\mathrm{C}_{6} \mathrm{H}_{5}\right)_{2}\right]_{2} \mathrm{O}$. Prolonged treatment leads to the formation of triphenylarsiue, $\mathrm{As}\left(\mathrm{C}_{6} \mathrm{H}_{5}\right)_{3}$. The tri-p-tolylarsine, $\mathrm{As}\left(\mathrm{C}_{6} \mathrm{H}_{4} \cdot \mathrm{CH}_{3}\right)_{3}$, is similarly prepared, but in this case is unaccompanied by the oxide. ${ }^{1}$ Magnesium benzyl bromide gives rise to dibenzylarsine hydroxide, $\mathrm{As}\left(\mathrm{CH}_{2} \cdot \mathrm{C}_{6} \mathrm{H}_{5}\right)_{2} \cdot \mathrm{OH}, \mathrm{H}_{2} \mathrm{O}$.

\section{Silicon Compounds.}

The chemistry of silicon derivatives offers many points for comparison with that of carbon compounds of similar structure, remarkable similarities and equally striking differences of behaviour being observed. Thus the silicones, the silicon analogues of the ketones, are not only compounds of considerable molecular complexity, tending to form molecules of the form $\left(\mathrm{R}_{2} \mathrm{SiO}\right)_{3}$ and boiling at very high temperatures, but they are not reduced by the usual reagents for reducing ketones, and do not form oximes or phenylhydrazones. The latter circumstance may be due to the readiness with which the $\mathrm{Si}-\mathrm{N}$ linking is broken by water. Benzylethylsilicone, $\mathrm{C}_{6} \mathrm{H}_{5} \cdot \mathrm{C}_{2} \mathrm{H}_{5}>\mathrm{Si}$.O, is prepared with ease by the action of water on benzylethylsilicon dichloride. Two isomeric dibenzylsilicols, $\mathrm{Si}\left(\mathrm{CH}_{2} \cdot \mathrm{C}_{6} \mathrm{H}_{5}\right)_{2}(\mathrm{OH})_{2}$, were obtained, differing considerably in stability, but both yielding the silicone by loss of water. The nature of the isomerism remains unexplained, and other results which have been obtained suggest that the isomerism of silicon-oxygen compounds may prove to be of a nature not hitherto encountered amongst carbon compounds. ${ }^{2}$

Stereoisomeric silicon compounds of such optical activity as to leave no doubt as to the occurrence of optical antipodes in this series, have now been prepared by sulphonating benzylethylpropylsilicyl oxide and the corresponding compound containing isobutyl in place of propyl, and crystallising the salts of the sulphonic acids with active methylhydrindamines. The sodium salts of the active isobutyl compounds have a molecular rotation nearly twice as great as that of the propyl compounds. ${ }^{3}$

90 W. R. Lang, J. F. Mackey, and R. A. Gortner, Trans., 1908, 93, 1364.

1 F. Sachs and H. Kantorowicz, Ber., 1908, 41, 1031 ; A., i, 1031.

2 R. Robison and F. S. Kipping, Trans., 1908, 93, 439.

3 F. S. Kipping, ibid., 457 ; B. D. W. Luff and F. S. Kipping, ibid., 2004, 2090. 
The utility of the Grignard reaction is very apparent in this work. In the researches quoted above, for instance, benzylethylsilicon dichloride, $\mathrm{Si}\left(\mathrm{C}_{7} \mathrm{H}_{7}\right) \mathrm{EtCl}_{2}$, was caused to react with magnesium isobutyl bromide, giving benzylethylisobutylsilicyl chloride, which yields the required silicol or oxide on treatment with water. The siliconic acids, the analogues of the carboxylic acids, may be prepared by the action of magnesium alkyl or aryl haloids on silicon tetrachloride, and decomposition of the resulting compound with water. Thus silicobutyric acid (propylsiliconic acid) is prepared by the following reactions :

$$
\begin{aligned}
& \mathrm{PraMgBr}^{a}+\mathrm{SiCl}_{4}=\mathrm{Pr}^{a} \mathrm{SiCl}_{3}+\mathrm{MgClBr} . \\
& \mathrm{Pr}^{a} \mathrm{SiCl}_{3}+2 \mathrm{H}_{2} \mathrm{O}=\mathrm{Pr}^{a} \mathrm{SiO}_{2} \mathrm{H}+3 \mathrm{HCl} .
\end{aligned}
$$

The trichlorides form ortho siliconic esters with alcohol. ${ }^{4}$

These esters may also be prepared by the action of magnesium organic haloids on ethyl orthosilicate, $\mathrm{Si}(\mathrm{OEt})_{4}$, but it is only possible to replace one ethoxyl group by this process. In this way, various aryl-substituted orthosiliconic esters, such as the xylyl and a-naphthyl derivatives, have been prepared, yielding siliconic acids when decomposed with water. ${ }^{5}$

Silicochloroform reacts with aniline in benzene solution to form trianilinosilicon hydride, $\mathrm{SiH}(\mathrm{NHPh})_{3}$. This compound is useful as a source of silicoiodoform, which is obtained from it in good yield by the action of hydrogen iodide in benzene solution. ${ }^{6}$

\section{Sulphur Compounds.}

The properties of the organic derivatives of sulphur present many points of interest, and it is not surprising that the number of researches dealing with these substances is on the increase. The isomerism and tautomerism of many of them has an important bearing on a department of chemistry which still remains very obscure, namely, the structural arrangement of inorganic compounds.

The action of alkalis on sodium alkyl thiosulphates has previously been little investigated. The principal action appears to be the formation of the disulphide: $2 \mathrm{R} \cdot \mathrm{S}_{2} \mathrm{O}_{3} \mathrm{Na} \rightarrow \mathrm{R}_{2} \mathrm{~S}_{2}$. It is not necessary, for the preparation of the disulphide, that the thiosulphate should be isolated. Thus the product of the action of $p$-nitrobenzyl chloride on sodium thiosulphate, when treated with sodium carbonate, yields di-p-nitrobenzyl disulphide directly. ${ }^{7}$ The same is true of

4 W. Melzer, Ber., 1908, 41, 3390 ; A., i, 967.

5 E. Khotinsky and B. Seregenkoff, ibid., 2946 ; A., i, 1032.

6 O. Ruff, ?bid., 3738 ; A., i, 966.

7 T. S. Price and D. F. Twiss, Trans., 1908, 93, 1395, 1401. 
alkyl compounds, and the substance obtained in solution by Gutmann ${ }^{8}$ from sodium ethyl thiosulphate, and supposed by him to be EtSOH, is diethyl disulphide. Other disulphides may be better prepared by the electrolytic oxidation of thiosulphates, dithiodiglycollic esters, for instance, being prepared in this way. ${ }^{9}$

Certain disulphides, such as benzyl disulphide and $4: 4^{\prime}$-dithioacetanilide, are found to occur in two isomeric modifications, of which one is converted into the other by the action of light. ${ }^{10}$ The nature of this isomerism remains unexplained.

The oxidation of sulphides to sulphoxides is most satisfactorily performed by means of hydrogen peroxide, both for aromatic ${ }^{11}$ and fatty compounds. Thus thionyldiglycollic acid, $\mathrm{SO}\left(\mathrm{CH}_{2} \cdot \mathrm{CO}_{2} \mathrm{H}\right)_{2}$, is prepared in this way from thiodiglycollic acid..$^{12}$

The constitution of thianthren (diphenylene disulphide) has been definitely proved to be that of an ortho-compound, by oxidation to the disulphone and treatment with phosphorus pentachloride, the products being benzene-o-disuJphonyl chloride and $o$-dichlorobenzene:

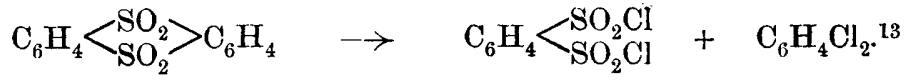

Organic polysulphides, unlike their inorganic analogues, are not readily prepared by the action of sulphui on alkyl mercaptides, oxidation taking place. They are obtained in certain cases by the action of sulphur on disulphides in absolute alcoholic solution, saturated with anhydrous ammonia, but quantitative yields of trisulphides are obtained by the action of thiongl chloride on mercaptans according to the equation

$$
4 \mathrm{R} \cdot \mathrm{SH}+\mathrm{SOCl}_{2}=\mathrm{R}_{2} \mathrm{~S}_{2}+\mathrm{R}_{2} \mathrm{~S}_{3}+\mathrm{H}_{2} \mathrm{O}+2 \mathrm{HCl}^{14}
$$

The di- and tri-sulphides are separated by fractional distillation. The tetrasulphide of acetic acid is obtained by the action of sulphur chloride on thiolacetic acid in ethereal solution.

Sulphination, or the introduction of sulphinic groups into aromatic compounds, is carried out by passing sulphur dioxide into a mixture of the compound to be sulphinated with aluminium chloride. This method has been described independently by two groups of workers. ${ }^{15}$ The process is accelerated by passing in hydrogen chloride simul-

A. Gutmann, Ber., 1908, 41, $1650 ;$ A., i, 497.

9 T. S. Price and D. F. Twiss, Trans., 1908, 93, 1645.

If O. Hinsberg, Ber., 1908, 41, $626 ; A$., i, 257.

11 Ibid., $2836 ; A^{2}, \mathrm{i}, 875$.

12 M. Gazdar and S. Smiles, Truns., 1908, 93, 1833.

13 J. J. B. Deuss, Ber., 1908, 41, 2329 ; A., i, 635.

14 B. Holmberg, Annalen, 1908, 359, $81 ;$ A., i, 308.

15 S. Smiles and R. Le Rossignol, Trans., 1908, 93, 745; E. Knoevenagel and J. Kenner, Ber., 1908, 41, $3315 ; A$., i, 970.

REP. - VOL. V. 
taneously with the sulphur dioxide. The work of Smiles and Le Rossignol has led to the recognition of interesting steric influences in this reaction. The sulphination will continue beyond the stage of the sulphinic acid to those of the sulphoxide and the sulphonium compound, the process being, in the case of phenetole:

$\mathrm{OEt} \cdot \mathrm{Ph} \rightarrow \mathrm{OEt} \cdot \mathrm{C}_{6} \mathrm{H}_{4} \cdot \mathrm{SO}_{2} \mathrm{H} \rightarrow$

$\left(\mathrm{OEt} \cdot \mathrm{C}_{6} \mathrm{H}_{4}\right)_{2} \mathrm{SO} \rightarrow\left(\mathrm{OEt} \cdot \mathrm{C}_{6} \mathrm{H}_{4}\right)_{3} \mathrm{~S} \cdot \mathrm{OH}$.

The group enters the same position as the sulphonic group in sulphonation. How far the reaction will proceed is dependent on two factors, the directive influence of such groups as ethoxyl, and steric hindrance by accumulation of ortho-substituents. Thus, with phenetole, the sulphinic group enters the para-position, and there being no ortho-substituents, the reaction proceeds to the formation of the sulphonium compound. In the ethers of quinol, sulphination takes place in the ortho-position, and progress beyond the sulphinic acid stage is rendered difficult, and almost impossible, by accumulation of ortho-substituents.
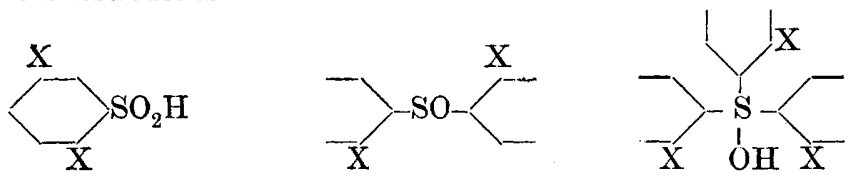

The relative influence of the two factors has been investigated in several cases.

The constitution of the aromatic sulphinic acids has been further studied by the examination of their oxidation products. ${ }^{16}$ Potassium permanganate, in glacial acetic acid, converts them into $a$-disulphones, which are identical with those obtained by the combination of sulphonyl chlorides with sodium arylsulphinates. This indicates that the acids react as $\mathrm{R} \cdot \mathrm{S}^{\mathrm{VI}} \mathrm{O}_{2} \cdot \mathrm{H}$, and not as $\mathrm{R} \cdot \mathrm{S}^{\mathrm{IV}} \mathrm{O} \cdot \mathrm{OH}$. The $a$-disulphones, such as $\mathrm{C}_{6} \mathrm{H}_{5} \cdot \mathrm{SO}_{2} \cdot \mathrm{SO}_{2} \cdot \mathrm{C}_{6} \mathrm{H}_{5}$, are stable, rather inert substances, only decomposed by hot concentrated alkalis.

Aldehydes and ketones react with alkaline sodium hyposulphite, forming compounds which appear to be esters of sulphoxylic acid,

$$
\mathrm{RR}^{\prime} \mathrm{CO}+\mathrm{Na}_{2} \mathrm{~S}_{2} \mathrm{O}_{4}+\mathrm{NaOH}=\mathrm{RR} \mathrm{C}(\mathrm{OH}) \cdot \mathrm{SO}_{2} \mathrm{Na}+\mathrm{Na}_{2} \mathrm{SO}_{3} \cdot{ }^{17}
$$

The sodium formaldehydesulphoxylate, known commercially as rongalite, probably has one of the two following structures :

$\mathrm{CH}_{2}\left\langle\mathrm{O}>\mathrm{SNa} \cdot \mathrm{OH}\right.$ or $\mathrm{OH} \cdot \mathrm{CH}_{2} \cdot \mathrm{O} \cdot \mathrm{SO}_{2} \mathrm{Na}$.

${ }_{16}$ T. P. Hilditch, Trans., 1908, 93, 1524.

17 E. Fromm, Ber., 1908, 41, 3397 ; A., i, 968. 
It forms a dibenzyl derivative,<smiles>CCOCOCOOOSOCC</smiles>

with benzyl chloride.

Sodium thiosulphate and formaldehyde react to form thioformaldehyde, which assumes the termolecular form, $\left(\mathrm{CH}_{2} \mathrm{~S}\right)_{3} \cdot{ }^{18}$

A few organic selenium and tellurium compounds have been prepared. A similar method to that employed for the preparation of sulphonium compounds leads to the formation of selenonium derivatives, namely, the condensation of phenolic ethers with selenium dioxide in presence of aluminium chloride. The selenonium bases are very stable, their salts are hardly acted on by sodium hydroxide, but yield hydroxides with silver oxide. ${ }^{19}$

Di-a-naphthyl selenide and telluride, $\left(\mathrm{C}_{10} \mathrm{H}_{7}\right)_{2} \mathrm{Se}$ and $\left(\mathrm{C}_{10} \mathrm{H}_{7}\right)_{2}{ }_{2} \mathrm{Te}$, and similar compounds have been prepared by the action of selenium or tellurium on mercury dinaphthyl and its analogues. ${ }^{20}$

Many of the researches not recorded in this Report, although of great importance, are omitted because they represent intermediate stages in the attack on one of the outstanding problems of this branch of chemistry. At this point it is often impossible to correlate and explain concisely the different lines along which the attack is being directed. But when success has been attained, it will then be found that these investigations will fall naturally into their places in the records of future reporters as necessary steps in the execution of another noteworthy achievement of organic analysis or synthesis.

Cecil H. Desch.

Gilbert T. Morgan.

${ }_{18}$ L. Vanino, J. pr. Chem., 1908, [ii], 77, $367 ; A .$, i, 318.

19 T. P. Hilditeh and S. Smiles, I'rans., 1908, 93, 1384.

20 R. E. Lyons and G. C. Bush, J. Amer. Chem. Soc., 1908, 30, 831 ; A., i, 417. 